\title{
PROGRAMA PARA ESTIMATIVA DO RENDIMENTO DAS CULTURAS PELA SIMULAÇÃO DA IRRIGAÇÃO POR BALANÇO HÍDRICO SEQUENCIAL
}

\author{
MARCO ANTONIO JACOMAZZI
}

Dissertação apresentada à Escola Superior de Agricultura "Luiz de Queiroz", da Universidade de São Paulo, para obtenção do título de Mestre em Agronomia, Área de Concentração: Irrigação e Drenagem.

PIRACICABA

Estado de São Paulo - Brasil Outubro - 2004 


\title{
PROGRAMA PARA ESTIMATIVA DO RENDIMENTO DAS CULTURAS PELA SIMULAÇÃO DA IRRIGAÇÃO POR BALANÇO HÍDRICO SEQUENCIAL
}

\author{
MARCO ANTONIO JACOMAZZI \\ Engenheiro Agrônomo
}

Orientador: Prof. Dr. JOSÉ ANTONIO FRIZZONE

\begin{abstract}
Dissertação apresentada à Escola Superior de Agricultura "Luiz de Queiroz", da Universidade de São Paulo, para obtenção do título de Mestre em Agronomia, Área de Concentração: Irrigação e Drenagem.
\end{abstract}

PI R A C I C A B A

Estado de São Paulo - Brasil

Outubro - 2004 


\section{Dados Internacionais de Catalogação na Publicação (CIP) DIVISÃO DE BIBLIOTECA E DOCUMENTAÇÃO - ESALQ/USP}

\section{Jacomazzi, Marco Antonio}

Programa para estimativa do rendimento das culturas pela simulação da irrigação por balanço hídrico seqüencial / Marco Antonio Jacomazzi. - - Piracicaba, 2004.

101 p. : il.

Dissertação (mestrado) - - Escola Superior de Agricultura Luiz de Queiroz, 2004.

Bibliografia.

1. Água do solo 2. Balanço hídrico 3. Estatística computacional 4. Evapotranspiração ! Irrigação 6. Planta cultivada 7. Probabilidade 8. Simulação I. Título

CDD 631.7 
A Deus,

OFEREÇO.

Para meus pais Josué e Rosmari,

e a minhas irmãs: Ana e Carla,

DEDICO. 


\section{AGRADECIMENTOS}

A Deus pela vida e pelas graças alcançadas;

Ao Departamento de Engenharia Rural, Escola Superior de Agricultura "Luiz de Queiroz", Universidade de São Paulo, pela oportunidade oferecida, e a seus funcionários pelo apoio oferecidos;

A Davilmar, secretária do curso de pós graduação da engenharia rural, por nos ensinar o caminho das pedras em meio as complicações burocráticas;

A CAPES, pela concessão da bolsa de estudos;

Ao professor, orientador, José Antonio Frizzone, pelo estímulo, encorajamento e amizade;

Aos professores de irrigação e drenagem, Décio, Rubens, Follegati, Tarley, Sérgio pelo apoio.

Aos amigos da IRRIGART Engenharia e Consultoria em Recursos Hídricos e Meio Ambiente Ltda.

Agradeço, especialmente, à Antonio Melhem Saad, Érica de Camargo Bortholin, Guilherme Busi de Carvalho, José César Saad, Wulf Schmidt, pela ajuda e orientação profissional ao longo destes dois anos de convívio; Aos estagiários do curso de Engenharia Agronômica, especialmente GPID, por muito suor na camisa;

A todos os demais colegas pela amizade, apoio e paciência. 


\section{SUMÁRIO}

Página

LISTA DE FIGURAS................................................................... vii

LISTA DE TABELAS ......................................................................... ix

LISTA DE SÍMBOLOS...................................................................

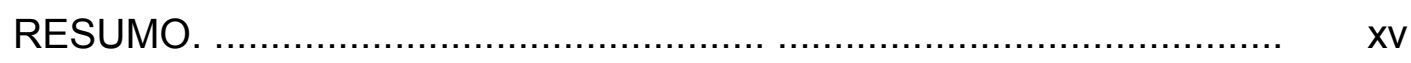

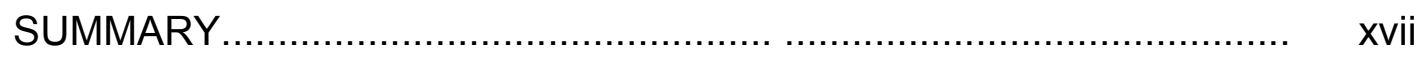

1 INTRODUÇÃO...................................................................

2 REVISÃO DE LITERATURA. ................................................ 5

2.1 Irrigação com déficit versus irrigação plena................................. 5

2.2 Balanço hídrico ................................................................ 8

2.3 Aplicação da análise de probabilidade em sistemas irrigados.... 23

2.4 FUNÇÕES DE PRODUÇÃO-ÁGUA CULTURA......................... 25

3 MATERIAL E MÉTODOS................................................ 28

3.1 Modelo computacional: descrição............................................. 28

3.2 Definição do momento de irrigação............................................ 30

3.3 Estimativa da duração do ciclo da cultura................................... 31

3.3.1 Estimativa dos graus dias acumulados................................................ 32

3.4 Variação da capacidade potencial de armazenamento de água 34 do solo.

3.5 Determinação da evapotranspiração potencial............................ 38

3.5.1 Método de Penman (1948) ............................................................................ 39

3.5.2 Método de Thornthwaite (1948) ................................................................ 42

3.5.3 Método do tanque classe A.................................................. 43 
3.6 Determinação da evapotranspiração máxima da cultura............ 43

3.7 O balanço hídrico diário sequencial (BHDS) ............................. 47

Estimativa da lâmina acumulada durante o ciclo da cultura e da lâmina de irrigação acumulada.

3.9 Análise de probabilidade.................................................... 60

3.9.1 Distribuição normal.................................................................................... 61

3.9.2 Distribuição gama incompleta. .................................................................... 62

3.9.3 Teste de Kolmogorov-Smirnov................................................................. 65

3.10 Estimativa da produtividade e da queda de rendimento dos 66

4 RESULTADOS E DISCUSSÃO ....................................... 68

4.1 Descrição do programa............................................................ 68

4.1.1 Entrada de dados no programa............................................. 70

4.1.1.1 Botão "PROPRIEDADES DO SOLO"...................................... 70

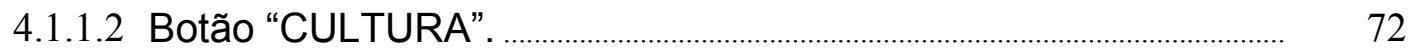

4.1.1.3 Botão "dados climáticos" ..................................................................................

4.1.2 Processamento dos dados.................................................. 77

4.1.2.1 Botão "BALANÇO HÍDRICO - PLANILHA" .............................. 78

4.1.2.2 Botão "Simulação". ..................................................................................................... 79

4.1.2.3 Botão “Análise Estatística” ............................................................................ 80

$4.2 \quad$ Exemplo de utilização................................................... 82

4.2.1 Dados disponíveis e critérios considerados............................ 82

4.2.2 Resultados Obtidos. ....................................................................................... 86

4.3 Considerações finais...................................................... 93

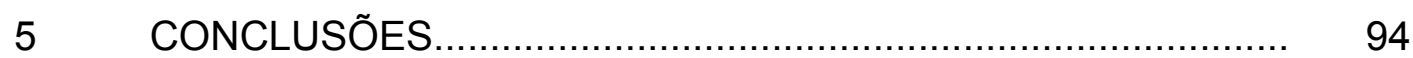

REFERÊNCIAS BIBLIOGRÁFICAS .......................................... 95 


\section{LISTA DE FIGURAS}

Página

1 Fluxograma geral do modelo computacional desenvolvido para estimativa do rendimento das culturas em áreas irrigadas.

2 Fluxograma para determinação da umidade mínima do solo para manejo da irrigação utilizando-se parâmetros do solo......

3 Fluxograma para estimativa diária do índice de duração do ciclo da cultura (IDC), pela metodologia de graus dias $[\mathrm{GD}(\mathrm{T})]$ e pela contabilização dos dias sucessivos após emergência (DAI).

4 Fluxograma para determinação do comprimento do sistema radicular da cultura em função do índice de duração do ciclo (IDC).

5 Fluxograma para determinação do coeficiente de cultura (kc) em função do índice de duração do ciclo (IDC)

6 - Fluxograma da estimativa diária da evapotranspiração potencial (ETP) e da evapotrasnpiração máxima da cultura (ETM) através das metodologias: Thorntwaite, modificada por Pereira (2004); Penman (1948); Priestley-Taylor e Tanque Classe A.

7 Fluxograma do balanço hídrico diário: determinação do armazenamento atual $\left(\mathrm{ARM}_{\mathrm{AT}}\right)$ e do negativo acumulado $\left(\mathrm{N}_{\mathrm{AT}}\right) \ldots \ldots \ldots \ldots . . . .$.

8 Fluxograma do balanço hídrico diário: determinação da lâmina de irrigação suplementar (IRR) e da lâmina de água total disponível (LAM). 
9 Fluxograma para a determinação do rendimento médio [Y(LAM)] e da queda de produtividade $[R(L A M)]$ em função da lâmina probabilística (LAM) .............................................................. 67

10 Tela inicial do aplicativo PLAN_IRR............................................. 69

11 Tela de entrada: propriedades do solo e dimensionamento da capacidade de armazenamento .................................................. $\quad 70$

12 Tela de entrada: características da cultura .................................. 72

13 Tela de entrada: dados climáticos ................................................. 74

14 Tela demonstrativa ETP ....................................................... 77

15 Tela demonstrativa: balanço hídrico............................................. 78

16 Tela de processamento: simulação.................................................... 79

17 Tela de processamento: análise estatística....................................... 80

18 Lâminas de água acumuladas esperadas, em base probabilística, para diferentes momentos de irrigação ........................................... 87

19 Lâminas de irrigação suplementar acumuladas, em base probabilística, para diferentes momentos de irrigação ...................... 89

20 Rendimento esperado em função das lâminas probabilísticas, para diferentes momentos de irrigação

21 Quebra do rendimento em função das lâminas probabilísticas, para diferentes momentos de irrigação 


\section{LISTA DE TABELAS}

Página

1 Principais métodos de estimativa da evapotranspiração potencial e suas respectivas categorias.

2 Média e desvio padrão do parâmetro ka, e número de dados (n), para dois períodos do ano e três locais do Estado de São Paulo.

3 Comparação entre os modelos de estimativa da evapotranspiração potencial em relação ao lisímetro de drenagem.

4 Valores da fração da água disponível no solo (p) segundo o grupo de culturas e a evapotranspiração máxima

5 Variáveis climáticas exigidas para cada modelo de estimativa da evapotranspiração potencial (ETP).

6 Modelos matemáticos que relacionam o fator $p$ de água disponível do solo (Doorenbos \& Kassan, 1979) com a evapotranspiração máxima (ETM), por grupo de culturas.

7 Valores de $\Gamma(\mathrm{g})$ para $1 \leq \mathrm{g} \leq 2$.

8 Parâmetros de ajuste da equação de van Genuchten.

9 Parâmetros do manejo da irrigação adotados: umidades volumétricas estimadas.

10 Parâmetros do manejo da irrigação adotados: armazenamento unitário de água estimado.

11 Parâmetros do manejo da irrigação adotados: profundidades consideradas de exploração do solo.

12 Características da cultura: Valores do coeficiente kc para a cultura de milho e respectivos DA. 
13 Características da cultura: Valores da profundidade do sistema radicular da cultura do milho $\left(\mathrm{Z}_{\mathrm{RAIZ}}\right)$ e respectivos DA..................... 85

14 Características da cultura: Coeficientes de Ajuste do Modelo da Função de Resposta.

15 Valores simulados da lâmina total acumulada $(\mathrm{mm})$ para diferentes níveis de probabilidade e diferentes momentos de irrigação.

16 Valores simulados da lâmina de irrigação suplementar acumulada $(\mathrm{mm})$ para diferentes níveis de probabilidade e diferentes momentos de irrigação.

17 Valores simulados do rendimento esperado $\left(\mathrm{kg} \mathrm{ha}^{-1}\right)$ em função da lâmina probabilística para diferentes níveis de probabilidade e diferentes momentos de irrigação

18 Valores simulados da quebra do rendimento esperado $\left(\mathrm{kg} \mathrm{ha}^{-1}\right) \mathrm{em}$ função da lâmina probabilística para diferentes níveis de probabilidade e diferentes momentos de irrigação. 


\section{LISTA DE SÍMBOLOS}

$\alpha, \mathrm{m}, \mathrm{n} \quad$ - Coeficientes de regressão do modelo de van Genuchten;

$\beta \quad$ - Parâmetro de escala da função gama;

$\Delta \quad$ - Tangente da curva de saturação do vapor d'agua, $\mathrm{kPA}^{\circ} \mathrm{C}^{-1}$;

$\triangle \mathrm{ARM} \quad$ - Variação do armazenamento, $\mathrm{mm}$;

$\Delta_{\mathrm{BH}} \quad$ - Saldo diário de lâmina do balanço hídrico, mm;

$\Delta \mathrm{e} \quad$ - Déficit de saturação da atmosfera, $\mathrm{kPa}$;

$\Delta \mathrm{N}_{\mathrm{AC}} \quad$ - Variação do negativo acumulado, $\mathrm{mm}$;

$\Delta \mathrm{z} \quad$ - Profundidade da sub camada de solo explorada, $\mathrm{mm}$;

$\phi \quad$ - Latitude local, graus;

$\Gamma(\mathrm{g}) \quad$ - Função gama;

$\gamma \quad$ - Constante psicrométrica;

9 - Declinação magnética, graus;

$\kappa \alpha$ - Coeficiente de Priestley-Taylor;

$\lambda \quad$ - Calor latente de vaporização da água, $\mathrm{J} \mathrm{kg}^{-1}$;

$\lambda$ Ea $\quad-$ Termo adiabático da equação de Penman, $\mathrm{MJ} \mathrm{m}^{-2} \mathrm{dia}^{-1}$;

$\mu \quad$ - Média aritmética amostral;

$\mu_{G} \quad$ - Média geométrica amostra;

$\theta_{\mathrm{cc}} \quad$ - Umidade volumétrica, na capacidade de campo, $\mathrm{m}^{3} \mathrm{~m}^{-3}$;

$\theta_{\text {CRIT }} \quad$ - Umidade volumétrica crítica, $\mathrm{m}^{3} \mathrm{~m}^{-3}$;

$\theta_{\text {MIN }} \quad$ - Umidade volumétrica mínima, $\mathrm{m}^{3} \mathrm{~m}^{-3}$;

$\theta_{\mathrm{PMP}} \quad$ - Umidade volumétrica, no ponto de murcha permanente, $\mathrm{m}^{3} \mathrm{~m}^{-3}$;

or $\quad$ - Umidade volumétrica residual do solo, $\mathrm{m}^{3} \mathrm{~m}^{-3}$; 
Os $\quad$ - Umidade volumétrica de saturação do solo, $\mathrm{m}^{3} \mathrm{~m}^{-3}$;

$\sigma \quad$ - Desvio padrão;

$\Psi_{\mathrm{CC}} \quad$ - Potencial mátrico na capacidade de campo, kPa;

$\Psi_{\text {CRIT }} \quad$ - Potencial mátrico crítico, ou momento de irrigação, kPa;

$\Psi \mathrm{m} \quad$ - Potencial mátrico, $\mathrm{kPa}$;

$\Psi_{\mathrm{PMP}} \quad$ - Potencial mátrico no ponto de murcha permanente, kPa;

A - Coeficiente de ajuste de unidades da equação de Tetens, kPa;

a,b - Parâmetros regionais de ajuste da equação de vento;

$a_{c} \quad$ - coeficiente de ajuste de calor da expressão de Thornthwaite

ALT - Alteração do armazenamento de água do solo, $\mathrm{mm}$;

$\mathrm{ARM}_{\mathrm{AT}}$ - Armazenamento atual de água no solo, $\mathrm{mm}$;

Amp - Amplitude da variação térmica diária, ${ }^{\circ} \mathrm{C}$;

$\mathrm{ARM}_{\mathrm{ANT}}$ - Armazenamento anteriorl de água no solo, $\mathrm{mm}$;

$\mathrm{ARM}_{\mathrm{CRIT}}$ - Armazenamento crítico de água no solo, $\mathrm{mm}$;

$\mathrm{ARM}_{\mathrm{MIN}}$ - Armazenamento mínimo de água no solo, $\mathrm{mm}$;

$\mathrm{ARM}_{\mathrm{REF}}$ - Armazenamento de referência de água no solo, $\mathrm{mm}$;

As - Coeficiente de assimetria da distribuição gama;

CAD - Capacidade de água disponível, $\mathrm{mm}$;

$\mathrm{CH}$ - Precipitação pluviométrica efetiva, $\mathrm{mm}$;

$\mathrm{cp} \quad$ - Calor específico do ar atmosférico, $\mathrm{J} \mathrm{kg}^{-10} \mathrm{C}^{-1}$;

d - Distância tabelada de probabilidade do teste de kolmogorovSmirnov;

D - Distância observada de probabilidade do teste de kolmogorov-Smirnov;

DAE - Dias após emergência;

DEF - Deficiência, mm;

E - Altitude local;

ea - Pressão de vapor do ar atmosférico, $\mathrm{kPa}$;

ECA - Evaporação do tanque Classe A, mm; 


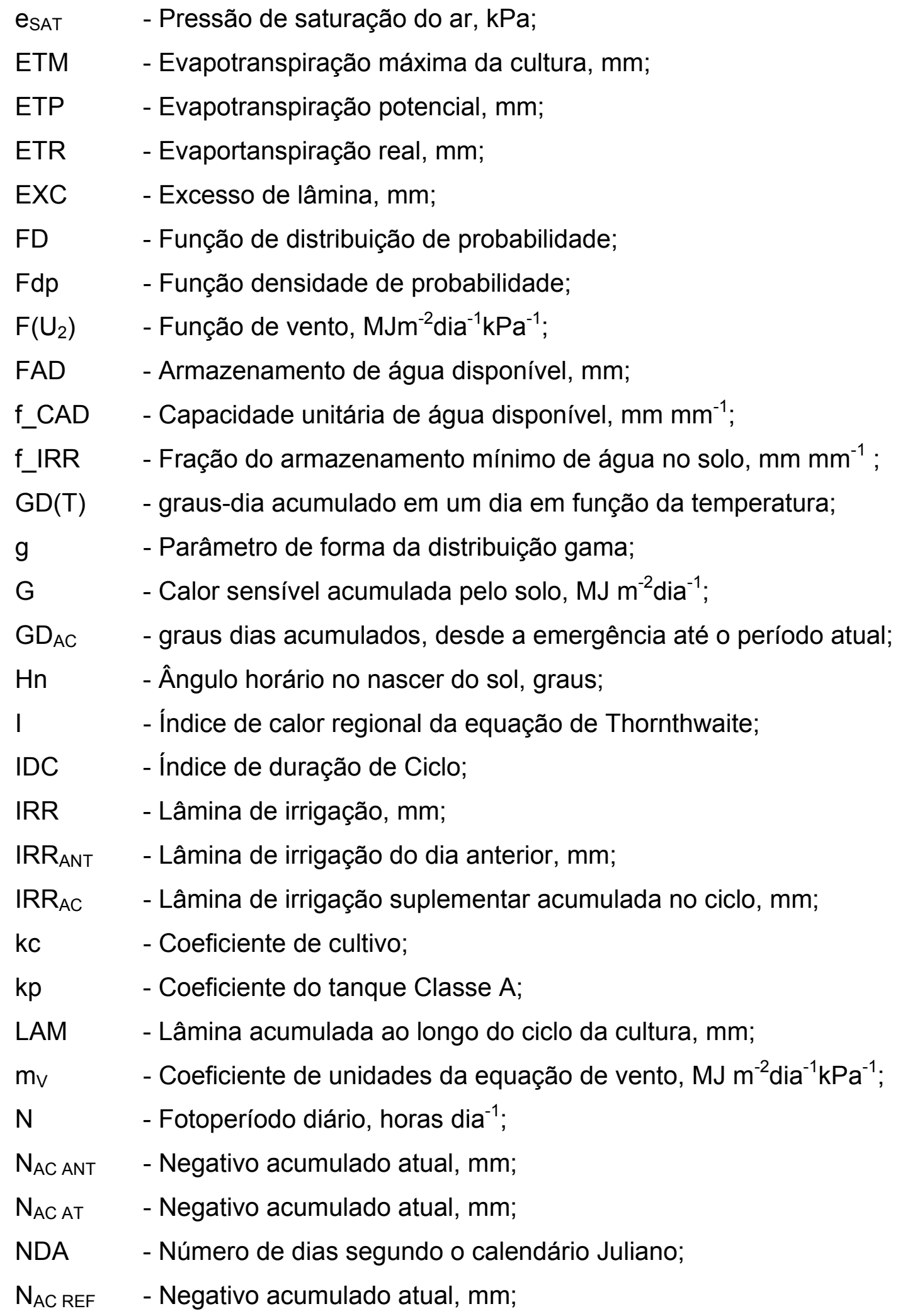


p - Fração de água disponível no solo;

Patm - Pressão atmosférica local, $\mathrm{kPa}$;

R(LAM) - Quebra do rendimento em função dà lâmina acumulada, $\mathrm{kg} \mathrm{ha}^{-1}$;

$\mathrm{q}$ - Percolação profunda ou drenagem interna de água, $\mathrm{mm} \mathrm{dia}^{-1}$;

R - Escoamento superficial, $\mathrm{mm}$;

$\mathrm{Rn} \quad$ - Radiação líquida na superfície do solo, $\mathrm{MJm}^{-2} \mathrm{dia}^{-1}$;

$\mathrm{S}(\mathrm{x}) \quad$ - Distribuição empírica de probabilidade;

t $\quad$ - Variável auxiliar da função de distribuição normal;

Tb - Temperatura basal, ${ }^{\circ} \mathrm{C}$;

$\mathrm{T}_{\mathrm{M}} \quad$ - Temperatura média, ${ }^{\circ} \mathrm{C}$;

$\mathrm{T}_{\mathrm{EF}} \quad$ - Temperatura efetiva, ${ }^{\circ} \mathrm{C}$;

$\mathrm{T}_{\mathrm{EF}}{ }^{*} \quad$ - Temperatura efetiva, corrigida para o fotoperíodo, ${ }^{\circ} \mathrm{C}$;

$\mathrm{T}_{\text {MAX }} \quad$ - Temperatura máxima observada no dia, ${ }^{\circ} \mathrm{C}$;

$\mathrm{T}_{\mathrm{MIN}} \quad$ - Temperatura mínima observada no dia, ${ }^{\circ} \mathrm{C}$;

$\mathrm{U}_{2} \quad$ - Velocidade do vento a 2 metros da superfície, $\mathrm{ms}^{-1}$;

UR - Umidade relativa, \%;

w - Parâmetro estatístico de correção da temperatura efetiva;

Xi - Variável aleatória;

y $\quad$ - Variável reduzida da distribuição de probabilidade Normal;

Y(LAM) - Função de resposta da cultura à lâmina acumulada, $\mathrm{kg} \mathrm{ha}^{-1}$

$Z_{\mathrm{EF}} \quad$ - Profundidade efetiva, $\mathrm{mm}$;

Z

Z $Z_{R E F} \quad$ - Profundidade de referência do solo, $\mathrm{mm}$; 


\section{PROGRAMA PARA ESTIMATIVA DO RENDIMENTO DAS CULTURAS PELA SIMULAÇÃO DA IRRIGAÇÃO POR BALANÇO HÍDRICO SEQUENCIAL}

AUTOR: MARCO ANTONIO JACOMAZZI

Orientador: Prof. Dr. JOSÉ ANTONIO FRIZZONE

\section{RESUMO}

A utilização de recursos computacionais para o planejamento do uso racional da água em sistemas irrigados é cada vez mais freqüente na agricultura moderna tecnificada. Devido a constante melhoria desses recursos, torna-se, essencial a atualização dos programas desenvolvidos, específicos na área de irrigação e drenagem, incorporando as recentes tecnologias desenvolvidas neste setor. $O$ objetivo deste trabalho foi elaborar uma ferramenta computacional de acesso simplificado, que proporcionasse ao usuário, a liberdade quanto aos critérios empregados nas áreas irrigadas. $\mathrm{O}$ programa desenvolvido é específico para o planejamento de sistemas irrigados. Esse programa foi desenvolvido para auxiliar na tomada de decisão sobre o nível de manejo de irrigação a ser adotado; com base numa previsão de chuvas simulada a partir de uma série histórica de dados e qual a máxima produtividade esperada da cultura para um determinado momento de irrigação. Como parâmetros de entrada o aplicativo requer dados sobre os parâmetros climáticos regionais; as características da cultura irrigada; as propriedades do solo quanto à capacidade de armazenamento de água e operação do manejo de água adotado. O aplicativo permite, a partir dos dados climáticos disponíveis, estimar a evapotrasnpiração potencial utilizando-se desde o modelo de Penman, que exige maior número de variáveis até o de Thornthwaite 
que se baseia apenas na temperatura. Simulando-se diferentes níveis de manejo da irrigação para a região de Piracicaba, onde o déficit hídrico não é acentuado, as simulações não apresentaram diferenças significativas, entretanto, supõem-se que os contrastes poderão ser potencializados para regiões mais áridas. Essa ferramenta apresentou-se ser bastante útil para o usuário, para as diferentes regiões climáticas no país e os dados climáticos disponíveis para cada caso. 


\section{SOFTWARE TO ESTIMATE CROP YIELD BY SIMULATING IRRIGATION USING SEQUENTIAL WATER BALANCE}

Author: MARCO ANTONIO JACOMAZZI

Adviser: Prof. Dr. JOSÉ ANTONIO FRIZZONE

\section{SUMMARY}

The use of computers resources for planning the rational water use in irrigated systems is even more frequent in the modern technical agriculture. Due to the constant improvements of those resources, it is essential to update the developed software's, specifically in the irrigation and drainage area, by incorporating the most recent technologies developed in this segment. The objective of this work was to elaborate a computation easy to handle tool, which allows freedom to act in relation to the used criteria in irrigated farming. The developed software is specific for planning of irrigated systems. It was developed to help decisions taking about the irrigation management level to be adopted; based on a rainfall forecast simulated on an historically sequence and the maximum crop yield expected for a specific irrigation moment. As input data, the software will need (i) regional climatic parameters, (ii) the characteristics of irrigated crop, (iii) soil properties related to water storage capacity and (iv) the adopted water management. Based on available data, user can choose among several methods of calculate the potential evapotranspiration, from Penman, which will need more climatic data, until Thornthwaite based on temperature data only. By running the program with data from Piracicaba region, where there is not a significant water deficit along the year, no difference was shown among the different methods used, but it is to suppose that in more arid regions the 
contrast among them will be more significantly. The developed tool presents to be useful for the user by being flexible regarding the different climatic regions of the country and also regarding available data set for each case. 


\section{INTRODUÇÃO}

O manejo da irrigação diz respeito ao uso criterioso do recurso hídrico disponível para se atingir um determinado objetivo, por exemplo, alcançar alta produtividade das culturas com o uso eficiente da água, da energia e de outros fatores da produção. As práticas convencionais de irrigação baseiam-se em duas especificações chaves: necessidade de água da cultura e eficiência de uso de água.

Para dar suporte à formulação de calendários de irrigação, por muitos anos, as pesquisas guiadas por várias idéias sobre o nível desejável de uso de água, tentaram relacionar a produção das culturas com a quantidade de água.

Assim foram estabelecidos dois princípios básicos para o manejo da irrigação: (a) irrigação para máxima produção por unidade de área - com esse objetivo utiliza-se a irrigação plena, isto é, satisfaz-se totalmente a necessidade de água da cultura para evitar perdas de produtividade ou qualidade do produto (Doorenbos e Pruitt, 1977) e fica implícito que a disponibilidade de água não é fator limitante da produção; e (b) irrigação para maximizar a produção por unidade de volume de água aplicada - com esse objetivo visa-se economizar água pelo aumento da eficiência de aplicação de água (Phene, 1989), pressupondo-se que a disponibilidade de água constitui limitação à produção agrícola e que o manejo da irrigação deve priorizar a minimização das perdas de água. Neste caso, a água aplicada deve ser efetivamente utilizada para a produção. 
Outros objetivos do manejo da irrigação podem ser estabelecidos, como por exemplo, maximizar a produção vegetal por unidade de custo da mão-deobra, do capital investido ou da energia consumida.

Os níveis de eficiência preconizados são aqueles possíveis de serem obtidos com um grau de adequação da irrigação de $90 \%$ para culturas de alto ou médio valor econômico, ou 75\% para culturas de baixo valor (Cuenca, 1989). A irrigação convencional é desse modo definida em termos da quantidade de água aplicada requerida para evitar déficit hídrico em $75 \%$ ou $90 \%$ da área. Esses parâmetros constituem, até hoje, os fundamentos da irrigação padrão em todo o mundo.

O Grau de adequação se refere à fração da área que deve receber água suficiente para evitar perdas de produtividade ou qualidade do produto. Se a lâmina de irrigação for menor que a necessidade de água da cultura, o grau de adequação será reduzido, as produtividades serão menores, mas, como resultado, ocorre redução da percolação, aumento da eficiência de aplicação, redução nos custos operacionais da irrigação e redução da lixiviação de produtos químicos.

Do exposto, depreendem-se duas estratégias para estabelecer um calendário de irrigação: (a) suprir totalmente a necessidade de água da cultura - irrigação plena; e (b) suprir parcialmente a necessidade de água da cultura irrigação com déficit. $\mathrm{Na}$ irrigação plena o objetivo é aplicar uma lâmina média capaz de suprir totalmente o déficit hídrico e proporcionar a máxima produção por unidade de área. Como a aplicação de água não é totalmente uniforme no espaço, o excesso de água poderá reduzir a produção da cultura pela redução da aeração do solo, por lixiviação de nutrientes e por doenças associadas a solos úmidos. Já na irrigação com déficit o objetivo é aplicar uma lâmina média de água inferior àquela para máxima produtividade para aumentar a eficiência no uso da água.

A irrigação para atender plenamente a demanda de água da cultura é um problema relativamente simples e claramente definido, com um objetivo único. 
Entretanto, uma mudança fundamental deverá ocorrer nas práticas da irrigação nos próximos anos, em decorrência das pressões econômicas sobre os agricultores, da crescente competição pelo uso da água e dos impactos ambientais da irrigação. Estes fatores deverão motivar uma mudança de paradigma da irrigação, enfocando-se mais a eficiência econômica do que a demanda de água da cultura.

O desenvolvimento tecnológico de outras atividades industriais e o crescimento populacional, ambos, subsidiados pelo uso crescente dos recursos hídricos, tem agravado a competição pelo uso da água para irrigação. Dessa forma, torna-se urgente a implantação de ações de gestão integrada de recursos hídricos visando seus múltiplos usuários.

Como originalmente concebido e geralmente praticado, o manejo da irrigação visa maximizar a produtividade, uma vez que os procedimentos não consideram explicitamente os custos e os lucros. Já a otimização considera explicitamente esses fatores econômicos, porém irrigar para maximizar a lucratividade é um problema substancialmente mais complexo e desafiador. Identificar estratégias ótimas de irrigação necessitará de modelos detalhados das relações água-cultura e eficiência de irrigação. Fatores econômicos, como custos de produção, preços do produto, custos de oportunidade da água, deverão ser explicitamente incorporados nas análises.

O setor brasileiro de irrigação ainda segue os roteiros tradicionais de natureza imediatista, comumente empregados para o dimensionamento de sistemas de irrigação, não considerando a contribuição da precipitação no atendimento parcial das necessidades hídricas das culturas e a disponibilidade hídrica regional dos rios e córregos.

Para implantar programas estratégicos de desenvolvimento agrícola local ou regional baseados na disponibilidade dos recursos hídricos superficiais, torna-se essencial quantificar as necessidades de água das culturas ao longo do ciclo produtivo. 
Uma técnica eficaz para estimativa do consumo de água pelas culturas para fins de irrigação é o balanço hídrico, originalmente proposto por Thornthwaite \& Matter (1955), modificado, posteriormente, com base em estudos realizados por Denmead \& Shaw (1962). O balanço hídrico é amplamente utilizado, por possibilitar a estimativa da variação temporal do armazenamento de água no solo, com estimativas da evapotranspiração real, déficit hídrico, excedente hídrico e da lâmina de irrigação complementar.

Este trabalho tem como objetivo desenvolver um modelo computacional para quantificar o rendimento das culturas e a quebra de produtividade com base probabilística, através da simulação da aplicação de água por irrigação. Essas simulações serão realizadas a partir de balanços hídricos seqüenciais utilizando uma série histórica de dados. Visa-se com este modelo obter estimativas criteriosas das necessidades de irrigação das culturas 


\section{REVISÃO DE LITERATURA}

\subsection{Irrigação com déficit versus irrigação plena}

O desenvolvimento das plantas é controlado diretamente pelo estresse hídrico fisiológico da cultura e indiretamente pela disponibilidade de água no solo (Kramer, 1959). Esse estresse é resultado de um balanço interno de água, contabilizado pela taxa de perda de água através das folhas, mensurada pela transpiração, e pela taxa de absorção de água pelo sistema radicular, controlada pela disponibilidade de água no solo. Quando a transpiração é superior a taxa de absorção pelas raízes ocasiona a perda de turgidez celular, caracterizando o desbalanço interno de água. Para regular essa desproporção entre a perda e a absorção de água, a planta atua na abertura estomática, reduzindo-a. Entretanto, diminui a entrada do dióxido de carbono, reduzindo, a taxa de fotossíntese.

A irrigação com déficit implica menores lâminas aplicadas em relação à irrigação plena, com conseqüente redução da produtividade da cultura. Embora as afirmações de Kramer (1959) não são passíveis de contestação do ponto de vista fisiológico, para a produção agrícola, a irrigação com déficit tem algumas vantagens significativas sobre a irrigação plena, conforme relatadas por English e Nuss (1982) e English (1990). Os benefícios potenciais da irrigação com déficit advêm de três fatores: aumento da eficiência de irrigação; redução dos custos da irrigação e redução dos riscos associados aos impactos ambientais adversos da irrigação plena. 
Muitos pesquisadores analisaram os benefícios econômicos da irrigação com déficit em circunstâncias específicas e concluíram que esta técnica pode aumentar a receita líquida das culturas irrigadas (Stewart et al., 1974; Peri et al., 1979; Kumar \& Khepar, 1980; English \& Nuss, 1982, Frizzone, 1986; English \& Nakamura, 1989; English, 1990; Frizzone et al., 1995; Frizzone et al., 1997; Calheiros et al., 1996; English \& Raja, 1996; Sousa et al., 1998; Heinemann et al., 2000; Andrade Júnor et al., 2001; Heinemann et al., 2001; Paz et al., 2002; English et al., 2002; Gorantiwar \& Smout, 2003).

Embora a irrigação com déficit tem sido tema de pesquisa por mais de três décadas, nenhum procedimento ótimo, sistemático e rigoroso, está sendo usado na agricultura produtiva atualmente. English et al. (2002) citam uma revisão de literatura sobre esse tema, apontando muitos artigos baseados em teorias, mas, não citam exemplos de irrigação deficitária sistemática em condições de campo. Apresentam uma pesquisa informal com 42 profissionaischave em irrigação, perguntando aos entrevistados se eles estavam conscientes de qualquer aplicação sistemática dos princípios da irrigação com déficit em áreas de produção agrícola. A conclusão foi que nenhum podia citar qualquer exemplo de estratégia de uso dessa técnica com base científica rigorosa, em nenhuma parte do mundo, apesar de que muitos relataram algumas estratégias intuitivas visualizadas por algum produtor.

Uma revisão dos livros-textos de irrigação mais comuns mostra que sempre é recomendado o dimensionamento formal da irrigação para a máxima produtividade das culturas. Alguns textos recomendam que o sistema de irrigação deverá aplicar a quantidade de água necessária para satisfazer a demanda total da cultura (Walker \& Skogerboe, 1987; American Society of Civil Engineers, 1990). Em outros textos o procedimento é baseado na máxima depleção admissível de água no solo. Embora o nível de depleção seja escolhido pelo projetista, sempre implica irrigação plena (James, 1988; Keller \& Bliesner, 1990; Bernardo, 1995). Apenas um dos textos revisados (Cuenca, 1989) sugere que sob algumas circunstâncias pode ser permitida maior 
depleção de água no solo, resultando na diminuição da produtividade e no aumento da lucratividade, em relação aos maiores custos da irrigação plena. Entretanto, o autor chama a atenção para o fato de que esta prática poderá aumentar o risco de uma grande redução da produtividade devido às inesperadas falhas do equipamento de irrigação ou a ocorrência de condições climáticas adversas.

A aparente relutância para explorar completamente o conceito de irrigação com déficit em um contexto formal nos livros texto, deve-se possivelmente à crença de que os benefícios desta técnica podem não justificar os riscos associados (English \& Raja, 1996). Assim, embora a estratégia de irrigação a ser escolhida deve ser aquela que maximiza a expectativa de lucro, o problema de decisão pode ser complicado pelo fato de que os tomadores de decisão têm aversão ao risco. Estratégias de irrigação que oferecem o maior retorno líquido esperado podem também estar associadas a um maior risco de perda. Isso é particularmente verdadeiro quando a água é bastante restrita. Se o plano ótimo aponta simultaneamente para a redução da lâmina de irrigação e para o aumento da área irrigada, qualquer perda econômica poderá ser ampliada para uma maior área irrigada (English et al. 2002).

Entre optar por uma estratégia de alto risco com uma elevada expectativa de lucro e por uma estratégia alternativa com menor potencial de lucro, mas com menor probabilidade de perda, como é o caso da prática da irrigação plena, um produtor que apresenta aversão ao risco pode preferir essa última opção. A significância da aversão ao risco foi demonstrada por Frizzone et al. (2001) que usaram a teoria da árvore de decisão e da função utilidade para estudar a viabilidade da irrigação suplementar da cana-de-açúcar na região norte do estado de São Paulo.

Em algumas culturas perenes como maçã, café e laranja, um adequado déficit hídrico pode ser importante na regulação do ciclo de produção, uma vez que atua diretamente na quebra de dormência das gemas florais, garantindo a uniformidade de florescimento e, portanto, de colheita. Por outro lado, em 
algumas culturas, como melancia e melão, entre outras, um déficit de água elevado pode reduzir o peso médio dos frutos $\mathrm{e}$, conseqüentemente, a qualidade do produto, tornando-os inaceitáveis no mercado consumidor (Andrade Júnior et al., 2001).

\subsection{Balanço hídrico}

O balanço hídrico é empregado em larga escala como ferramenta para estimativa do potencial climático regional quanto à disponibilidade de água às culturas, definindo melhores épocas de plantio, risco de atendimento da demanda hídrica pelas culturas e, finalmente, possibilitando o zoneamento agrometeorológico.

Joshi et al. (1995), objetivando desenvolver uma ferramenta que auxiliasse na predição do teor da água no solo, em áreas irrigadas, elaborou uma rotina computacional, denominada como CROSOWAT, a qual baseava-se em balanços hídricos seqüenciais, em escala diária.

Esse balanço hídrico considerava como parâmetros de entrada do modelo: variáveis hidrológicas como a precipitação efetiva, evapotranspiração máxima da cultura, escoamento superficial, percolação profunda; parâmetros da cultura como o crescimento radicular; eficiência de aplicação de água pelo sistema e a irrigação suplementar. Segundo o autor esta ferramenta apresentou-se eficaz sendo recomendada para auxiliar nos projetos de planejamento de uso de água pelas propriedades agrícolas.

O balanço hídrico pode ser empregado como ferramenta para subsidiar a o dimensionamento da infraestrutura necessária nos projetos de irrigação como canais de distribuição, reservatórios de abastecimento, barragens e outras obras de importância.

Panigrahi \& Panda (2003), baseando-se na teoria do balanço hídrico, desenvolveu uma rotina computacional para o dimensionamento ótimo 
econômico de reservatórios de água para abastecimento da irrigação suplementar. Esse modelo apresentou resultados satisfatórios para a cultura de arroz, no oeste da Índia.

O balanço hídrico climatológico, descrito por Thornthwaite \& Matter (1955) citado em Pereira (1997), é um dos meios de monitorar o armazenamento de água no solo, através de dados climáticos locais, constituindo-se, portanto, em excelente ferramenta para planejamento de projetos hidroagrícolas.

Conforme Reichardt (1996), a partir do suprimento de água no solo, representado pela precipitação efetiva $(\mathrm{CH})$ ou pela lâmina de irrigação (IRR) e da demanda atmosférica, simbolizada pela evapotranspiração máxima (ETM), considerando uma capacidade de água disponível (CAD), apropriada ao tipo de planta cultivada e a condição edáfica local, o balanço hídrico climatológico, fornece estimativas da evapotranspiração real (ETR), da deficiência (DEF) e do excedente (EXC), e da variação do armazenamento de água no solo (ARM), tanto na escala diária como mensal.

Aplicando o princípio da conservação da massa, o balanço de água em um volume de controle, definido pela profundidade efetiva do sistema radicular da cultura, pode ser, matematicamente, representado pela Equação (1), descrita em Reichardt (1996).

$$
\begin{aligned}
& \int_{\mathrm{t} 1}^{\mathrm{t} 2}(\mathrm{CH}+\mathrm{IRR}-\mathrm{ETR} \pm \mathrm{q}-\mathrm{R})=\int_{0}^{\mathrm{z}} \int_{\mathrm{t} 1}^{\mathrm{t} 2} \frac{\partial \theta}{\partial \mathrm{t}} \mathrm{dtdz} \\
& \int_{\mathrm{t} 1}^{\mathrm{t} 2} \mathrm{CHdt}+\int_{\mathrm{t} 1}^{\mathrm{t} 2} \mathrm{IRRdt}-\int_{\mathrm{t} 1}^{\mathrm{t} 2} \mathrm{ETRdt} \pm \int_{\mathrm{t} 1}^{\mathrm{t} 2} \mathrm{PEdt}-\int_{\mathrm{t} 1}^{\mathrm{t} 2} \mathrm{ROdt}=\mathrm{z} \int_{\mathrm{t} 1}^{\mathrm{t} 2} \frac{\partial \theta}{\partial \mathrm{t}} \mathrm{dt}
\end{aligned}
$$

Simplificando a equação (1) para duração de um dia, obtém-se a Equação (2): 
$\mathrm{CH}+\mathrm{IRR}-\mathrm{ETR} \pm \mathrm{PE}-\mathrm{R}=\Delta \mathrm{ARM}$

em que:

$\mathrm{CH}$ - precipitação pluviométrica efetiva, $\mathrm{mm}$;

IRR - quantidade de água infiltrada aplicada na forma de irrigação, $\mathrm{mm}$;

ETR - quantidade de água que sai do volume de controle na forma de evapotranspiração real, $\mathrm{mm} \mathrm{dia}^{-1}$;

PE - quantidade de água que ultrapassa o limite do sistema considerado através da percolação profunda (perda) ou da ascensão capilar (ganho), mm;

RO - quantidade de água que chega à superfície do solo e não é infiltrada, sendo perdida por deflúvio superficial, mm;

$\triangle \mathrm{ARM}$ - variação do armazenamento de água no volume de controle, durante o intervalo de tempo considerado, $\mathrm{mm}$.

Para que não houvesse nem excesso, nem deficiência hídrica, originalmente, a chuva deveria ser igual a ETP, denominada como chuva ideal segundo Thornthwaite \& Matter (1955), citado em Pereira (1997). Esta situação é hipotética, pois em algumas regiões há excesso praticamente o ano todo, enquanto em regiões áridas e semi-áridas isso nunca acontece. Em regiões tropicais, é mais comum haver excesso numa época do ano e deficiência em outras.

O balanço hídrico permite quantificar esses termos sendo permitindo, também, estudar a viabilidade de implantação e monitoramento de sistemas de irrigação, como também adaptabilidade de determinadas culturas para as condições locais de uma região.

Wrege et al. (1997), trabalhando com 32 estações meteorológicas no Estado do Paraná, definiram quatro regiões distintas quanto ao risco de deficiência hídrica na cultura do feijoeiro, durante a safra das águas. Baseado em balanços hídricos diários os autores estimaram a deficiência hídrica através 
da determinação da disponibilidade de água no solo, possibilitando a definição das melhores épocas de plantio dessa cultura para cada região.

Em uma superfície vegetada ocorrem, simultaneamente, os processos de evaporação do solo e de transpiração das plantas. O primeiro é controlado por parâmetros físicos da atmosfera e pelas propriedades hidráulicas do solo e o segundo por fenômenos fisiológicos. Este uso conjunto de água foi denominado como evapotranspiração, conforme Thornthwaite (1944), citado em Braga (1982).

Segundo Pereira (1997), a evapotranspiração é função da disponibilidade de energia incidente na superfície vegetada, da demanda atmosférica, e da disponibilidade de água controlada pelo solo.

Peres (1994) define como evapotranspiração potencial o uso da água do solo, na forma de vapor d'água, decorrente dos processos de evaporação e transpiração, em uma extensa superfície vegetada padrão, normalmente com grama batatais (Paspalum notatum L.), em crescimento ativo e cobrindo totalmente o terreno, sem restrição hídrica, ou seja, em nenhum momento a demanda atmosférica é restringida por falta d'água no solo.

Doorenbos \& Pruitt (1977), definem a evapotranspiração de referência como aquela que ocorre em uma extensa superfície de grama com altura de 0,08 a $0,15 \mathrm{~cm}$, em pleno desenvolvimento, cobrindo totalmente o terreno e sem restrição hídrica do solo. Logo a evapotranspiração de referência coincide, quantitativamente, com a evapotranspiração potencial.

Existem diversos métodos de estimativas e medidas diretas da evapotranspiração potencial citados na literatura específica. A escolha de um destes dependerá basicamente da disponibilidade de dados climatológicos locais, dos parâmetros regionais de correção do modelo geral empregado e do nível de conhecimento dos técnicos responsáveis.

Segundo Pereira (1997), de acordo com os princípios físicos envolvidos, os métodos de estimativa da evapotranspiração potencial são reunidos em cinco categorias, conforme apresenta a Tabela 1: 
Tabela 1. Principais métodos de estimativa da evapotranspiração potencial e suas respectivas categorias

\begin{tabular}{ll}
\hline \multicolumn{1}{c}{ Categoria } & \multicolumn{1}{c}{ Método de estimativa } \\
\hline 1. Empíricos & - Método do tanque Classe A \\
- Método de Thornthwaite \\
- Método de Makkink \\
- Método da Radiação Solar - método FAO 24 \\
- da radiação \\
- Método de Linacre \\
- Método de Jesen-Haise \\
- Método de Hargreaves-Samani
\end{tabular}

2. Aerodinâmicos

3. Balanço de Energia

4. Combinados
- Método da Razão de Bowen

- Método de Priestley-Taylor

- Método de Penman

- Método de Penman-Monteith

5. Correlação dos Turbilhões

Procurando sintetizar os principais métodos de estimativa da evapotranspiração potencial, Doorenbos \& Pruitt (1977) selecionaram os métodos de Penman, de Blaney-Criddle, da radiação e do tanque Classe $A$, calibrando-os com os valores medidos em diferentes condições climáticas e, portanto, apresentando correções generalizadas para outras regiões. 
Dentre todos os métodos citados, o de Penman-Monteith, seguido pelo de Penman são os que apresentam resultados mais consistentes e reais. Segundo Peres (1994), estes métodos facilitam o entendimento do processo físico da evaporação de superfícies naturais.

Embora o modelo de Penman-Monteith apresente rigorosa formulação teórica física, sua utilização prática é restrita devido à falta de parametrização da resistência do dossel bem como a demanda de grande número de dados climáticos.

Outro método que apresenta estimativas consistentes da evapotranspiração potencial é o de Priestley-Taylor, considerado como uma simplificação do modelo de Penman. Este método determina o valor da taxa potencial de evapotranspiração (ETP) através do termo radiativo (adiabático) da equação de Penman, corrigido por um coeficiente de ajuste $(\kappa \alpha)$, conhecido por parâmetro de Priestley-Taylor, conforme apresenta a Equação (4).

$$
\lambda \mathrm{ETP}=\kappa \alpha \frac{\Delta}{\Delta+\gamma}(\mathrm{Rn}-\mathrm{G})
$$

Segundo Pereira (1990), este método é uma excelente alternativa quando não se dispõe de dados referentes ao termo aerodinâmico do processo de evapotranspiração, desde que se disponha de valores de $\kappa \alpha$ calibrados para as condições locais.

A maior restrição à aplicabilidade do modelo de Priestley-Taylor está no estabelecimento do seu campo de aplicação, o qual está diretamente relacionado ao tipo de superfície evaporante, região e época do ano.

Entende-se que as diferenças observadas nos valores médios mensais de $\kappa \alpha$ durante o ano correlacionam-se a sazonalidade das chuvas, uma vez que há mudanças na partição do saldo de radiação da superfície evaporante de acordo com a umidade relativa do ar.

Pereira et al. (1997), analisando o efeito da sazonalidade climática sobre o parâmetro $\kappa \alpha$ de Priesthey-Taylor, determinou para três regiões distintas os 
valores calibrados desse coeficiente, conforme se apresenta na Tabela 2. O autor correlacionou, neste trabalho, os valores de evapotranspiração potencial (ETP) regionais, medidos através de lisímetros de drenagem, cultivados com grama batatais (Paspalum notatum), coletados por Camargo (1962), e os estimados pela equação de Priestley-Taylor.

Tabela 2. Média e desvio padrão do parâmetro ka, e número de dados (n), para dois períodos do ano e três locais do Estado de São Paulo

\begin{tabular}{lcccccc}
\hline \multirow{2}{*}{ Local } & \multicolumn{2}{c}{ Outubro - Março $(\mathrm{P}-\mathrm{V})$} & \multicolumn{3}{c}{ Abril - Setembro (O-I) } \\
& $\kappa \alpha$ & Desvio & & $\kappa \alpha$ & Desvio & \\
& Médio & Padrão & $\mathrm{n}$ & Médio & Padrão & $\mathrm{n}$ \\
\hline Campinas & 1,02 & 0,11 & 28 & 0,91 & 0,17 & 28 \\
Ribeirão Preto & 1,15 & 0,10 & 16 & 1,07 & 0,16 & 20 \\
Pindamonhangaba & 1,17 & 0,12 & 14 & 1,19 & 0,11 & 17 \\
\hline
\end{tabular}

Fonte: Pereira et al. (1997)

Segundo Peres et al. (1997), o modelo de Priestley - Taylor não se aplica à determinação da evapotranspiração potencial de uma vegetação esparsa, como aquela que ocorre nos estádios iniciais de culturas sob plantio em linha. O autor, trabalhando com a cultura de cana-de-açúcar, calibrou o coeficiente $\kappa \alpha$ para as condições climáticas de Araras. Este determinou os seguintes valores: $\kappa \alpha=1,30$ para a periodicidade decendial e $\kappa \alpha=1,34$ para a mensal, aplicáveis somente após o fechamento do dossel dessa cultura, quando o albedo da superfície torna-se, praticamente, constante.

Segundo Pereira (1990), Priestley-Taylor verificaram que o valor de $\kappa \alpha$ variou entre 1,08 e 1,34 e concluíram que o valor médio de 1,26 era a melhor estimativa. Entretanto, segundo Bruin \& Holtslag (1982), citado em Pereira (1990), o valor médio desse coeficiente se aplica apenas às superfícies saturadas, principalmente às de água livre e de solos cultivados, mantidos sob condições de alta umidade. Estes autores, analisando os valores coletados por 
Priesthey-Taylor, concluíram que $\kappa \alpha=2,67$ se aplica para superfície de água livre; $\kappa \alpha=1,08$ para as superfícies de solo nu e $\kappa \alpha=1,323$ para as superfícies vegetadas, com vegetação não esparsa.

De acordo com a revisão apresentada por Pereira (1990), o valor médio de 1,26 para o coeficiente de ajuste $\kappa \alpha$, proposto por Priesthey-Taylor, engloba a maior parte dos casos.

Embora a equação de Penman-Monteith seja considerada mais apropriada para a estimativa da evapotranspiração potencial, exige uma grande quantidade de variáveis climáticas, muitas vezes não disponíveis. Nestas condições de escassez de dados, os modelos empíricos são alternativas recomendadas, desde que se disponha de calibrações regionais.

Um dos primeiros modelos empíricos para estimativa da evapotranspiração potencial é o de Thornthwaite, o qual considera apenas a temperatura média mensal como variável que exprime o balanço de energia. Esse modelo é apenas recomendado para estimativas mensais, segundo Pereira et al. (1997), sendo representado pela Equação (4).

$$
\mathrm{ETP}=16\left(10 \frac{\mathrm{T}_{\mathrm{MES}}}{\mathrm{I}}\right)^{\mathrm{a}_{\mathrm{C}}} \frac{\mathrm{N}}{12} \frac{\mathrm{N}_{\text {DIAS }}}{30}
$$

em que:

ETP - evapotranspiração potencial mensal, $\mathrm{mm} \mathrm{mes}^{-1}$;

$\mathrm{T}_{\text {MES }}$ - temperatura média mensal, ${ }^{\circ} \mathrm{C}$;

$\mathrm{N}$ - fotoperíodo médio mensal, horas;

$\mathrm{N}_{\text {DIAS }}$ - número de dias do mês.

$\mathrm{a}_{\mathrm{C}}$ - coeficiente de ajuste de calor.

I - índice de calor regional, calculado a partir das normais climatológicas, segundo a Equação (5).

$$
I=\sum_{M E S=1}^{M E S=12}\left(0,2 T_{M E S}\right)^{1,514}
$$


A partir da estimativa do índice I, determina-se o valor do coeficiente a pela Equação (6).

$$
\mathrm{a}_{\mathrm{C}}=6,75 \cdot 10^{-7} \mathrm{I}^{3}-7,71 \cdot 10^{-5} * \mathrm{I}^{2}+1,7912 \cdot 10^{-2} \mathrm{I}+0,49239
$$

Segundo Camargo et al. (1999), a equação original de Thornthwaite é limitada às condições climáticas que foi desenvolvida, como qualquer outro método empírico. Logo sua estimativa é subestimada para as condições áridas e é superestimada para as condições de clima tropicas e sub tropicais.

Com o objetivo de corrigir a estimativa do modelo de Thornthwaite para outras condições climáticas, distintas daquelas em que foi desenvolvida, Camargo et al. (1999) propõe uma correção da temperatura média mensal. A correção proposta considera o ajuste da temperatura média, denominada com temperatura efetiva ( $\left.T_{E F}\right)$ a qual é função da temperatura média diária $\left(T_{M}\right)$ e da amplitude dos extremos de temperatura, conforme apresenta a equação (7).

$$
\mathrm{T}_{\mathrm{EF}}=\mathrm{w}\left(\mathrm{T}_{\mathrm{M}}+\mathrm{Amp}\right)
$$

em que:

w - parâmetro estatístico de correção = 0,72;

Amp - amplitude da variação térmica diária, ${ }^{\circ} \mathrm{C}$, [equação (8)].

$$
\text { Amp }=\mathrm{T}_{\text {MAX }}-\mathrm{T}_{\text {MIN }}
$$

em que:

$\mathrm{T}_{\mathrm{MAX}}$ - temperatura média máxima mensal, ${ }^{\circ} \mathrm{C}$;

$\mathrm{T}_{\mathrm{MAX}}$ - temperatura média mínima mensal, ${ }^{\circ} \mathrm{C}$;

$\mathrm{T}_{\mathrm{M}}$ - temperatura média mensal, ${ }^{\circ} \mathrm{C}$, calculada pela equação (9).;

$$
\mathrm{T}_{\mathrm{M}}=\frac{\mathrm{T}_{\mathrm{MAX}}+\mathrm{T}_{\mathrm{MIN}}}{2}
$$

Segundo Pereira et al. (2004), a correção acima descrita apresenta uma limitação, visto que essa estimativa não distingue evapotranspiração potencial para dois dias com $\mathrm{T}_{\mathrm{EF}}$ semelhantes, mas com fotoperíodos distintos. Para 
corrigir essa imprecisão, o autor propõe uma correção para a variável $T_{E F}$ em função da razão entre número de horas dia/noite, conforme Equação (10).

$$
\mathrm{T}_{\mathrm{EF}} *=\mathrm{T}_{\mathrm{EF}}\left(\frac{\mathrm{N}}{24-\mathrm{N}}\right)
$$

sendo:

$\mathrm{T}_{\mathrm{EF}}{ }^{*}$ - Temperatura efetiva, corrigida para o fotoperíodo, ${ }^{\circ} \mathrm{C}$;

$\mathrm{N}$ - o fotoperíodo médio mensal, em horas. $\mathrm{dia}^{-1}$.

Pereira et al. (2004), comparando dados estimados de evapotranspiração potencial pelo método de Penman-Monteith (PM); Thornthwaite baseado na temperatura média $\left(\mathrm{TH}-\mathrm{T}_{\mathrm{M}}\right.$ ); Thornthwaite baseado na temperatura média efetiva ( $\mathrm{TH}-\mathrm{T}_{\mathrm{EF}}$ ) e Thornthwaite baseado na temperatura média efetiva, corrigida pelo fotoperíodo ( $\mathrm{TH}-\mathrm{T}_{\mathrm{EF}}{ }^{*}$ ) em duas condições climáticas distintas, uma em Davis cujo clima é árido e a outra em Piracicaba, cujo clima é subtropical úmido, obtiveram os valores expressos na Tabela 3.

Tabela 3. Comparação entre os modelos de estimativa da evapotranspiração potencial em relação ao lisímetro de drenagem

\begin{tabular}{ccccccc}
\hline $\begin{array}{c}\text { Modelo de } \\
\text { Estimativa }\end{array}$ & $\begin{array}{c}\mathrm{ET} \\
\mathrm{mm} / \text { ciclo }\end{array}$ & $\begin{array}{c}\text { \% do } \\
\text { lisímetro }\end{array}$ & $\mathrm{R}^{2}$ & $\begin{array}{c}\mathrm{ET} \\
\mathrm{mm} / \text { ciclo }\end{array}$ & $\begin{array}{c}\% \text { do } \\
\text { lisímetro }\end{array}$ & $\mathrm{R}^{2}$ \\
\hline Lisímetro & $1.376,45$ & - & - & 564,10 & - & - \\
TH - $\mathrm{T}_{\mathrm{M}}$ & 807,85 & 59,0 & 0,5746 & 428,00 & 76,0 & 0,331 \\
TH - $\mathrm{T}_{\mathrm{EF}}$ & $1.328,61$ & 97,0 & 0,5296 & 546,40 & 97,0 & 0,4539 \\
TH - $\mathrm{T}_{\mathrm{EF}}{ }^{*}$ & $1.424,41$ & 103,0 & 0,7176 & 572,30 & 102,0 & 0,6044 \\
$\mathrm{PM}$ & $1.458,3$ & 106,0 & 0,8264 & 569,50 & $101 \%$ & 0,8158 \\
\hline
\end{tabular}

Fonte: Pereira et al. (2004)

Observa-se que a correção proposta para o fotoperíodo na temperatura média efetiva apresentou um ajuste eficiente (Tabela 3 ), sendo o seu valor 
$103 \%$ e $102 \%$ do medido pelo lisímetro de drenagem para as localidades de Davis e Piracicaba, respectivamente. Comparando os valores estimados por TH - $\mathrm{T}_{\mathrm{EF}}{ }^{*}$ e por Penman-Monteith, nota-se que são próximos, o que justifica a aplicação da correção na temperatura efetiva. Observa-se também que o modelo proposto por Pereira et al. (2004) apresenta elevada precisão de estimativa, com boa qualidade de ajuste da regressão, conforme apresenta 0 índice $r^{2}$, sendo este mais próximo do estimado pelo método de PM em comparação aos outros métodos de Thornthwaite.

Doorenbos \& Kassan (1979) definem como evapotranspiração máxima aquela que ocorre nas condições em que a água é suficiente para um adequado desenvolvimento da cultura comercial, condições fitossanitárias ótimas, cultivada em grandes extensões de área e sob correto manejo fitotécnico da área irrigada.

Segundo Doorenbos \& Pruitt (1977) há uma relação direta entre a evapotranspiração máxima e a evapotranspiração potencial, determinado por um valor de ajuste denominado como coeficiente de cultura - kc.

Como o coeficiente kc varia em função do tipo de cultura e de seu estádio de desenvolvimento, logo a evapotranspiração máxima é determinada para as condições regionais de clima (semelhantemente a evapotranspiração potencial), cultura e estágio de desenvolvimento.

Doorenbos \& Pruitt (1977) e Doorenbos \& Kassan (1979), apresentam de forma tabelada, valores gerais do coeficiente kc para diversas culturas, conforme apresenta. $\mathrm{Na}$ ausência de informações regionais de consumo de água pelas culturas adotam-se esses valores como referência.

Define-se como evapotranspiração real como aquela que ocorre numa superfície vegetada, independente de sua área, de seu porte e das condições de umidade do solo, sendo, portanto, aquela que ocorre nas condições reais. A estimativa desta é feita, principalmente, através do balanço hídrico climatológico, o qual considera o efeito da disponibilidade de água no solo na determinação da evapotranspiração real. 
O solo é um reservatório ativo, restringindo a evapotranspiração máxima da cultura de acordo com a demanda atmosférica e com seu teor de água. Denmead \& Shaw (1962), trabalhando com a cultura de milho em lowa (EUA), sob diferentes condições de disponibilidade de água no solo e de evaporação observaram: para valores de evapotranspiração potencial diária entre 3 a 4 $\mathrm{mmdia}^{-1}$, a taxa de evapotranspiração real da cultura foi inferior à potencial quando o teor de água no solo era inferior ao teor correspondente à tensão de água de -2 atm; para valores de evapotranspiração potencial entre 6 e 7 $\mathrm{mmdia}^{-1}$, a queda na evapotranspiração real era verificada quando atingia tensão de água inferior a $-0,3$ atm, e para valores de evapotranspiração potencial inferiores à $1,4 \mathrm{~mm} \cdot \mathrm{dia}^{-1}$, a redução da evapotranspiração real foi verificado nas tensões de água inferiores a -12 atm.

A partir desses dados, os autores concluíram que a evapotranspiração real da cultura é igual a evapotranspiração potencial até um certo valor de umidade do solo, o qual corresponde à determinada tensão total de água, sendo que esse valor é função da demanda atmosférica.

Considerando o efeito do solo na evapotranspiração real, Doorenbos \& Kassan (1979) definiram como fração da água disponível no solo, denominada por fração $(p)$, a quantidade de água que pode ser deduzida da capacidade de água total disponível no solo, sem que a evapotranspiração real se torne inferior a evapotranspiração máxima. Segundo esses autores, o valor da fração depende da cultura, da evapotranspiração máxima e do tipo solo.

Doorenbos \& Kassan (1979) apresentam valores da fração $(p)$ em quatro grupos principais de culturas de acordo com a evapotranspiração máxima dessas culturas, conforme apresenta a Tabela 4. 
Tabela 4. Valores da fração da água disponível no solo (p) segundo o grupo de culturas e a evapotranspiração máxima

\begin{tabular}{|c|c|c|c|c|c|c|c|c|c|}
\hline Grupo de & \multicolumn{9}{|c|}{ ETM $\left(\mathrm{mm} \cdot \mathrm{dia}^{-1}\right)$} \\
\hline Culturas & 2 & 3 & 4 & 5 & 6 & 7 & 8 & 9 & 10 \\
\hline 1 & 0,50 & 0,425 & 0,35 & 0,30 & 0,25 & 0,225 & 0,20 & 0,20 & 0,175 \\
\hline 2 & 0,675 & 0,575 & 0,475 & 0,40 & 0,35 & 0,325 & 0,275 & 0,25 & 0,225 \\
\hline 3 & 0,80 & 0,70 & 0,60 & 0,50 & 0,45 & 0,425 & 0,375 & 0,35 & 0,30 \\
\hline 4 & 0,875 & 0,80 & 0,70 & 0,60 & 0,55 & 0,50 & 0,45 & 0,425 & 0,40 \\
\hline
\end{tabular}

Fonte: Doorenbos \& Kassan (1979)

Thornthwaite \& Matter (1955), citado por Pereira (1997) consideraram que a taxa de perda de água no solo é diretamente proporcional ao armazenamento. Logo a hipótese basilar desse método é de que a taxa de perda de água por evapotranspiração varia linearmente com o armazenamento de água no solo, sendo máxima quando a umidade corresponde à capacidade de campo e nula quando corresponde ao ponto de murcha permanente. Matematicamente, pode ser descrito pela Equação (11).

$$
\frac{\mathrm{dB}}{\mathrm{dt}}=-\mathrm{kARM} \quad 0 \leq \mathrm{ARM} \leq \mathrm{CAD}
$$

O desenvolvimento matemático dessa hipótese é detalhado em Mendonça (1958), citado por Dourado Neto (1992). Integrando a equação acima e fazendo $B=C A D$ - ARM, obtém-se as relações para calcular o armazenamento atual do solo (ARM) em função da capacidade potencial de armazenamento de água no solo (CAD) e o déficit de armazenamento entre a CAD e o ARM denominado como negativo acumulado $\left(N_{A C}\right)$, conforme apresenta as Equações (12) e (13). 


$$
\begin{aligned}
& -\mathrm{N}_{\mathrm{AC}}=\mathrm{CAD} \ln \left(\frac{\mathrm{ARM}}{\mathrm{CAD}}\right) \\
& \mathrm{ARM}=\mathrm{CAD} \exp \left(\frac{-\mathrm{N}_{\mathrm{AC}}}{\mathrm{CAD}}\right)
\end{aligned}
$$

Baseando-se nas teorias desenvolvidas por Denmead \& Shaw (1962) e Rijtema \& Aboukhaled (1975), citado em Dourado Neto \& Van Lier (1993), a respeito do papel ativo do solo na taxa real de perda de água e, conseqüentemente, na determinação da água disponível deste, Braga (1982), propôs o mesmo modelo de depleção de água no solo, porém definido para os limites de água abaixo do armazenamento crítico, chegando na hipótese basilar, apresentada pelas Equações (14) e (15).

$$
\begin{array}{ll}
\frac{\mathrm{dB}}{\mathrm{dt}}=-\mathrm{k} & (1-\mathrm{p}) \mathrm{CAD} \leq \mathrm{ARM} \leq \mathrm{CAD} \\
\frac{\mathrm{dB}}{\mathrm{dt}}=-\mathrm{kARM} & 0 \leq \mathrm{ARM} \leq(1-\mathrm{p}) \mathrm{CAD}
\end{array}
$$

Integrando as Equações (14) e (15) obtém-se as Equações (16); (17); (18) e (19). Observa-se que $\Delta_{B H}$ representa $O$ saldo do déficit do armazenamento de água no solo ou o saldo do incremento do armazenamento de água no solo, sendo calculado pela diferença entre a precipitação efetiva e a evapotranspiração que ocorreram durante o período considerado.

$$
\begin{aligned}
& \mathrm{N}_{\mathrm{AC} \text { i }}=\mathrm{N}_{\mathrm{AC} \text { i-1 }}-\left|\Delta_{\mathrm{BH}}\right| \\
& \mathrm{ARM}=\mathrm{CAD}-\mathrm{N}_{\mathrm{AC}} \\
& \mathrm{N}_{\mathrm{AC}}=\mathrm{CAD}\left\{\mathrm{p}-\ln \left[\frac{\mathrm{ARM}}{(1-\mathrm{p}) \mathrm{CAD}}\right]\right\} \quad 0 \leq \mathrm{ARM} \leq(1-\mathrm{p}) \mathrm{CAD}
\end{aligned}
$$




$$
\mathrm{ARM}=(1-\mathrm{p}) \mathrm{CAD} \exp \left[\mathrm{p}-\frac{\mathrm{N}_{\mathrm{AC}}}{\mathrm{CAD}}\right]
$$

Dourado Neto \& Van Lier (1993), estudando 12 modelos de depleção da água no solo, através de 14 critérios estabelecidos, definiram que o modelo cosenoidal é o que apresenta melhores estimativas do armazenamento da água do solo, sendo, portanto, recomendado nos balanços hídricos. Sua hipótese basilar é apresentada pelas Equações (20) e (21).

$$
\begin{array}{ll}
\frac{\mathrm{dB}}{\mathrm{dt}}=-\mathrm{k} & 0 \leq \mathrm{ARM} \leq(1-\mathrm{p}) \mathrm{CAD} \\
\frac{\mathrm{dB}}{\mathrm{dt}}=\frac{\mathrm{k}}{2}\left\{1-\cos \left[\frac{\pi \mathrm{ARM}}{(1-\mathrm{p}) \mathrm{CAD}}\right]\right\} & (1-\mathrm{p}) \mathrm{CAD} \leq \mathrm{ARM} \leq \mathrm{CAD}
\end{array}
$$

Integrando esses dois modelos, desenvolvem-se as Equações (22); (23); (24) e (25):

$$
\begin{aligned}
& \mathrm{N}_{\mathrm{AC}}=\mathrm{N}_{\mathrm{AC} \mathrm{i}-1}-\left|\Delta_{\mathrm{BH}}\right| \\
& \mathrm{ARM}=\mathrm{CAD}-\mathrm{N}_{\mathrm{AC}} \\
& \mathrm{N}_{\mathrm{AC}}=\mathrm{CAD}\left\{\mathrm{p}+\frac{2}{\pi}(1-\mathrm{p}) \operatorname{tg}\left[\frac{\pi}{2}\left(1-\frac{\mathrm{ARM}}{(1-\mathrm{p}) \mathrm{CAD}}\right)\right]\right\} \\
& \mathrm{ARM}=(1-\mathrm{p}) \mathrm{CAD}\left\{1-\frac{2}{\pi} \operatorname{arctg}\left[\frac{\pi}{2}\left(\frac{\mathrm{N}_{\mathrm{AC}} / \mathrm{CAD}-\mathrm{p}}{1-\mathrm{p}}\right)\right](1-\mathrm{p}) \mathrm{CAD}\right. \\
&
\end{aligned}
$$

Durante o processo de secagem do solo, distinguem-se duas fases de disponibilidade de água para atendimento da demanda atmosférica, conforme descrito acima. Observa-se que até atingir a condição de $A R M_{A T} \leq A R M_{C R I T}$ 
assumiu-se que a depleção do armazenamento é linear com valor igual a ETM no período considerado. Quando $A R M_{A T} \geq A R M_{C R I T}$, essa depleção segue um modelo proposto por cada autor, demonstrando o incremento da resistência do solo à perda de água, através de sua retenção.

\subsection{Aplicação da análise de probabilidade em sistemas irrigados}

Algumas das principiais vantagens de análise da distribuição probabilística aos parâmetros climáticos são associados a:

- Quantificação da necessidade de irrigação suplementar das culturas comerciais;

- Fornece subsídios para o dimensionamento adequado da capacidade do sistema de irrigação;

- Possibilita a estimativa do risco de fracasso econômico e quebra de safra à atividade agrícola irrigada.

O emprego de modelos probabilísticos visando quantificar a freqüência de eventos climatológicos, como altura da precipitação efetiva, eventos extremos, evapotranspiração potencial, tem sido largamente estudado nos últimos anos. Estudos de análise probabilística são observados em trabalhos como Vivaldi (1973), Bernardo (1975), Frizzone (1979), Saad (1990), Piccinini (1993) e outros.

Bernardo (1975), empregando a distribuição de probabilidade gama incompleta, analisou a necessidade de irrigação suplementar para a região do Vale do Rio São Francisco no Nordeste Brasileiro. O autor elaborou uma rotina computacional a qual associava o balanço hídrico com a disponibilidade efetiva de precipitação. Esse programa estabelece a tomada de decisão sobre o momento de aplicação de lâmina de irrigação suplementar ao longo do ciclo das culturas. 
Alfonsi et al. (1997) estimaram a probabilidade de atendimento da demanda hídrica na cultura do milho, pela chuva, no Estado de São Paulo, empregando a distribuição gama incompleta. O autor definiu como demanda hídrica ideal da cultura a somatória decendial da evapotranspiração máxima.

Para a precipitação e a evapotranspiração é notória a não constância destes fenômenos em períodos sucessivos, o que impossibilita o planejamento confiável da produtividade agrícola.

Saad (1990), trabalhando com análise de probabilidade da precipitação e da evapotrasnpiração potencial em Piracicaba, não recomenda o emprego de valores médios dessas variáveis. $O$ autor afirma que o valor médio de uma série histórica não corresponde a uma faixa de confiança satisfatória.

Para Piracicaba as probabilidades correspondentes às precipitações médias, variaram de 28 a 42\% para o mês de março, e de 26 a 39\% para o mês de setembro, sendo que o valor recomendado está em torno de $75 \%$, segundo Saad (1990). O autor observa que o uso da evapotranspiração média para fins de dimensionamento de sistemas de irrigação resulta em projetos subdimensionados.

Segundo Frizzone (1979) em muitos casos utiliza-se o valor da precipitação média mensal de vários anos, no balanço hídrico para fins de dimensionamento de sistemas de irrigação. Este fato acarreta o subdimensionamento dos projetos visto que o valor médio da altura de precipitação corresponde, em geral, à probabilidade igual ou inferior a 50\%.

Doorenbos \& Pruitt (1977) recomendam níveis de probabilidade para a análise de precipitação entre 75 a $80 \%$ na maioria das regiões irrigadas. Para esses autores, níveis acima de $75 \%$ podem ser adotados no caso de culturas muito sensíveis ao déficit hídrico e que apresentem alta rentabilidade.

Existem muitas distribuições de probabilidade para dados contínuos, no caso do evento altura de chuva, geralmente emprega-se a distribuição gama, definida por Thom (1958), citado em Vivaldi (1973), Frizzone (1979), Saad (1990), Assis (1996). 
Normalmente, quando se analisa intervalos curtos de tempo (5, 7 e 10 dias), ocorrem valores nulos de totais de chuva, impossibilitando o uso de algumas distribuições de probabilidades contínuas como a normal.

Frizzone (1979) estudou algumas distribuições de probabilidade para caracterizar a chuva em diversos períodos no ano. O autor concluiu que a distribuição gama mista é a mais adequada para este evento.

Vivaldi (1973) utilizou a distribuição Gama e fez uma análise das estimativas dos seus parâmetros, concluindo que o modelo mostrou-se eficiente, para qualquer período considerado.

A distribuição gama incompleta não se aplica a valores nulos, uma vez que seus parâmetros são definidos para valores sempre maiores que zero. Para estes casos, recomenda-se a distribuição gama mista.

\subsection{FUNÇÕES DE PRODUÇÃO-ÁGUA CULTURA}

Frizzone (1998), define função de produção das culturas como uma relação física entre as quantidades utilizadas de certo conjunto de insumos e as quantidades físicas máximas que se pode obter do produto, para uma dada tecnologia conhecida. Considerando o grande número de variáveis que influencia a produtividade das culturas e a complexidade das relações que afetam a quantidade e a qualidade do produto, a produtividade pode ser expressa exclusivamente em função de um único fator, por exemplo a água aplicada quando se trata de irrigação, com tanto que os demais fatores da produção permaneçam fixos, em níveis ótimos.

Neste contexto, a resposta final que é a produtividade da cultura em função da quantidade total de água aplicada durante o ciclo da cultura, depende do manejo da irrigação e das condições edafoclimáticas locais. Considerando a quantidade de água como único fator variável, a função de produção águacultura pode ser expressa pela seguinte Equação: 


$$
\mathrm{Y}=\mathrm{Y}(\mathrm{LAM})_{\mathrm{p}, \mathrm{q}, \mathrm{r}, \mathrm{s}}
$$

sendo LAM a quantidade de água aplicada e os índices p,q,r,s representam, respectivamente, os fatores meteorológicos (exceto chuva), os fatores referentes ao solo (adubação), o material genético (variedade, híbrido etc) e os fatores fitotécnicos (época de plantio, tipo de poda, espaçamento adotado, controle de fitopredadores e fitopatógenos, etc, exceto irrigação).

Stewart \& Hagan (1973) e Hargreaves \& Samani (1984), elaboraram uma revisão detalhada sobre os esforços da pesquisa em obter funções de produção em função à água. Esses autores destacaram que as duas principais variáveis independentes são a evapotranspiração real acumulada (ETR) ou a lâmina de água disponível (LAM). A lâmina de água LAM contabiliza a precipitação efetiva e as irrigações aplicadas.

Esses autores afirmam que enquanto a evapotranspiração é o parâmetro mais diretamente associado à produtividade $(\mathrm{Y})$, a lâmina de água aplicada é o de maior interesse prático, pois, possibilita as análises sobre os sistemas de irrigação além de estudos econômicos, essências no planejamento da atividade agrícola irrigada. Da mesma forma Frizzone (1998) afirma que as funções de produção água-cultura deveriam se basear na evapotranspiração, em vez de relacionar a produtividade com a água aplicada, porque seriam mais independentes do sistema de irrigação, do solo e de outros fatores locais que influenciam a forma da curva. Mas, na prática, os irrigantes controlam a lâmina aplicada e não a evapotranspiração.

Para desenvolver estratégias ótimas de irrigação é necessário, portanto, utilizar relações entre a água aplicada e a produtividade. Para baixos níveis de irrigação, inferiores a cerca de $50 \%$ da irrigação plena, a produção tende a variar linearmente com a água aplicada (Vaux e Pruitt, 1983; Hargreaves e Samani, 1984). Além desse ponto, a relação se torna curvilínea com o aumento da quantidade de água aplicada, como conseqüência das perdas por percolação profunda, escoamento superficial e evaporação, até atingir um máximo. Para quantidades de irrigação superiores a esse ponto de máxima 
produção, ocorre um decaimento da curva, refletindo perdas de produção devido a condições anaeróbicas nas raízes, doenças e lixiviação de nutrientes associadas ao uso excessivo de água.

Figuerêdo (1998), trabalhando com a cultura de feijão de inverno nas condições de cerrado, estabeleceu como momento de irrigação as seguintes tensões de água no solo: $33 \mathrm{kPa}, 50 \mathrm{kPa}, 70 \mathrm{kPa}, 100 \mathrm{kPa}, 500 \mathrm{kPa}$ e 1000 $\mathrm{kPa}$, o que gerou produtividades diferenciadas para cada nível acima estabelecido e, conseqüentemente, quantidades de água aplicada distintas. Objetivando a maximização do rendimento das culturas, o autor definiu que a cultura de feijão apresenta máximo rendimento quando for adotado como momento de irrigação a tensão de água do solo em torno de $37 \mathrm{kPa}$.

Geralmente, as funções de produção água-cultura apresentam duas tendências: uma ascendente, na qual o rendimento é crescente com o aumento da quantidade de água aplicada até um limite máximo, o que corresponde ao ponto ótimo da curva, e a outra descendente, na qual o rendimento diminui com a quantidade crescente de lâmina aplicada (Frizzone, 1998).

Segundo Dantas Neto (1994), o comportamento ascendente da curva é associado ao déficit de produção devido à quantidade insuficiente do insumo água. A perda do rendimento das culturas na fase descendente decorre do aumento no nível de infestação de fungos no solo, asfixia do sistema radicular e a lixiviação de nutrientes. Além dessas considerações fitotécnicas, há as perdas por percolação profunda com o aumento da lâmina total, o que ocasiona as baixas eficiências de água aplicada. 


\section{MATERIAL E MÉTODOS}

\subsection{Modelo computacional: descrição}

Desenvolveu-se um modelo computacional para estimar o rendimento esperado de cultivos em áreas irrigadas, bem como a quebra da produtividade média em relação à máxima e as lâminas de água acumuladas ao longo do ciclo da cultura.

Esse modelo baseia-se na estimativa da irrigação suplementar, simulada por meio de balanços hídricos seqüenciais, em escala de tempo diária, ao longo de uma série histórica de dados disponibilizada pelo usuário.

A partir dos valores de lâmina de água disponível para a cultura (LAM), a qual contabiliza a precipitação e as irrigações simuladas, e da lâmina líquida de irrigação suplementar (IRR), ambas acumuladas ao longo do ciclo, aplica-se análise de probabilidade.

Aplicando-se os valores probabilísticos de LAM em funções de produção específicas, estima-se o rendimento médio esperado e a sua quebra em relação ao máximo esperado.

Com dados referentes à distribuição de água pelo sistema de irrigação, esse modelo estima a produção esperada em toda a área irrigada.

A Figura 1 apresenta o fluxograma das principais etapas realizadas pelo modelo proposto. 


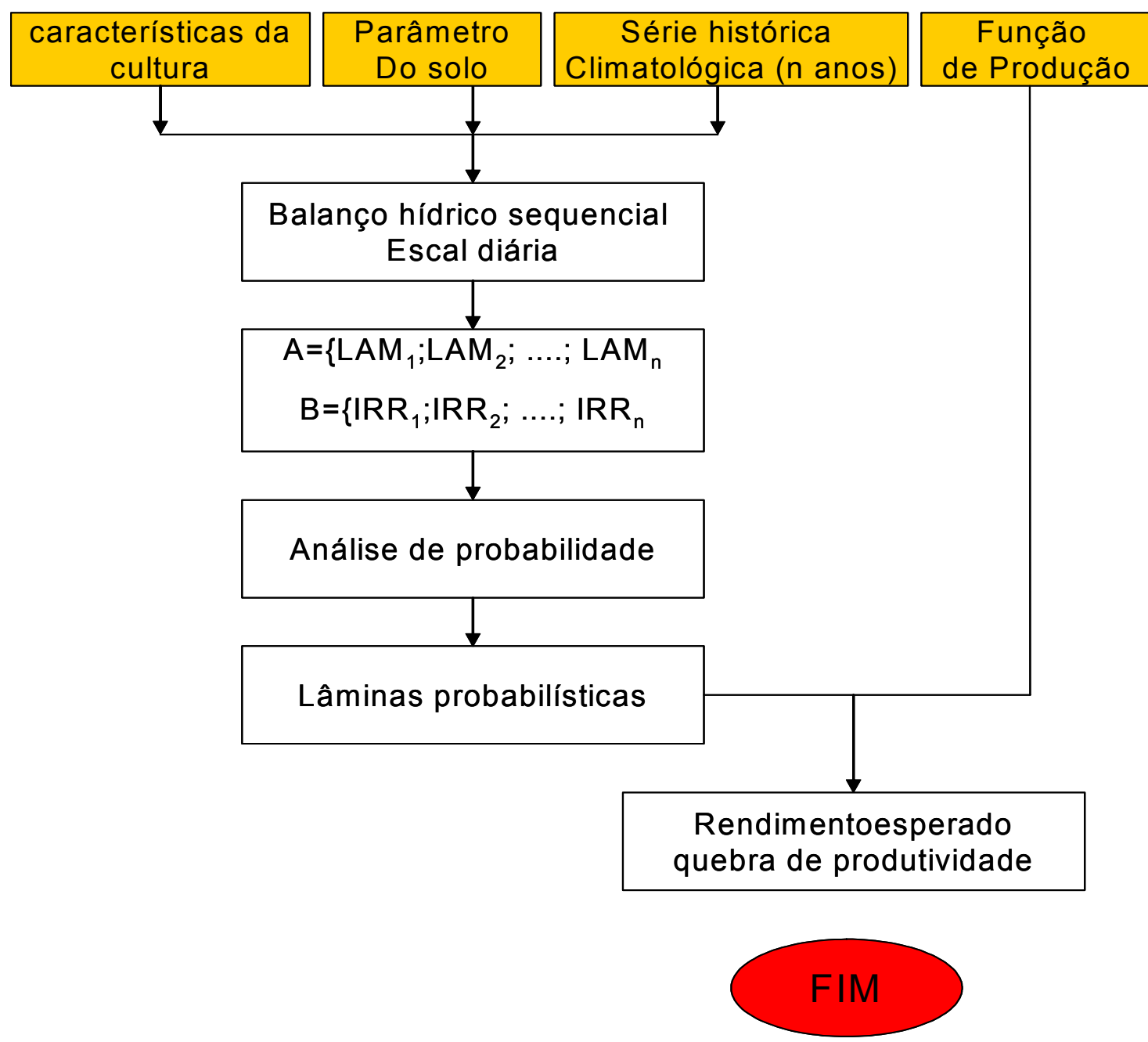

Figura 1 - Fluxograma geral do modelo computacional desenvolvido para estimativa do rendimento das culturas em áreas irrigadas

O modelo computacional foi codificado em linguagem Visual Basic usando a plataforma do Excel.

O modelo requer os seguintes parâmetros de entrada:

1. Propriedades do solo:

- Parâmetros da equação de van Genuchten - $\alpha$; $\theta$ s; $\theta$ r; $n$; m - se disponíveis;

2. Características da cultura: 
- Profundidade efetiva do sistema radicular;

- Duração do ciclo (em dias ou graus dias acumulados);

- Duração do ciclo quando o sistema radicular atinge profundidade máxima;

- Potencial mátrico crítico da cultura;

- Época de suspender as irrigações;

- Função de resposta das culturas à irrigação;

3. Dados climáticos:

- Dados diários de precipitação;

- Escolha do modelo de estimativa da evapotranspiração potencial e os respectivos dados climáticos necessários;

\subsection{Definição do momento de irrigação}

Definido como o momento de aplicação de água no solo. O momento de irrigar é determinado por meio da definição de uma umidade do solo considerada mínima $\left(\theta_{\mathrm{MIN}}\right)$, o que corresponde, diretamente, a uma tensão crítica da água do solo ( $\left.\Psi_{\mathrm{CRIT}}\right)$, ou seja, a partir da qual há apreciável redução do rendimento da cultura analisada.

Esse valor de $\Psi_{\text {CRIT }}$ é definido pelo usuário do modelo proposto, sendo sua fonte a literatura científica específica ou mesmo a prática local do agricultor irrigante.

A obtenção da $\theta_{\text {MIN }}$ é feita a partir do estabelecimento do valor de $\Psi_{\text {CRIT }}$ constante durante todo o ciclo da cultura, no horizonte de tempo estudado, e da curva de retenção de água do solo, segundo modelo de van Genuchten (1980), cujos parâmetros são inseridos no início da rotina operacional. A partir desse, calcula-se o armazenamento mínimo de água no solo ( $\left(\mathrm{RM}_{\mathrm{MIN}}\right)$, conforme apresenta a Equação (27). 


$$
\mathrm{ARM}_{\mathrm{MIN}}=\left(\theta_{\mathrm{CC}}-\theta_{\mathrm{CRIT}}\right) \mathrm{z}_{\mathrm{EF}}
$$

Caso o usuário não disponibilize dos parâmetros da curva característica do solo, opta-se por um valor direto $A_{R M} M_{M I N}$.

A Figura 2 apresenta o fluxograma para determinação da umidade mínima do solo, utilizando-se a equação de van Genutchen.

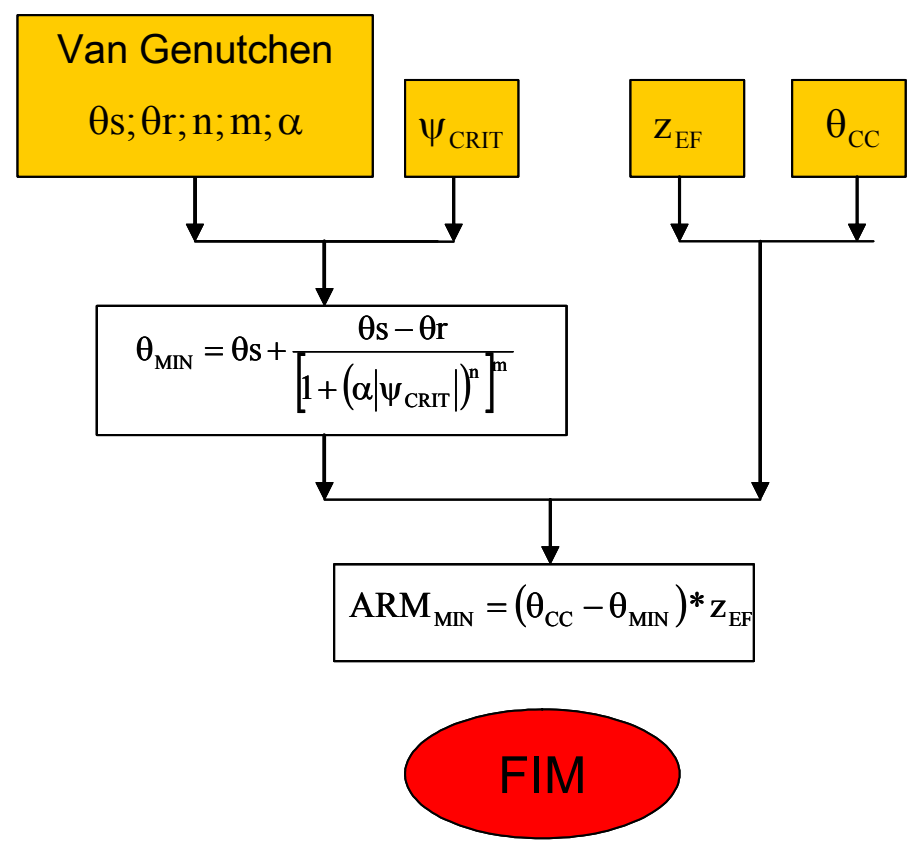

Figura 2 - Fluxograma para determinação da umidade mínima do solo para manejo da irrigação utilizando-se parâmetros do solo

\subsection{Estimativa da duração do ciclo da cultura}

Para estimativa da duração do ciclo da cultura foram propostos dois métodos: a estimativa dos graus dias acumulados ou contabilização dos dias sucessivos do ciclo. 


\subsubsection{Estimativa dos graus dias acumulados}

O desenvolvimento das plantas é condicionado pelo clima que ocorre durante o seu ciclo. Sob condições ideais, sem limitações, e estando os fatores de produção em equilíbrio, a performance das plantas é máxima.

Para determinar a duração dos ciclos sucessivos das culturas estudadas baseou-se no conceito de somatória de unidades térmicas, normalmente, denominado como graus-dia. Conforme Ometto (1981) este método é uma simplificação eficiente da estimativa da energia à disposição de uma planta, em cada dia. Neste procedimento contabiliza-se o acúmulo diário da energia que se situa acima da condição mínima e abaixo da máxima exigida pela planta.

O valor dos graus-dia diário foi determinado segundo as Equações (28) e (29) para as diferentes condições de temperatura mínima que ocorreram no dia em questão:

$$
\mathrm{T}_{\mathrm{MIN}} \geq \mathrm{Tb}:
$$

$$
\mathrm{GD}(\mathrm{T})=\mathrm{T}_{\mathrm{M}}-\mathrm{Tb}
$$

em que:

$\mathrm{GD}(\mathrm{T})$ - graus-dia acumulado em um dia em função da temperatura;

$\mathrm{T}_{\mathrm{M}}$ - temperatura média que ocorreu no dia, ${ }^{\circ} \mathrm{C}$;

$\mathrm{Tb}$ - temperatura basal, ${ }^{\circ} \mathrm{C}$.

$\mathrm{T}_{\mathrm{MIN}}$ - temperatura mínima observada no dia, ${ }^{\circ} \mathrm{C}$.

$\mathrm{T}_{\text {MIN }}<\mathrm{Tb}:$

$$
\mathrm{GD}(\mathrm{T})=\frac{\left(\mathrm{T}_{\mathrm{MAX}}-\mathrm{Tb}\right)^{2}}{2\left(\mathrm{~T}_{\mathrm{MAX}}-\mathrm{T}_{\mathrm{MIN}}\right)}
$$

em que:

$\mathrm{T}_{\text {MAX }}$ - temperatura máxima que ocorreu no dia, ${ }^{\circ} \mathrm{C}$. 
Observa-se que durante o desenvolvimento da cultura os graus-dia serão acumulados durante o período até que se atinja um valor máximo que indicará o ponto de maturidade fisiológica da produção, o qual encerra o ciclo da cultura.

A somatória dos graus dias acumulados até um período qualquer do ciclo da cultura é calculada pela Equação (30).

$$
\mathrm{GD}_{\mathrm{AC}}=\int_{\text {emergência }}^{\text {atual }} \mathrm{GD}(\mathrm{T}) \mathrm{dt}=\sum_{\text {emergência }}^{\text {atual }} \mathrm{GD}(\mathrm{T})
$$

em que:

$\mathrm{GD}_{\mathrm{AC}}$ - graus dias acumulados, desde a emergência até o período atual.

Para generalizar a utilização dos dois métodos acima descritos, utiliza-se uma sigla referência denominada por Índice da duração do ciclo (IDC), que denota tanto os $\mathrm{GD}_{\mathrm{AC}}$, quanto os dias após início da emergência (DAI).

A Figura 3 apresenta o fluxograma da estimativa diária da duração do ciclo pela contabilização dos dias após a emergência (DAí) e pelos graus dias acumulados $\mathrm{GD}_{\mathrm{AC}}$. 


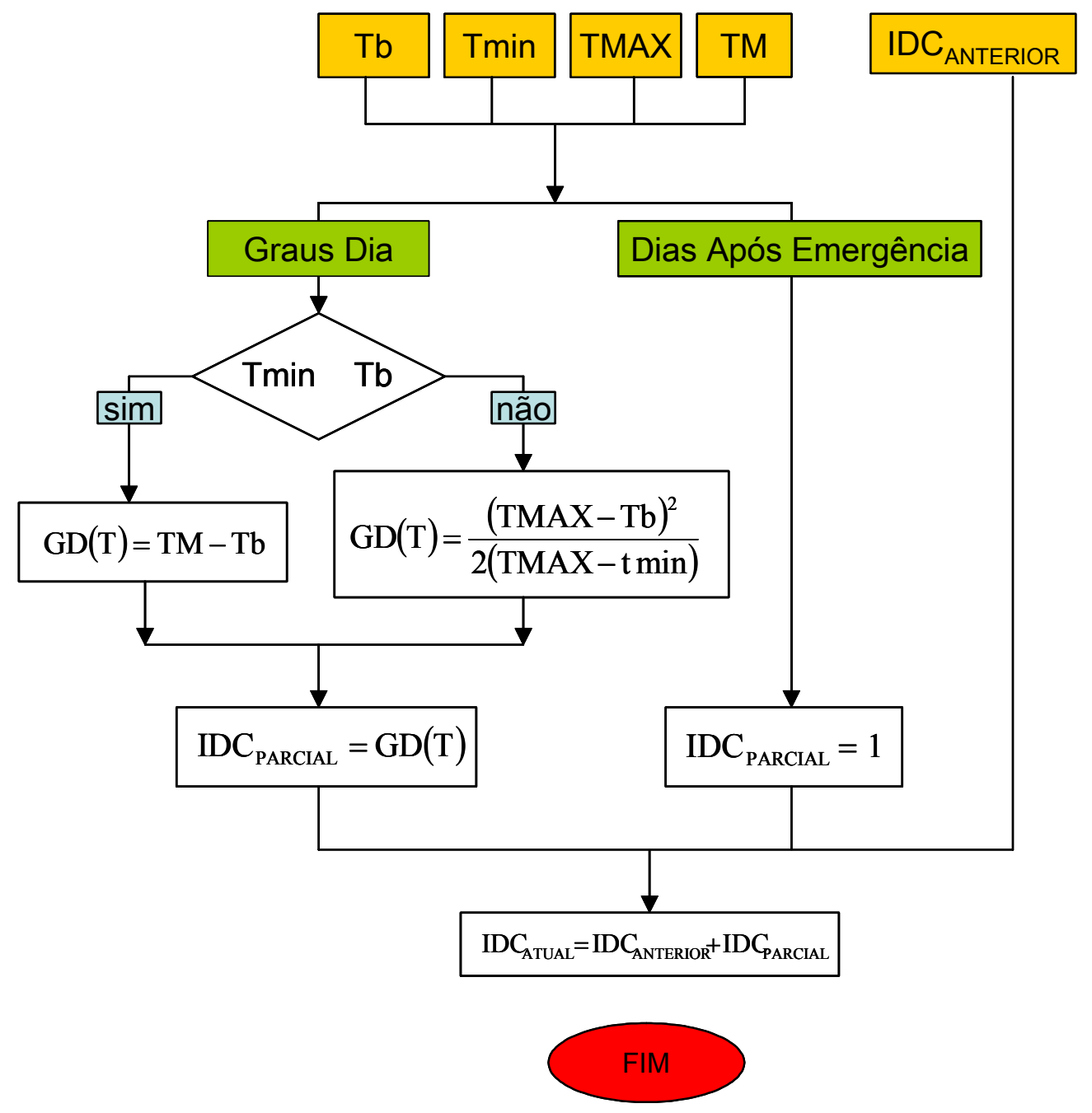

Figura 3 - Fluxograma para estimativa diária do índice de duração do ciclo da cultura (IDC), pela metodologia de graus dias $[\mathrm{GD}(\mathrm{T})]$ e pela contabilização dos dias sucessivos após emergência (DAI)

\subsection{Variação da capacidade potencial de armazenamento de água do solo}

De acordo com PEREIRA (1997), a equação geral para o cálculo da capacidade de água disponível no solo (CAD) para uma determinada profundidade pode ser determinada pela Equação (31). 
$\mathrm{CAD}=(\theta \mathrm{cc}-\theta \mathrm{pmp}) \sum \mathrm{z}_{\mathrm{EF}}$

em que:

$\theta_{\mathrm{CC}}$ - umidade à base de volume, na capacidade de campo, $\mathrm{m}^{3} \mathrm{~m}^{-3}$;

$\theta_{\mathrm{PMP}}$ - umidade à base de volume, no ponto de murcha permanente, $\mathrm{m}^{3} \mathrm{~m}^{-3}$

$\mathrm{Z}_{\mathrm{EF}}$ - profundidade efetiva do solo, $\mathrm{mm}$.

A umidade no ponto de murcha permanente foi considerada como a umidade correspondente à tensão da água do solo de $1.500 \mathrm{kPa}$, visto que seu conceito é complexo e, portanto seu o valor de difícil definição, conforme descreve Reichardt (1988).

Essas umidades são determinadas por meio da curva característica do solo, segundo o modelo de regressão de van Genuchten (1980), conforme Equação (32).

$$
\theta=\theta \mathrm{r}+\frac{\theta \mathrm{s}-\theta \mathrm{r}}{\left[1+\left(\alpha\left|\psi_{\mathrm{m}}\right|\right)^{\mathrm{n}}\right]^{\mathrm{m}}}
$$

em que:

$\theta$ s - umidade volumétrica de saturação do solo, $\mathrm{m}^{3} \mathrm{~m}^{-3}$;

$\theta r$ - umidade volumétrica residual do solo, $\mathrm{m}^{3} \mathrm{~m}^{-3}$;

$\alpha$ - parâmetro de ajuste de forma, $\mathrm{kPa}^{-1}$;

n, m - parâmetros adimensionais da equação.

Segundo Driessen (1986), citado em Dourado Neto (1992), a profundidade do sistema radicular ( $\mathrm{Z}_{\mathrm{RAIZ}}$ ) progride linearmente a partir de um valor inicial, até atingir uma profundidade máxima. Já, Dourado Neto (1992), descreve que o crescimento radicular segue um padrão sigmoidal.

A fim de contemplar ambas as metodologias supra descritas propõe-se uma simplificação para estimativa do $Z_{\text {RAIZ }}$ baseando-se nos seguintes critérios:

- Será fornecido ao modelo valores de $z_{\text {RAIZ }}$ com os seus respectivos IDC em forma de uma tabela; 
- A partir destes valores fornecidos serão traçados segmentos de reta que interliguem os $Z_{\text {RAIZ }}($ IDC) seqüencialmente;

- $O$ valor do $Z_{\text {RAIZ }}(I D C)$ atual será resultante da interpolação linear entre os dois valores tabelados mais próximos.

A Figura 4 apresenta o fluxograma geral para determinação da profundidade atual do sistema radicular da cultura ( $\left.Z_{R A I Z}\right)$ em função da duração do ciclo.

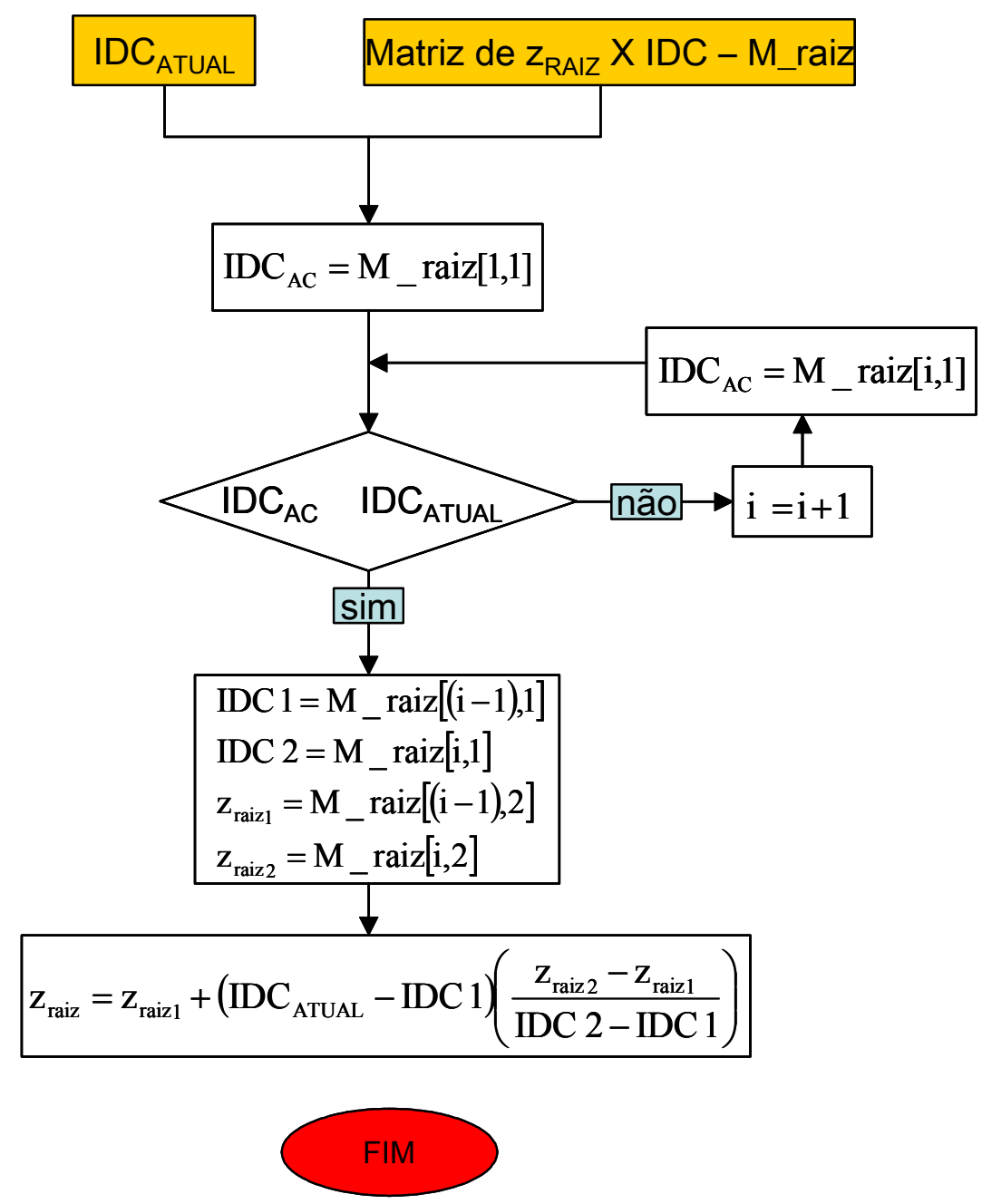

Figura 4 - Fluxograma para determinação do comprimento do sistema radicular da cultura em função do índice de duração do ciclo (IDC) 
Esse incremento na profundidade do sistema radicular proporciona aumento no armazenamento potencial da água do solo, portanto, haverá incremento da Capacidade de Água Disponível (CAD) para a cultura.

Embora o crescimento radicular seja contínuo, não há instrumentação comercial disponível que possibilite uma medição contínua do "status" da água do solo ao longo de todo o perfil explorado. Para tanto, faz-se a divisão desse perfil em camadas onde são instalados equipamentos de monitoramento do "status" de água em profundidades de referência $\left(Z_{R E F}\right)$, que representam uma média da respectiva camada de solo.

Objetivando fazer com que as simulações da reposição de água no solo representassem adequadamente a prática usual de manejo de irrigação, foram adotados os seguintes critérios:

- Manejo de irrigação a semelhança dos instrumentos de medida do "status" da água no solo como sonda de nêutrons, tensiômetro ou TDR;

- A profundidade empregada para o cálculo da CAD acompanha o desenvolvimento da profundidade radicular $\left(Z_{R A I Z}\right)$ de forma estratificada. Assim, dividiu-se a profundidade total em camadas as quais apresentam uma profundidade de referência, denominada por $z_{R E F}$ respectiva. $A$ profundidade referente à camada só será contabilizada para dimensionamento da profundidade efetiva do solo quando o crescimento radicular atingir esta $z_{R E F}$, ou seja, quando $Z_{R A I Z}>Z_{R E F}$.

Exemplificando, considere-se uma profundidade máxima explorada de solo de $35 \mathrm{~cm}$, sendo esta dividida em 3 camadas. A primeira camada, mais superficial, com $15 \mathrm{~cm}$ de espessura e as outras duas subseqüentes com espessura de $10 \mathrm{~cm}$. Empregando a metodologia acima descrita, supõe-se que tenham sido instalados 3 tensiômetros nas profundidades de 10,20 e $30 \mathrm{~cm}$, respectivamente. $A z_{R E F}$ considerada seria de $15 \mathrm{~cm}$ enquanto $z_{R A I z}$ não atingisse comprimento de $20 \mathrm{~cm}$. Quando $z_{R A I Z}=20 \mathrm{~cm}$, o valor de $z_{R E F}$ passaria a ser $25 \mathrm{~cm}$. Assim, quando $z_{R A I Z}$ atingisse $30 \mathrm{~cm} z_{R E F}$ seria de $35 \mathrm{~cm}$. Observa- 
se que o $Z_{\text {REF }}$ para estimativa da CAD apresenta 3 valores, 15, 25 e 35, demonstrando 0 crescimento estratificado a ser considerado nessa metodologia.

\subsection{Determinação da evapotranspiração potencial}

Para estimativa da evapotranspiração potencial (ETP) foram propostos quatro modelos distintos.

A Tabela 5 apresenta, resumidamente, as principais variáveis climáticas exigidas para cada modelo.

Tabela 5. Variáveis climáticas exigidas para cada modelo de estimativa da evapotranspiração potencial (ETP)

\begin{tabular}{lccccc}
\multicolumn{1}{c}{ Modelos } & \multicolumn{5}{c}{ Variáveis climáticas } \\
& T & UR & U2 & Rn & ECA \\
\hline Penman & $\mathrm{X}$ & $\mathrm{X}$ & $\mathrm{X}$ & $\mathrm{X}$ & \\
Pristhey-Taylor & $\mathrm{X}$ & & & $\mathrm{X}$ & \\
Thornthawite & $\mathrm{X}$ & & & & \\
Classe A & & $\mathrm{X}$ & $\mathrm{X}$ & & $\mathrm{X}$ \\
\hline
\end{tabular}

Observa-se que além desses modelos de estimativa da ETP o programa permite, também, que o usuário insira, diretamente, o valor da ETP, caso já existente, no balanço hídrico seqüencial.

A seguir são apresentados os métodos de determinação da evapotranspiração de referência utilizados no modelo. 


\subsubsection{Método de Penman (1948)}

Utilizou-se a expressão proposta por Penman (1948), descrita em Pereira (1997), Saad (1990) e Braga (1982), sendo apresentada pela Equação (33).

$$
\lambda \mathrm{ETP}=\frac{\Delta}{\Delta+\gamma} \mathrm{Rn}+\frac{\gamma}{\Delta+\gamma} \lambda \mathrm{Ea}
$$

em que:

$\Delta$ - tangente da curva de saturação do vapor de água, $\mathrm{kPa}^{\circ} \mathrm{C}^{-1}$;

$\gamma$ - constante psicrométrica, $\mathrm{kPa}^{\circ} \mathrm{C}^{-1}$;

$\mathrm{Rn}$ - Saldo de radiação na superfície, $\mathrm{MJ} \mathrm{m}^{-2} \mathrm{dia}^{-1}$;

$\lambda \mathrm{Ea}$ - termo aerodinâmico da equação de Penman, $\mathrm{MJ} \mathrm{m}^{-2} \mathrm{dia}^{-1}$.

Para calcular o fator $\Delta$, empregou-se a equação da curva de saturação do vapor d'água de Tetens, apresentada em Ometto (1981).

$$
\mathrm{e}_{\mathrm{SAT}}=\mathrm{A} 10\left(\frac{7,5 \mathrm{~T}_{\mathrm{M}}}{237,3+\mathrm{T}_{\mathrm{M}}}\right)
$$

em que:

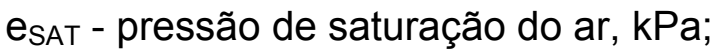

A - coeficiente de ajuste de unidades, $(0,061) \mathrm{kPa}$;

$\mathrm{T}_{\mathrm{M}}$ - temperatura do ar, ${ }^{\circ} \mathrm{C}$.

Derivando-se a Equação (34) em função da temperatura, obtém-se a tangente da curva de variação da pressão de saturação de vapor, apresentada pela Equação (35).

$$
\Delta=\frac{\partial \mathrm{e}}{\partial \mathrm{T}} \therefore \Delta=\frac{2.499,79510^{\left(\frac{7,5 \mathrm{~T}}{237,3+\mathrm{T}}\right)}}{(237,3+\mathrm{T})^{2}}
$$


A constante psicrométrica é calculada pela Equação (36).

$\gamma=\frac{\mathrm{cpPatm}}{0,622 \lambda}$

em que:

$\mathrm{cp}$ - calor específico do ar atmosférico, (1005) $\mathrm{Jkg}^{-10} \mathrm{C}^{-1}$;

$\lambda$ - calor latente de vaporização da água, $\mathrm{Jkg}^{-1}$, calculado pela Equação (37);

$\lambda=2491146-2135,268 \mathrm{~T}$

sendo :

Patm - pressão atmosférica local, kPa, calculada pela Equação (38).

Patm $=101,325\left(1-\frac{0,0065 E}{288}\right)^{5,2568}$

em que:

E - altitude local, $m$.

O poder evaporante do ar é estimado pela Equação (39).

$\lambda \mathrm{Ea}=\mathrm{f}\left(\mathrm{U}_{2}\right) \Delta \mathrm{e}$

em que:

$f\left(U_{2}\right)$ - função de vento preconizada por Penman (1948), $\mathrm{MJm}^{-2} \mathrm{dia}^{-1} \mathrm{kPa}^{-1}$;

$\mathrm{U}_{2}$ - velocidade do vento a 2 metros da superfície, $\mathrm{ms}^{-1} \mathrm{e}$;

$\Delta \mathrm{e}$ - déficit de saturação, kPa, calculado pela Equação (40).

$\Delta \mathrm{e}=\mathrm{e}_{\mathrm{SAT}}-\mathrm{e}_{\mathrm{a}}$

em que:

$e_{a}$ - pressão de vapor do ar atmosférico, kPa, calculado pela Equação (41). 


$$
\mathrm{e}_{\mathrm{a}}=\frac{\mathrm{UR} \mathrm{e}_{\mathrm{SAT}}}{100}
$$

em que:

UR - umidade relativa do ar, \%.

A função de vento, descrita por uma relação linear que toma por base a velocidade do vento, é calculada pela Equação (42).

$$
\mathrm{f}\left(\mathrm{U}_{2}\right)=\mathrm{m}_{\mathrm{V}}\left(\mathrm{a}+\mathrm{bU}_{2}\right)
$$

em que:

$m_{\mathrm{V}}$ - coeficiente de ajuste de unidades, $(6,43) \mathrm{MJm}^{-2} \mathrm{dia}^{-1} \mathrm{kPa}^{-1}$;

a, b - parâmetros de ajuste da equação de vento regional;

\subsubsection{Método de Pristley - Taylor}

Utilizou-se a expressão proposta por Pristley-Taylor, descrita em Pereira (1990) e Peres (1994), sendo apresentada pela Equação (43).

$$
\lambda \mathrm{ETP}=\kappa \alpha \frac{\Delta}{\Delta+\gamma} \mathrm{Rn}
$$

em que:

$\kappa \alpha$ - coeficiente de Pristley-Taylor;

Objetivando apresentar uma alternativa que proporcionasse a aplicação de parâmetros regionais, foi contemplada, no modelo computacional, a possibilidade de inserir o valor do coeficiente $\kappa \alpha$ em escala mensal. Dessa forma, pode-se atribuir um valor médio constante de 1,26 ao longo do ano, ou atribuir um valor mensal de acordo com as condições climáticas locais. 


\subsubsection{Método de Thornthwaite (1948)}

Proposto para estimativa da ETP média mensal, sendo apresenta pela Equação (3).

O modelo proposto permite também a correção da temperatura efetiva apresentada por Pereira \& Pruitt. (2004).

O fotoperíodo (N) foi calculado pela Equação (44).

$$
\mathrm{N}=\frac{\mathrm{Hn}}{15}
$$

em que:

Hn - horário ao nascer do sol.

O Hn pode ser determinado pela equação (45).

$$
\mathrm{Hn}=\operatorname{arcos}[-\tan \mathrm{g}(\phi) \tan \mathrm{g}(\vartheta)]
$$

em que:

$\phi$ - latituide local:

$\vartheta$ - declinação magnética.

A declinação magnética é determinada pela Equação (46).

$\vartheta=23,45 \operatorname{sen}[0,986(\mathrm{NDA}-81)]$

em que:

NDA - número de dias segundo o calendário juliano (de 1 até 365 dias).

Quando for usado o método de Thorntwaite, a ETP será constante para todo o mês, uma vez que será empregada a temperatura média mensal. 


\subsubsection{Método do tanque classe A}

Mede diretamente o efeito integrado do balanço energético, das condições aerodinâmicas locais e das condições de umidade atmosférica sobre a evaporação de uma superfície de água livre. Como a cultura responde às mesmas condições climáticas, pode-se estabelecer correspondência direta entre a ETP e a evaporação do tanque classe A (ECA), multiplicando-se esta variável por um coeficiente de proporcionalidade denominado por coeficiente de tanque (kp), conforme apresentado na Equação (47).

$$
\mathrm{ETP}=\mathrm{kp} \mathrm{ECA}
$$

Com o mesmo intuito descrito na inserção do coeficiente $\kappa \alpha$ do modelo de Pristley \& Taylor, ao se escolher o método do tanque Classe A, deve-se fornecer, na escala diária, juntamente com o valor de ECA, o valor do $\mathrm{kp}$ estimado ou medido.

\subsection{Determinação da evapotranspiração máxima da cultura}

O consumo de água por uma cultura qualquer, sem haver restrição hídrica é estimado pela Equação (48), apresentada por Doorenbos \& Kassan (1979). Nesta equação a ETP é relacionada à evapotranspiração máxima da cultura (ETM) por meio de um coeficiente de cultura denominado por $\mathrm{kc}($ IDC).

$$
\mathrm{ETM}=\mathrm{kc}(\mathrm{IDC}) \mathrm{ETP}
$$

O valor de kc é função do desenvolvimento do ciclo da cultura - kc(IDC), medido tanto em dias do ciclo total quanto em $\mathrm{GAD}_{\mathrm{AC}}$. Portanto, esse coeficiente varia em função do estágio fenológico atual o que corresponde, 
indiretamente, a eventos fisiológicos (florescimento, frutificação, etc) e a evolução da área foliar, conforme descreve Villa Nova et al. (1996).

Os valores tabelados de kc(IDC) propostos pela FAO-24 (1994), revisados por Allen (1998), descrevem, matematicamente, a evolução do $\mathrm{kc}(\mathrm{IDC})$ por meio de quatro segmentos linearizados.

A fim de contemplar ambas as metodologias descritas, propõe-se uma simplificação para estimativa do kc(IDC) baseando-se na linearização descrita para estimativa do crescimento do sistema radicular.

A luz da metodologia acima descrita, a Figura 5 apresenta o fluxograma para determinação do valor do kc em função da duração do ciclo da cultura. 


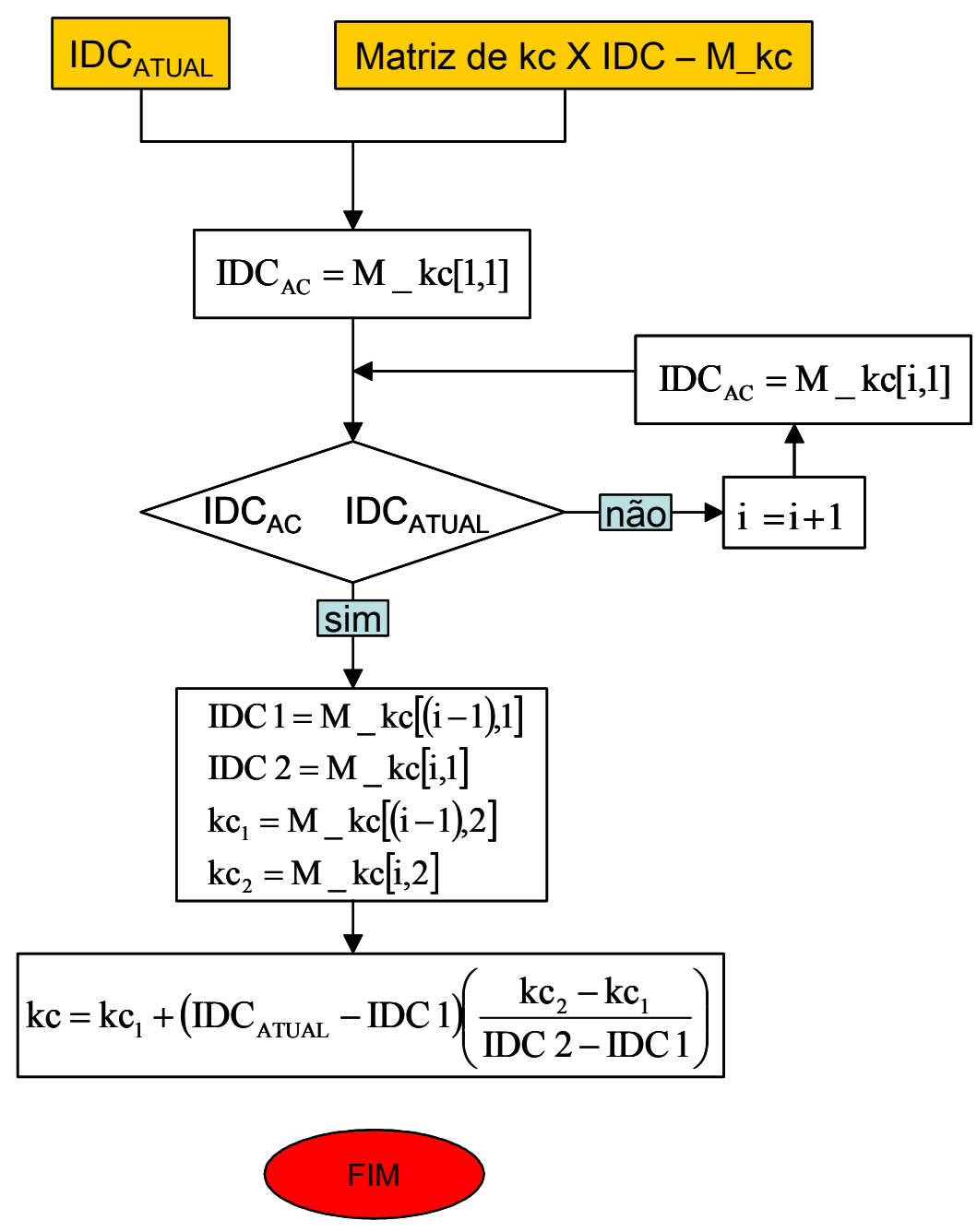

Figura 5 - Fluxograma para determinação do coeficiente de cultura (kc) em função do índice de duração do ciclo (IDC)

A Figura 6 apresenta o fluxograma geral para estimativa diária da evapotranspiração potencial (ETP) e da evapotranspiração máxima da cultura (ETM), proposto no modelo computacional. 


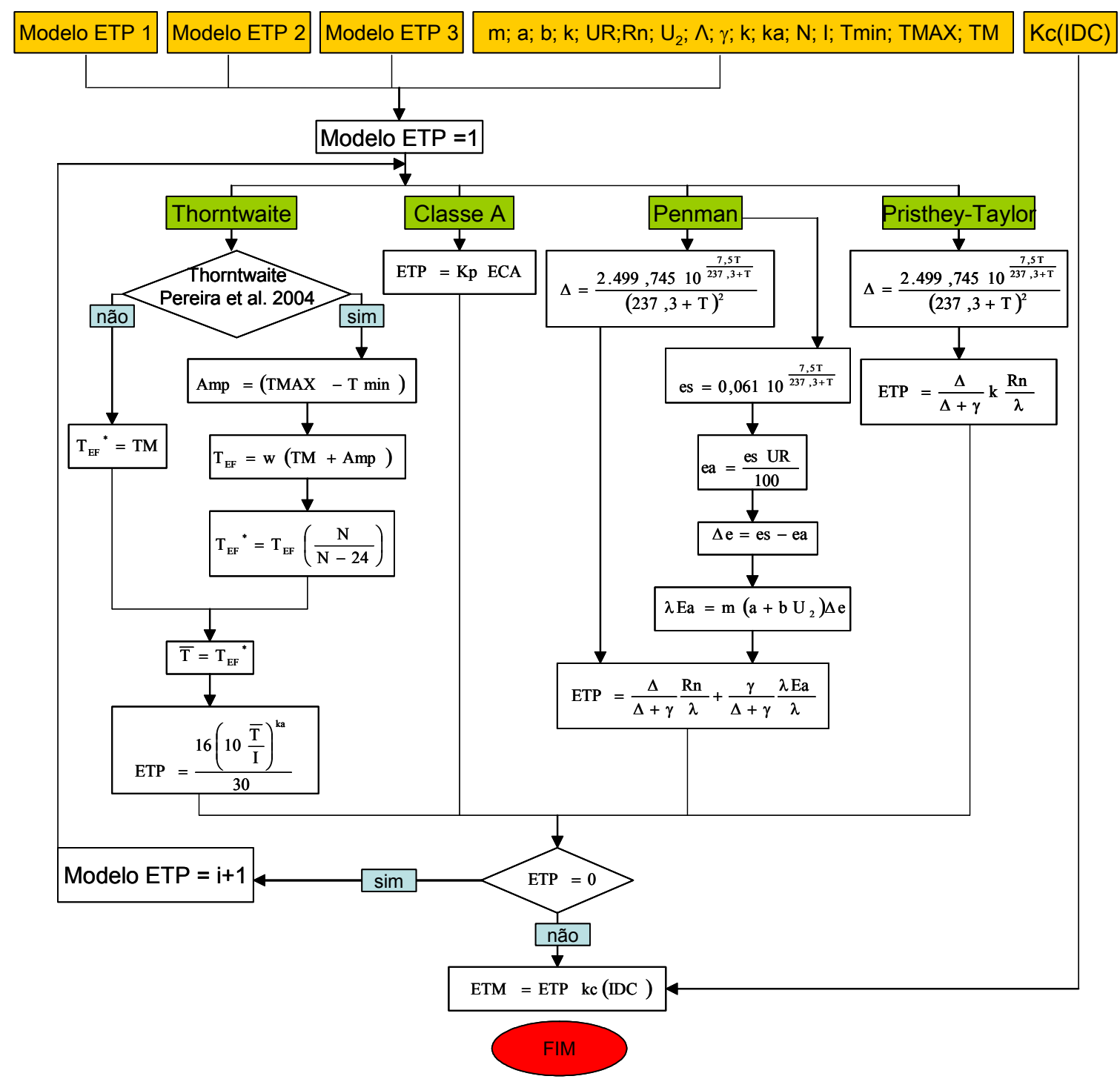

Figura 6 - Fluxograma da estimativa diária da evapotranspiração potencial (ETP) e da evapotrasnpiração máxima da cultura (ETM) através das metodologias: Thorntwaite, modificada por Pereira (2004); Penman (1948); Priestley-Taylor e Tanque Classe A 


\subsection{O balanço hídrico diário sequencial (BHDS)}

Baseia-se na contabilização entre as entradas e as saídas de água num volume definido do sistema solo, quantificando o armazenamento de água neste volume e sua variação em tempo real.

A precipitação $(\mathrm{CH})$ e a lâmina de irrigação líquida (IRR) são as principais entradas consideradas nesse sistema, sendo que a quantidade de água que excede os limites estabelecidos pela CAD, é considerada como excesso (EXC), e, portanto, não é adicionada ao sistema. Este excesso (EXC) é considerado como perda de água ou por percolação profunda ou por deflúvio superficial.

De acordo com as metodologias propostas por Braga (1982) e Dourado Neto \& van Lier (1993) que baseiam na complementação de diferentes critérios e teorias existentes, como os empregados por Thornthwaite \& Matter (1955), citado em Pereira (1997), FAO (1977) e Denmead \& Shaw (1962), a evapotranspiração real da cultura (ETR) considera não apenas a capacidade máxima de água disponível no solo, mas também a cultura empregada, a demanda atmosférica, quantificada pela evapotranspiração potencial (ETP) e a disponibilidade de água no solo, medida pela fração de água disponível (FAD).

O modelo proposto de balanço hídrico seqüencial permite incorporar o manejo da irrigação planejado por meio da definição de um armazenamento mínimo que será utilizado para definir o momento de irrigação e a variação progressiva da CAD de forma estratificada.

Salienta-se que este modelo permite utilizar como modelo de depleção do armazenamento de água no solo tanto o apresentado por Braga (1982) quanto o proposto por Dourado Neto \& van Lier (1993). 


\subsubsection{Seqüência dos cálculos do BHDS:}

\section{- Inicialização do BHDS}

Como o sistema agrícola é irrigado, foi considerado que, no início do balanço hídrico, a umidade do solo encontra-se na capacidade de campo e, portanto, o $\mathrm{ARM}_{\mathrm{at}}=\mathrm{CAD}$, conseqüentemente, $\mathrm{N}_{\mathrm{at}}=0$.

Esse critério justifica-se pela prática de irrigar o sistema agrícola após a sua implantação (no caso de culturas anuais) ou no reinício da atividade produtiva (culturas perenes ou de ciclo longo). Desta forma, trabalha-se na expectativa de "encher a caixa de água do solo" ou seja, aplica-se uma lâmina de irrigação até atingir a capacidade de campo em grande profundidade. Objetiva-se com isto garantir um "stand" de plantas uniforme ou retomada de ciclo uniforme, como no caso do florescimento de culturas perenes.

\section{- Coluna $\mathrm{CH}$}

Nesta coluna é introduzido o valor diário da altura de chuva efetiva $(\mathrm{CH})$, em mm. Adotou-se como critério, que as alturas de chuvas que ocorreriam deveriam ser pelo menos de $1,0 \mathrm{~mm}$.

Esse critério está de acordo com Saad (1990), o qual adotou como critério de aproximação da altura de chuva para $1,0 \mathrm{~mm}$ no caso de $0,5<\mathrm{CH}<$ $1,0 \mathrm{~mm}$, e considerada como nula no caso de $\mathrm{CH}<0,5 \mathrm{~mm}$.

\section{- Coluna ETM}

Refere-se à evapotranspiração máxima (ETM) obtida a partir da metodologia descrita no item 3.5. 


\section{- Coluna FAD}

Seguindo a metodologia proposta por Braga (1982) e por Dourado Neto (1992), os quais adotaram as idéias preconizadas por Demnand \& Shaw (1962), a fração de água disponível no solo (FAD) representa a quantidade de água do reservatório potencial do solo CAD que está livremente disponível para a demanda da cultura, ou seja, somente após a FAD ser toda consumida, o solo apresenta resistência a extração de água, determinando uma condição de estresse hídrico para a planta. Neste momento a evapotranspiração real (ETR) torna-se menor que a ETM.

Essa fração de água é calculada pela Equação (49).

$$
\mathrm{FAD}=\mathrm{p}(\mathrm{ETM}) \mathrm{CAD}
$$

A fração remanescente de água no solo, denominada por Armazenamento crítico (ARM $\mathrm{CRIT}_{\mathrm{T}}$ ), é definida matematicamente pela Equação (50), uma vez que se conhece o valor de $\mathrm{p}(\mathrm{ETM})$.

$$
\mathrm{ARM}_{\mathrm{CRIT}}=[1-\mathrm{p}(\mathrm{ETM})] \mathrm{CAD}
$$

A partir dos dados que correlacionam a fração de água disponível no solo (p) com a demanda atmosférica (evapotranspiração potencial - ETP), fornecidos por Doorenbos \& Kassan (1979), foram ajustados quatro equações de regressão, conforme se observa na Tabela 6. Observa-se que a divisão dos grupos segue a mesma proposta pelo autor, que a definiu segundo grupo de culturas e nível de sensibilidade ao estresse hídrico. 
Tabela 6. Modelos matemáticos que relacionam o fator $\mathrm{p}$ de água disponível do solo (Doorenbos \& Kassan, 1979) com a evapotranspiração máxima (ETM), por grupo de culturas

\begin{tabular}{cc}
\hline Grupo & Equações de ajuste \\
\hline 1 & $\mathrm{p}=\mathrm{A}+\mathrm{B} \mathrm{ETM}+\mathrm{CETM} \mathrm{ET}^{3}+\mathrm{D} \mathrm{e}^{\mathrm{ETM}}+\mathrm{E} \frac{\ln (\mathrm{ETM})}{\mathrm{ETM}^{2}}$ \\
2 & $\mathrm{p}=\mathrm{A}+\mathrm{BETM}+\frac{\mathrm{C}}{\mathrm{ETM}}+\mathrm{DETM}^{2}+\frac{\mathrm{E}}{\mathrm{ETM}^{2}}+\mathrm{FETM}^{3}+\frac{\mathrm{G}}{\mathrm{ETM}^{3}}+\mathrm{HETM}^{4}$ \\
3 & $\mathrm{p}=\mathrm{A}+\mathrm{BETM}+\mathrm{CETM} \ln (\mathrm{ETM})+\frac{\mathrm{D}}{\mathrm{ETM}^{0,5}}+\frac{\mathrm{E}}{\mathrm{e}^{\mathrm{ETM}}}$ \\
4 & $\mathrm{p}=\left(\mathrm{A}+\mathrm{B} \mathrm{ETM}+\mathrm{CETM}{ }^{2}+\mathrm{D} \mathrm{ETM}^{3}+\mathrm{E} \mathrm{ETM}^{4}+\mathrm{FETM}^{5}\right)^{2}$ \\
\hline
\end{tabular}

Grupo 1:

$A=0,65901183 ; B=-0,084107482 ; C=0,00045060343 ; D=-4,2577435^{\star} 10-6$;

$E=0,034627265$.

Grupo 2:

$A=1,5387125 ; B=-0,58830496 ; C=0,46444382 ; \quad D=0,11066466 ; E=-$ 0,$6705633 ; F=-0,009788843 ; G=-0,97093282 ; H=0,0003251322$.

Grupo 3:

$A=-15,534037 ; \quad B=2,5036442 ; \quad C=-0,67883144 ; \quad D=20,327811 ; E=-$ 15,562625 .

Grupo 4:

$A=0,7208473 ; B=0,29982062 ; C=-0,13775306 ; D=0,024516978 ; E=-$ 0,$0020126571 ; F=6,2990315^{*} 10-5$.

Ao invés de empregar ETP como variável indicativa da demanda atmosférica foi utilizada a ETM. Segundo BRAGA (1982), estes valores 
prestam-se melhor para estudos de balanço hídrico para uma cultura e épocas de plantios específicos, isto para uma condição local e para sistema de produção planejado. O mesmo autor afirma que se utilliza a ETP para estimativa da fração $p$, no âmbito regional, o qual envolve aspectos gerais climatológicos, para fins de zoneamento.

\section{- Coluna (CH-ETM+IRR $\left.R_{\text {ANT }}\right)$}

Obtida a partir da subtração da coluna de precipitação $(\mathrm{CH})$ e evapotranspiração (ETM) adicionado à lâmina líquida de irrigação do dia anterior (IRR $\left.\mathrm{ANT}_{\mathrm{A}}\right)$, conforme a Equação (51).

$$
\Delta_{\mathrm{BH}}=\mathrm{CH}-\mathrm{ETM}+\mathrm{IRR}_{\mathrm{ANT}}
$$

Esta coluna demonstra se, no período considerado, houve água fornecida pela precipitação ou pela irrigação, suficientes para suprir a demanda atmosférica (ETM) definindo dois regimes hídricos distintos no solo:

- $\Delta_{\mathrm{BH}}>0$ : choveu ou irrigou-se mais que a demanda evapotranspiratória, ou seja, o solo recebeu uma quantidade de água adicional, portanto o armazenamento atual será maior que o anterior $\left(A R M_{A T}>A R M_{A N T}\right)$, definindo a condição de MOLHAMENTO do solo;

- $\Delta_{\mathrm{BH}}<0$ : choveu ou irrigou-se menos que a demanda evapotranspiratória, ou seja, o solo perdeu uma quantidade de água armazenada, portanto o armazenamento atual será menor que o anterior $\left(A_{R} M_{A T}\right.$ $<\mathrm{ARM}_{\mathrm{ANT}}$ ), definindo a condição de SECAMENTO do solo. 
- Colunas negativo acumulado atual (NA $\mathrm{N}_{\mathrm{AT}}$ ) e armazenamento atual $\left(\mathrm{ARM}_{\mathrm{AT}}\right)$ :

A metodologia apresentada por Braga (1982) e Dourado Neto \& van Lier (1993) que contempla as idéias propostas por Denmead \& Shaw (1962) propõem que tanto o armazenamento do solo (ARM) e o negativo acumulado $\left(N_{A C}\right)$ sejam funções também da fração $p(E T M)$.

Neste contexto, os modelos propostos não apresentam uma única função de armazenamento, conseqüentemente, nem uma única função do negativo acumulado, porém uma família de curvas $A R M\left[N_{A C}, p(E T M)\right]$ e uma família de curvas $\mathrm{N}_{\mathrm{AC}}[\mathrm{ARM}, \mathrm{p}(\mathrm{ETM})]$. Essa situação pode acarretar imprecisão na estimativa do armazenamento do solo e do negativo acumulado.

Estas duas colunas são calculadas simultaneamente, sendo que a rotina de cálculo utilizada é apresentada como se segue abaixo:

$$
\Delta_{\mathrm{BH}}=\left(\mathrm{CH}-\mathrm{ETM}+\mathrm{IRR} \mathrm{R}_{\mathrm{ANT}}\right)>0-\text { MOLHAMENTO DO SOLO }
$$

1. Estimativa da taxa de variação do negativo acumulado a partir da derivada da função $\mathrm{N}_{\mathrm{AC}}[\mathrm{ARM}, \mathrm{p}(\mathrm{ETM})]$ :

$$
\frac{\partial \mathrm{N}_{\mathrm{AC}}}{\partial \mathrm{ARM}}=\mathrm{N}_{\mathrm{AC}}{ }^{\prime}\left[\mathrm{ARM}_{\mathrm{REF}}, \mathrm{p}(\mathrm{ETM})\right]
$$

em que:

$A_{R} M_{\text {REF }}$ Armazenamento de referência, sendo calculado pela Equação (53).

$$
\mathrm{ARM}_{\mathrm{REF}}=\mathrm{ARM}_{\mathrm{ANT}}+\frac{\left|\Delta_{\mathrm{BH}}\right|}{2}
$$


2. Estimativa da variação total do negativo acumulado a partir da taxa de variação calculada e da variação potencial $\Delta_{\mathrm{BH}}$ :

$$
\Delta \mathrm{N}_{\mathrm{AC}}=\left|\Delta_{\mathrm{BH}}\right| \mathrm{N}_{\mathrm{AC}}{ }^{\prime}\left[\mathrm{ARM}_{\mathrm{REF}}, \mathrm{p}(\mathrm{ETM})\right]
$$

As derivadas das equações do negativo acumulado propostas por Braga (1982) e Dourado Neto \& van Lier (1993) desses modelos são apresentadas pelas Equações (55) e (56).

Braga (1982):

$$
\frac{\partial \mathrm{N}_{\mathrm{AC}}}{\partial \mathrm{ARM}}=\frac{-\mathrm{CAD}}{\mathrm{ARM}_{\mathrm{REF}}}
$$

Dourado Neto \& van Lier (1993):

$$
\frac{\partial \mathrm{N}_{\mathrm{AC}}}{\partial \mathrm{ARM}}=-\sec ^{2}\left\{\frac{\pi}{2}\left[1-\frac{\mathrm{ARM}_{\mathrm{REF}}}{[1-\mathrm{p}(\mathrm{ETM})] \mathrm{CAD}}\right]\right\}
$$

3. Incremento de $\Delta_{B H}$ no $A R M_{A T}$ do solo. Se o valor do $A R M_{A T}$ for maior que a capacidade potencial do solo $C A D$, considera-se que $A R M_{A T}=C A D$. $A$ diferença é considerada como perda por excesso (EXC), conforme apresenta a Equação (57).

$$
\mathrm{ARM}_{\mathrm{AT}}=\mathrm{ARM}_{\mathrm{ANT}}+\Delta_{\mathrm{BH}}
$$

4. Estimativa do $\mathrm{NA}_{\mathrm{AT}}$ :

Para ARM $_{A T}>$ ARM $_{C R I T}$ 
$\mathrm{N}_{\mathrm{AC} \mathrm{AT}}=\mathrm{CAD}-\mathrm{ARM}_{\mathrm{AT}}$

Para $\mathrm{ARM}_{\mathrm{AT}}<\mathrm{ARM}_{\mathrm{CRIT}}$

$\mathrm{N}_{\mathrm{AC} \text { AT }}=\mathrm{N}_{\mathrm{AC} \text { ANT }}+\mid \Delta \mathrm{N}_{\mathrm{AC}}\left[\mathrm{ARM}_{\mathrm{AT}}, \mathrm{p}(\mathrm{ETM})\right]$

$$
\Delta_{\mathrm{BH}}=\left(\mathrm{CH}-\mathrm{ETM}+\mathrm{IRR}_{\mathrm{ANT}}\right)<0-\text { SECAMENTO DO SOLO }
$$

1. Estimativa da taxa de variação do armazenamento a partir da derivada da função ARM[N,p(ETM)], conforme equação (60)

$\frac{\partial \mathrm{ARM}}{\partial \mathrm{N}_{\mathrm{AC}}}=\mathrm{ARM}^{\prime}\left(\mathrm{N}_{\mathrm{AC} \text { REF }}, \mathrm{ETM}\right)$

em que:

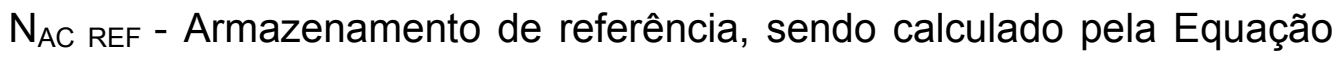
(61):

$\mathrm{N}_{\mathrm{AC} \text { REF }}=\mathrm{N}_{\mathrm{AC} \text { ANT }}+\frac{\left|\Delta_{\mathrm{BH}}\right|}{2}$

2. Estimativa da variação total do armazenamento a partir da taxa de variação calculada pela equação $A R M '\left[N_{A c}, p(E T M)\right]$ e da variação potencial $\Delta_{\mathrm{BH}}$ :

$$
\Delta \mathrm{ARM}=\left|\Delta_{\mathrm{BH}}\right| \operatorname{ARM}^{\prime}\left(\mathrm{N}_{\mathrm{AC} \text { REF }}, \mathrm{ETM}\right)
$$

As derivadas das equações do armazenamento são apresentadas pelas Equações (63) e (64). 
Braga (1982):

$\frac{\partial \mathrm{ARM}}{\partial \mathrm{N}_{\mathrm{AC}}}=-[1-\mathrm{p}(\mathrm{ETM})] \exp \left[\mathrm{p}(\mathrm{ETM})-\left|\mathrm{N}_{\mathrm{AC}} \mathrm{REF}\right| / \mathrm{CAD}\right]$

Dourado Neto \& van Lier (1993):

$$
\frac{\partial \mathrm{ARM}}{\partial \mathrm{N}_{\mathrm{AC}}}=\frac{-4[1-\mathrm{p}(\mathrm{ETM})]^{2}}{4[1-\mathrm{p}(\mathrm{ETM})]^{2}+\pi^{2}\left[\left|\mathrm{~N}_{\mathrm{AC}}\right| / \mathrm{CAD}-\mathrm{p}(\mathrm{ETM})\right]^{2}}
$$

3. Acréscimo de $\Delta_{B H}$ no $N A_{A C}$ AT:

$$
\mathrm{N}_{\mathrm{AC} \quad \mathrm{AT}}=\mathrm{N}_{\mathrm{AC} \text { ANT }}+\left|\Delta_{\mathrm{BH}}\right|
$$

No momento em que o $\mathrm{ARM}_{\mathrm{AT}}$ equivale ao $\mathrm{ARM}$ CRIT, pode-se utilizar as seguintes modificações algébricas.

$$
\begin{gathered}
\mathrm{ARM}_{\mathrm{CRIT}}=[1-\mathrm{p}(\mathrm{ETM})] \mathrm{CAD} \Leftrightarrow \mathrm{CAD}-\mathrm{ARM}_{\mathrm{CRIT}}=\mathrm{p}(\mathrm{ETM}) \mathrm{CAD} \\
\mathrm{N}_{\mathrm{AC} \mathrm{AT}}=\mathrm{p}(\mathrm{ETM}) \mathrm{CAD}
\end{gathered}
$$

Pelo desenvolvimento acima, nota-se que é possível averiguar se o

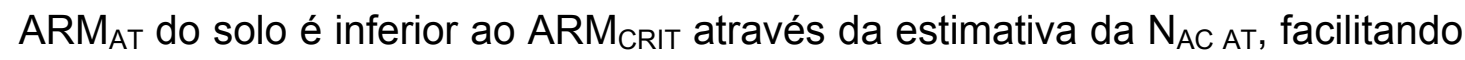
a rotina operacional do balanço hídrico, como apresentado abaixo.

4. Estimativa do $\mathrm{ARM}_{\mathrm{AT}}$ :

Para $\mathrm{N}_{\mathrm{AC} \text { AT }}<\mathrm{p}(\mathrm{ETM})^{\star} \mathrm{CAD}$ 
$\mathrm{ARM}_{\mathrm{AT}}=\mathrm{ARM}_{\mathrm{ANT}}-\left|\Delta_{\mathrm{BH}}\right|$

Para $\mathrm{N}_{\mathrm{AC} \text { AT }}>\mathrm{p}(\mathrm{ETM})^{\star} \mathrm{CAD}$

$$
\mathrm{ARM}_{\mathrm{AT}}=\mathrm{ARM}_{\mathrm{ANT}}+\left|\Delta \mathrm{ARM}\left[\mathrm{N}_{\mathrm{AC} \text { AT }}, \mathrm{p}(\mathrm{ETM})\right]\right|
$$

- Coluna IRR:

Quando o $A R M_{A T}$ da água do solo for menor que o $A R M_{M I N}$, definido no item 3.2, o modelo proposto simula a aplicação de uma lâmina de irrigação..

A lâmina líquida de irrigação aplicada foi calculada como a altura de água necessária para repor a umidade do solo até a capacidade de campo, conforme apresenta a equação (68).

$$
\mathrm{IRR}=\mathrm{CAD}-\mathrm{ARM}_{\mathrm{AT}}
$$

\section{- Coluna ALT:}

A coluna alteração $(A L T)$ refere-se à variação do armazenamento do solo durante dois períodos sucessivos, representando se houve incremento (sendo $\operatorname{ALT}>0$ ) ou perda de água (sendo ALT < 0):

$$
\mathrm{ALT}=\mathrm{ARM}_{\mathrm{AT}}-\mathrm{ARM}_{\mathrm{ANT}}
$$

\section{- Coluna ETR:}

A coluna evapotranspiração real (ETR) representa a quantidade de água que a cultura efetivamente evapotranspirou. Conforme descrito nos itens anteriores, a ETR equivale a ETM enquanto a FAD não for totalmente 
consumida, ou seja, $A R M_{A T} \leq A R M_{C R I T}$, quando não há déficit hídrico para a cultura. Quando toda o armazenamento atual estiver abaixo do armazenamento crítico a ETR será calculada pela Equação (70).

$$
\mathrm{ETR}=\mathrm{CH}+|\mathrm{ALT}|
$$

\section{- Coluna DEF:}

Quantifica a deficiência (DEF) que ocorreu durante o período considerado. Caso a demanda atmosférica seja atendida plenamente então este valor será igual a zero $(E T M=E T R)$ e a cultura não sofrerá quedas de produtividade, por outro lado, se houver deficiência hídrica, caracteriza a situação de deficiência hídrica e o reflexo será na queda de produtividade, sendo esse valor mensurado pela Equação (71).

$$
\mathrm{DEF}=\mathrm{ETM}-\mathrm{ETR}
$$

\section{- Coluna EXC:}

Toda a precipitação que ocorrer num período e não for armazenada pelo solo (significando que a capacidade de armazenamento de água do solo foi ultrapassada) será perdida ou por escoamento superficial ou por drenagem interna do próprio solo. Todo o excesso (EXC) será mensurado pela Equação (72).

$$
\mathrm{EXC}=\Delta_{\mathrm{BH}}+\mathrm{ARM}_{\mathrm{ANT}}-\mathrm{CAD}
$$

A Figura 7 e a Figura 8 apresentam os fluxogramas do balanço hídrico diário proposto no modelo computacional. 


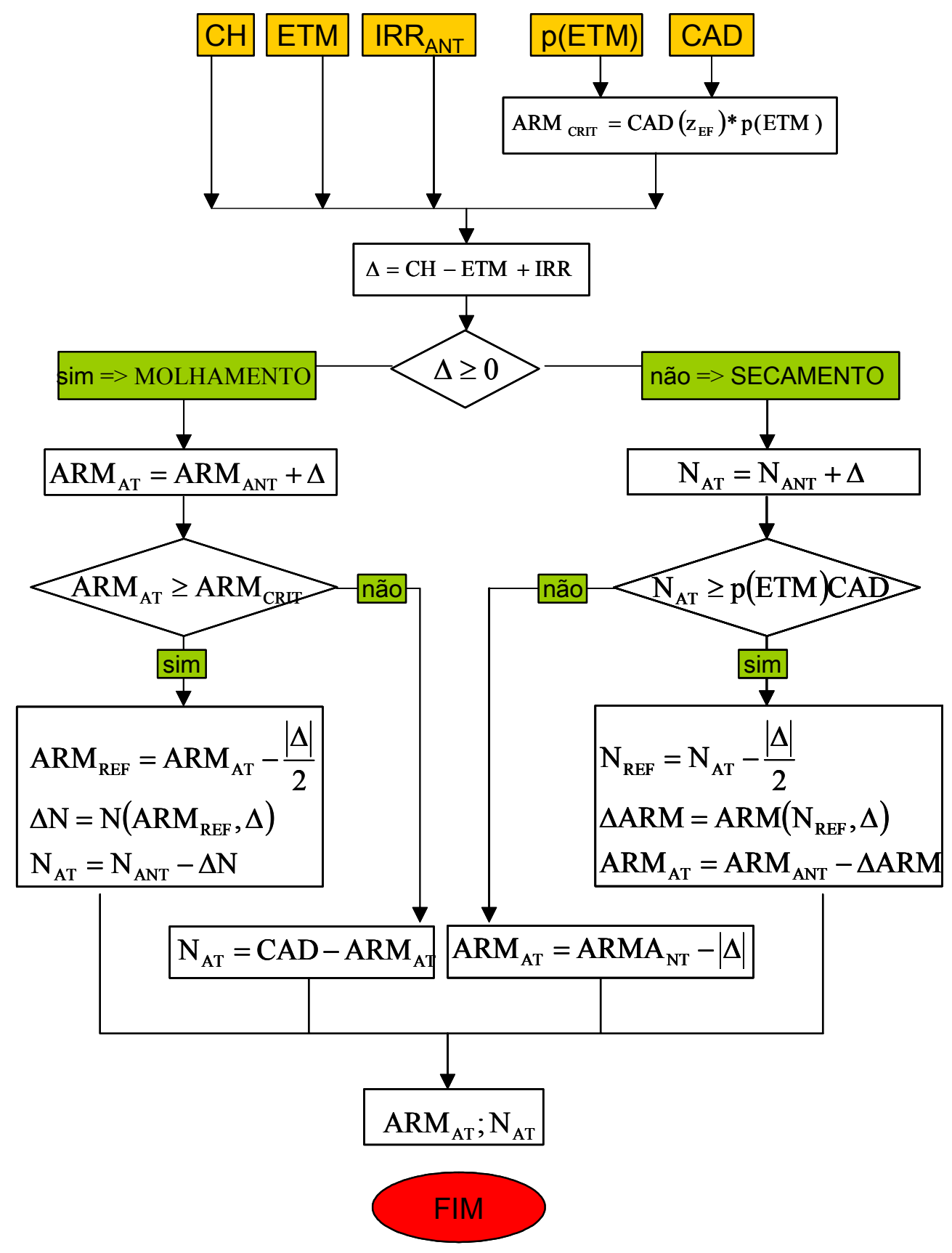

Figura 7 - Fluxograma do balanço hídrico diário: determinação do armazenamento atual $\left(\mathrm{ARM}_{\mathrm{AT}}\right)$ e do negativo acumulado $\left(\mathrm{N}_{\mathrm{AT}}\right)$ 


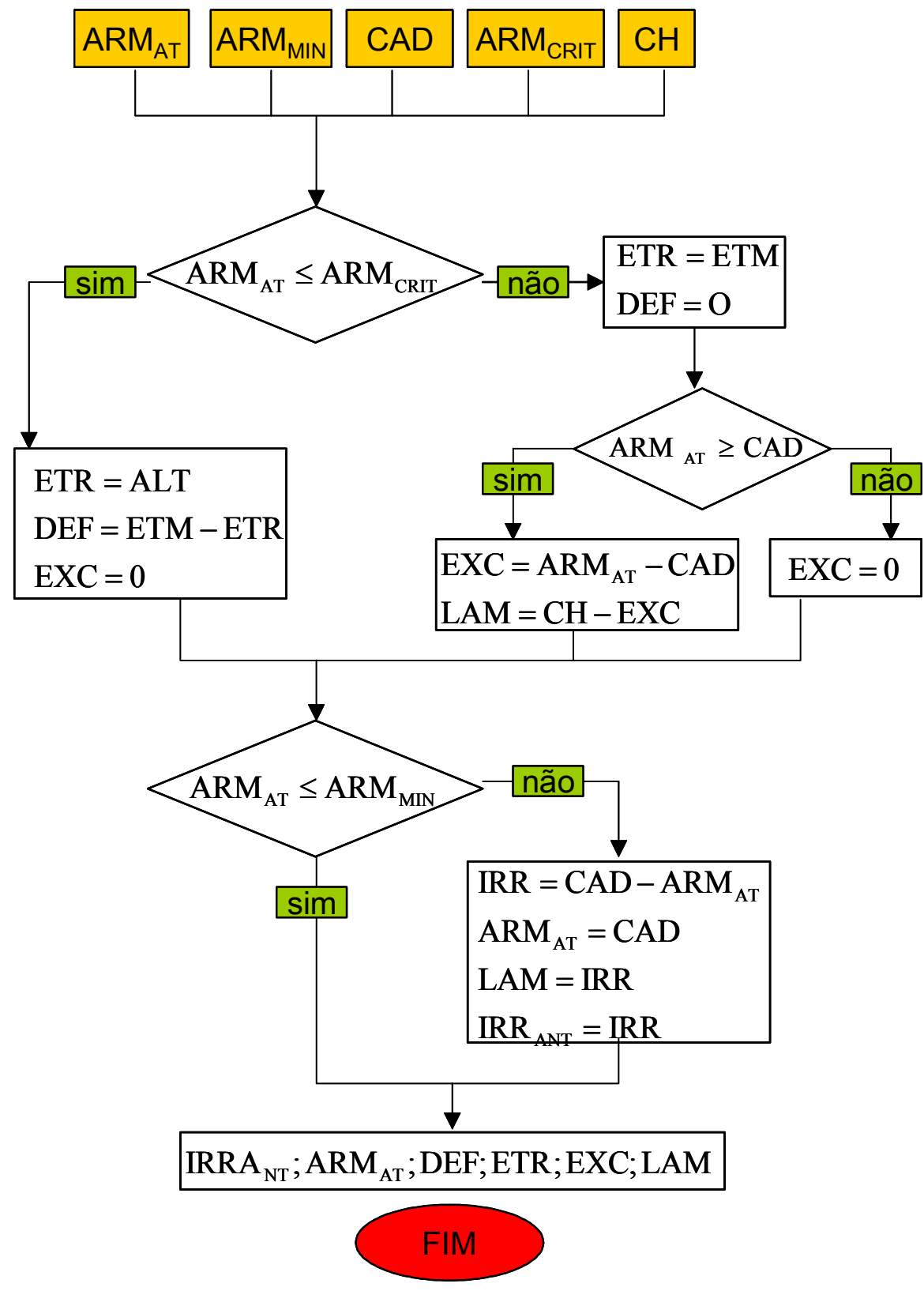

Figura 8 - Fluxograma do balanço hídrico diário: determinação da lâmina de irrigação suplementar (IRR) e da lâmina de água total disponível (LAM) 


\subsection{Estimativa da lâmina acumulada durante o ciclo da cultura e da lâmina de irrigação acumulada}

Após a simulação de cada balanço hídrico, foi contabilizada a quantidade de água disponível durante o ciclo da cultura. Desta forma, montou-se um histórico de aplicação de água com todas as irrigações simuladas e com as precipitações que ocorreram durante o mesmo período, sendo subtraído o excedente calculado, o qual é considerado como perda. As Equações (73) e (74), apresentam a contabilização dessas lâminas de água.

$$
\begin{aligned}
& \mathrm{IRR}_{\mathrm{AC}}=\sum_{\mathrm{i}=\text { emergência }}^{\mathrm{pmf}} \mathrm{IRRi} \\
& \mathrm{LAM}_{\mathrm{AC}}=\sum_{\mathrm{i}=\text { emergência }}^{\mathrm{pmf}}(\mathrm{CH}+\mathrm{IRR}-\mathrm{EXC})_{\mathrm{i}}
\end{aligned}
$$

A partir desta matriz gerada é possível obter informações a respeito da operação do sistema de irrigação que são: a lâmina total aplicada devido somente à irrigação $\left(I_{R} R_{A C}\right)$ e a lâmina total $\left(L A M_{A C}\right)$ a disposição da cultura (irrigação + chuva - excedente), ao longo do ciclo.

\subsection{Análise de probabilidade}

Considerando a matriz com os valores de lâminas de água, o modelo possibilita ajustar distribuições teóricas de probabilidade a fim de atribuir a freqüência de ocorrência do evento e, conseqüentemente, considerar um erro provável de estimativa, com certo risco envolvido. 


\subsubsection{Distribuição normal}

A distribuição normal é a mais importante das distribuições de variável contínua; seu grande emprego se deve a facilidade de cálculo quando comparada às outras, pois, necessita de dois parâmetros: a média amostral $(\mu)$ e o desvio padrão $(\sigma)$. A função densidade de probabilidade é apresentada pela Equação (75).

$$
\mathrm{fdp}(\mathrm{x})=\frac{1}{\sigma \sqrt{2 \pi}} \exp \left(-\frac{1}{2}\left[\frac{(\mathrm{x}-\mu)^{2}}{\sigma^{2}}\right]\right)
$$

em que:

$\mathrm{fdp}(\mathrm{x})$ - função densidade de probabilidade;

$\sigma$ - desvio padrão, $\mathrm{mm}$;

$\mu$ - média amostra, mml

x - variável aleatória contínua (LAM ou IRR) definida entre os intervalos $\infty<\mathrm{y}<+\infty$

Para a estimativa da freqüência acumulada da variável reduzida (y) para os valores de lâmina utilizou-se a aproximação polinomial de Abromowitx \& Stegun (1972), citado em Paz (1995), conforme Equação (76).

$$
\mathrm{FD}(\mathrm{y})=\frac{1}{\sqrt{2 \pi}} \mathrm{e}^{\frac{-\mathrm{y}^{2}}{2}}\left(\mathrm{~b}_{1} \mathrm{t}+\mathrm{b}_{2} \mathrm{t}^{2}+\mathrm{b}_{3} \mathrm{t}^{3}+\mathrm{b}_{4} \mathrm{t}^{4}+\mathrm{b}_{5} \mathrm{t}^{5}\right)
$$

Em que:

$$
\begin{aligned}
& b_{1}-0,31938153 \\
& b_{2}--0,356563782 \\
& b_{3}-1,781477937 \\
& b_{4}--1,821255778 \\
& b_{5}-1,330274429
\end{aligned}
$$$$
\text { FD(y) - Função de distribuição de probabilidade; }
$$ 
t - variável auxiliar, estimada pela Equação (77).

$$
t=\frac{1}{1+0,2316419 y}
$$

y - variável reduzida da função de distribuição, sendo calculada pela Equação (78).

$$
\mathrm{y}=\frac{\mathrm{X}_{\mathrm{i}}-\mu}{\sigma}
$$

$X i$ : lâmina de água ( $\left(L A M_{A C}, I_{R} R_{A C}\right)$ em cada observação.

\subsubsection{Distribuição gama incompleta}

A função densidade de probabilidade definida por Thom (1958), descrito em Saad (1990), é apresentada pela Equação (79). Observa-se que a equação é definida para $x>0$, sendo $\alpha$ e $\beta>0$.

$$
\mathrm{fdp}(\mathrm{Xi})=\frac{1}{\Gamma(\mathrm{g}) \beta^{\mathrm{g}}} \mathrm{Xi}{ }^{(\mathrm{g}-1)} \exp (-\mathrm{Xi} / \beta)
$$

em que:

g: parâmetro de forma,

$\beta$ : $\quad$ parâmetro de escala,

Xi : variável aleatória $\left(\operatorname{LAM}_{A C}\right.$ ou IRRA $\left.\mathrm{ICC}_{\mathrm{AC}}\right)$.

$\Gamma(\mathrm{g})$ : função gama completa calculada pela Equação (80);

$$
\Gamma(g)=\int_{0}^{\infty} \exp (-x) x^{(g-1)} d x
$$




\section{Sendo $g>0$}

Como a função gama é uma integral imprópria e, portanto, sem solução direta, a estimativa do seu valor torna-se trabalhoso.

Para valores de $g$ maiores que 1 e menores que 2. Saad (1990) recomenda utilizar os valores de $\Gamma(\mathrm{g})$, da Tabela 7 . A partir desses valores tabelados, foi ajustada a regressão apresentada pela Equação (81).

Tabela 7. Valores de $\Gamma(\mathrm{g})$ para $1 \leq \mathrm{g} \leq 2$

\begin{tabular}{cc}
\hline $\mathrm{g}$ & $\Gamma(\mathrm{g})$ \\
\hline 1,00 & 1,0000 \\
1,10 & 0,9514 \\
1,20 & 0,9182 \\
1,30 & 0,8975 \\
1,40 & 0,8873 \\
1,50 & 0,8862 \\
1,60 & 0,8935 \\
1,70 & 0,9086 \\
1,80 & 0,9314 \\
1,90 & 0,9618 \\
2,00 & 1,0000
\end{tabular}

Fonte: Spegel (1976), citado em Saad (1990).

$$
\begin{aligned}
\Gamma(\mathrm{g})= & \mathrm{K} 1+\mathrm{K} 2 \ln (\mathrm{g})+\mathrm{K} 3 \ln (\mathrm{g})^{2}+\mathrm{K} 4 \ln (\mathrm{g})^{3}+\mathrm{K} 5 \ln (\mathrm{g})^{4}+\mathrm{K} 6 \ln (\mathrm{g})^{5}+ \\
& +\mathrm{K} 7 \ln (\mathrm{g})^{6}+\mathrm{K} 8 \ln (\mathrm{g})^{7}+\mathrm{K} 9 \ln (\mathrm{g})^{8}+\mathrm{K} 8 \ln (\mathrm{g})^{9}
\end{aligned}
$$

em que:

$$
\begin{aligned}
& K 1=0,999999998 \\
& K 2=-0,57474285 \\
& K 3=0,66472388 \\
& K 4=0,18951607
\end{aligned}
$$




$$
\begin{aligned}
& K 5=-0,32948238 \\
& K 6=0,45091177 \\
& K 7=0,48032586 \\
& K 8=-0,3340846 \\
& K 9=-0,5436327 \\
& K 10=0,57364349
\end{aligned}
$$

Empregou-se a aproximação proposta por Striling, descrita em Saad (1990), quando os valores de g são maiores que 2. Essa aproximação é apresentada pela Equação (82).

$$
\Gamma(\mathrm{g}+1)=\sqrt{2 \pi \mathrm{g}} \mathrm{g}^{\mathrm{g}} \mathrm{e}^{-\mathrm{g}}\left(1+\frac{1}{12 \mathrm{~g}}+\frac{1}{288 \mathrm{~g}^{2}}-\frac{139}{51840 \mathrm{~g}^{3}}+\ldots\right)
$$

Os parâmetros g e $\beta$ são calculados através das Equações a seguir, que são obtidos pela estimativa de máxima verossililhança, segundo Thom (1966), citado em Vivaldi (1972) e Assis (1991).

$$
g=\frac{1}{4 \mathrm{As}}\left[1+\sqrt{1+\frac{4 \mathrm{As}}{3}}\right]
$$

em que:

As : coeficiente de assimetria, calculado pela Equação (84).

$$
\text { As }=\ln (\mu)-\mu_{\mathrm{G}}
$$

em que:

$\mu$ e $\mu_{\mathrm{G}}$ - médias aritméticas e geométricas, respectivamente, calculadas pelas equações (85) e (86) 


$$
\begin{aligned}
& \mu=\frac{1}{N} \sum_{1}^{N} X i \\
& \mu_{G}=\frac{1}{N} \sum_{1}^{N} \ln (X i)
\end{aligned}
$$

Para o cálculo da função de distribuição de probabilidade foi empregada a integração numérica por Simpson.

\subsubsection{Teste de Kolmogorov-Smirnov}

Para avaliar se os dados se ajustaram à distribuição de probabilidade teórica aplicou-se o teste de Kolmogorov-Smirnov.

Segundo Campos (1983), este teste verifica a adaptação de uma distribuição teórica específica e conhecida $(F)$ aos dados provenientes de uma distribuição desconhecida $\left(\mathrm{F}^{\circ}\right)$. Procura-se confrontar as probabilidades estimadas pela distribuição conhecida com as da função empírica de distribuição(S) a partir dos dados provenientes de uma amostra.

Para se proceder este teste é inicialmente calculado a função empírica de distribuição, que é a freqüência relativa de observações menores ou iguais para um dado valor, ou seja: $\mathrm{S}(\mathrm{x})=\frac{\mathrm{N}_{0}}{\mathrm{~N}_{\text {Total }}}$, em que $\mathrm{N}_{0}$ é o número de observações Xi maiores que zero e menores ou iguais a observação x, e $\mathrm{N}_{\text {Total }}$ é o tamanho da amostra.

$\mathrm{D}=|\mathrm{F}(\mathrm{x})-\mathrm{S}(\mathrm{x})|$, onde $\mathrm{D}$ representa esta distância. O maior $\mathrm{D}$ obtido dentro de cada período é comparado com o d (distância máxima para os níveis de significância de 0,01 e 0,05).

Assim são testadas duas hipóteses:

$\mathrm{H}_{0}: \mathrm{F} \equiv \mathrm{F}_{0}$ vs $\mathrm{H}_{\mathrm{a}}: \mathrm{F} \neq \mathrm{F}_{0}$, para pelo menos um valor de $\mathrm{x}$, rejeita-se a hipótese de nulidade se $\mathrm{D}>\mathrm{d}$. 
Espera-se a não rejeição da hipótese de nulidade, ou seja, que os dados ajustem-se à distribuição de probabilidade.

\subsection{Estimativa da produtividade e da queda de rendimento dos cultivos}

O modelo desenvolvido considera que a função de resposta da cultura à lâmina de água disponível é uma equação polinomial, conforme apresenta a Equação (87).

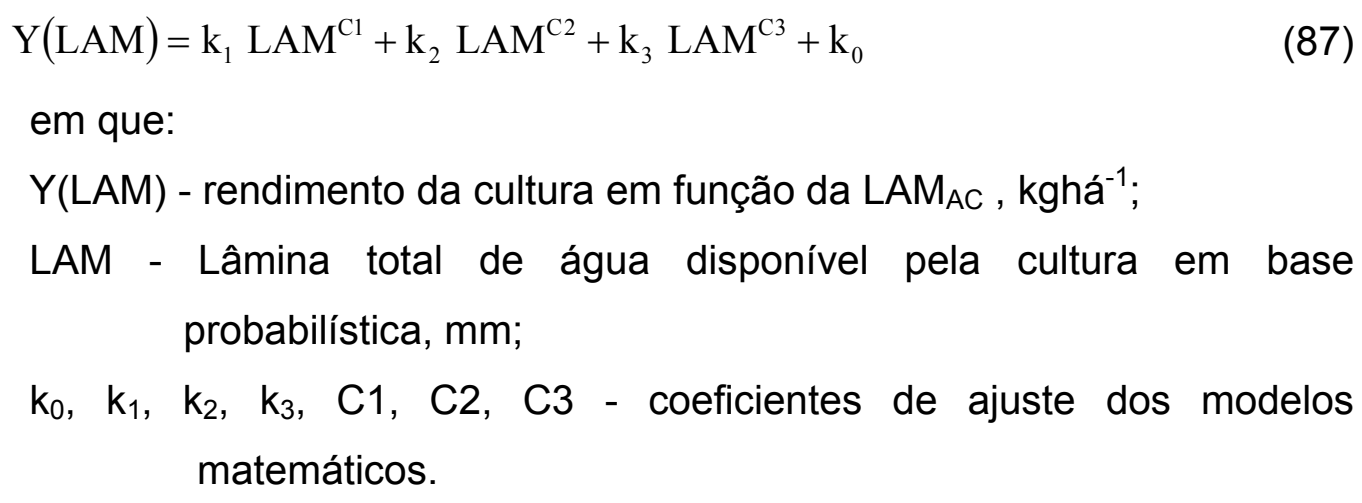

Observa-se que como a lâmina de água apresenta base probabilística, logo o rendimento estimado também.

Estima-se o rendimento máximo ( $\mathrm{Y}_{\mathrm{MAX}}$ ) por meio da raiz da derivada primeira da equação acima. Logo a estimativa da queda de rendimento [R(LAM)] é feita através da subtração do rendimento máximo com o rendimento atual, conforme apresenta a equação (88).

$$
\mathrm{R}(\mathrm{LAM})=\mathrm{Y}_{\mathrm{MAX}}-\mathrm{Y}(\mathrm{LAM})
$$

A Figura 9 apresenta o fluxograma para determinação do rendimento médio esperado e da queda de produtividade em função da lâmina de água probabilística. 


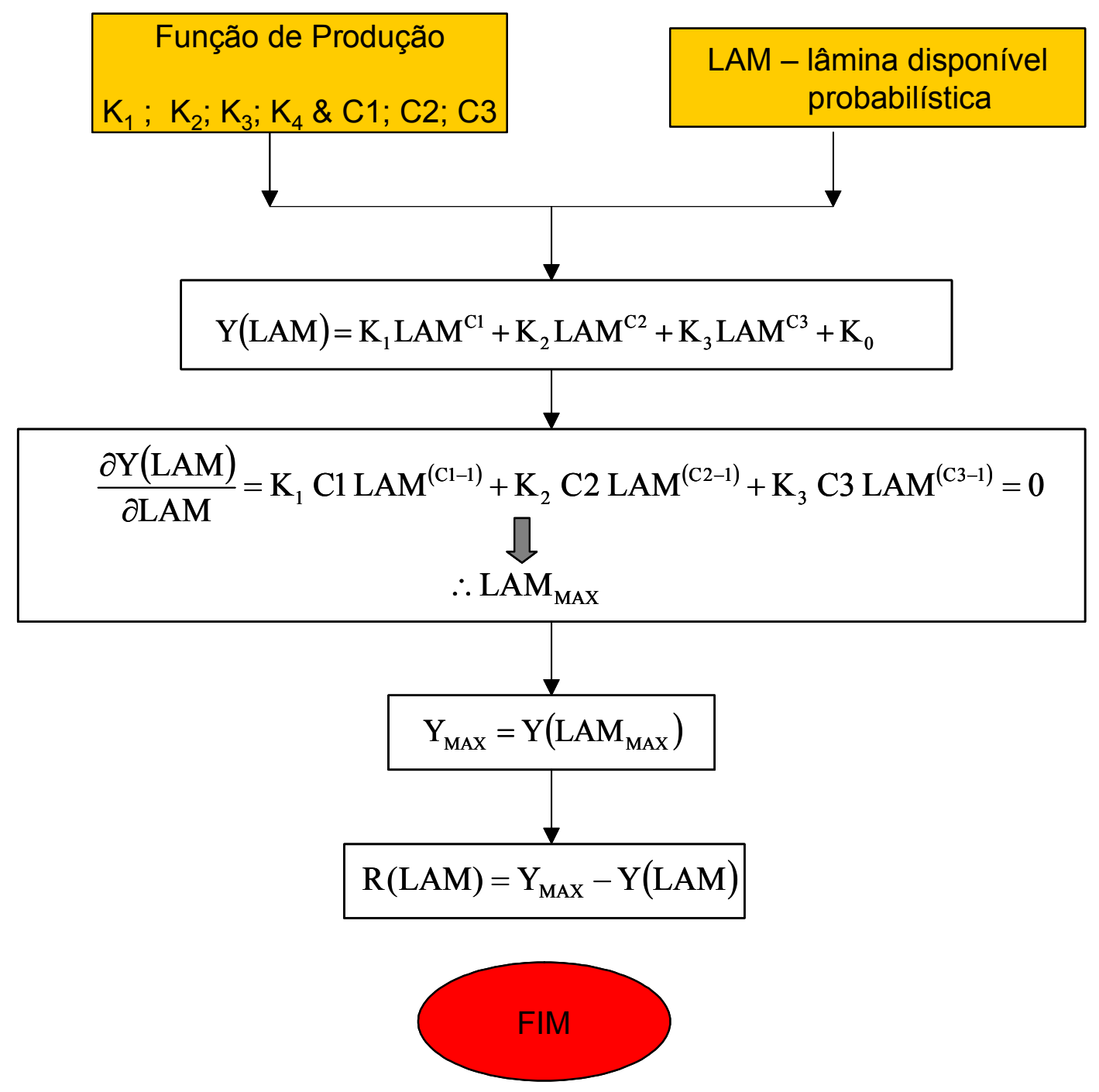

Figura 9 - Fluxograma para a determinação do rendimento médio [Y(LAM)] e da queda de produtividade $[R(L A M)]$ em função da lâmina probabilística (LAM) 


\section{RESULTADOS E DISCUSSÃO}

\subsection{Descrição do programa.}

O programa "PLAN_IRR" é um aplicativo específico para ser utilizado no planejamento de sistemas irrigados. Esse programa foi desenvolvido para auxiliar na tomada de decisão sobre. (i) nível de manejo de irrigação a ser adotado; (ii) previsão da ocorrência da disponibilidade de chuvas e (iii) qual a produtividade máxima esperada da cultura, para o momento de irrigação determinado.

O objetivo principal deste trabalho foi elaborar uma ferramenta computacional de acesso simplificado, que proporcionasse o livre arbítrio do usuário quanto aos critérios empregados na área irrigada em questão. Essa ferramenta visa atender, principalmente, os profissionais qualificados da área de irrigação.

Esse aplicativo considera: (i) parâmetros climáticos regionais; (ii) características da cultura irrigada; (iii) propriedades do solo quanto à capacidade de armazenamento de água e (iv) operação do manejo de água adotado.

Ao se executar o programa PLAN_IRR, aparece a tela de apresentação, demonstrada na Figura 10. 


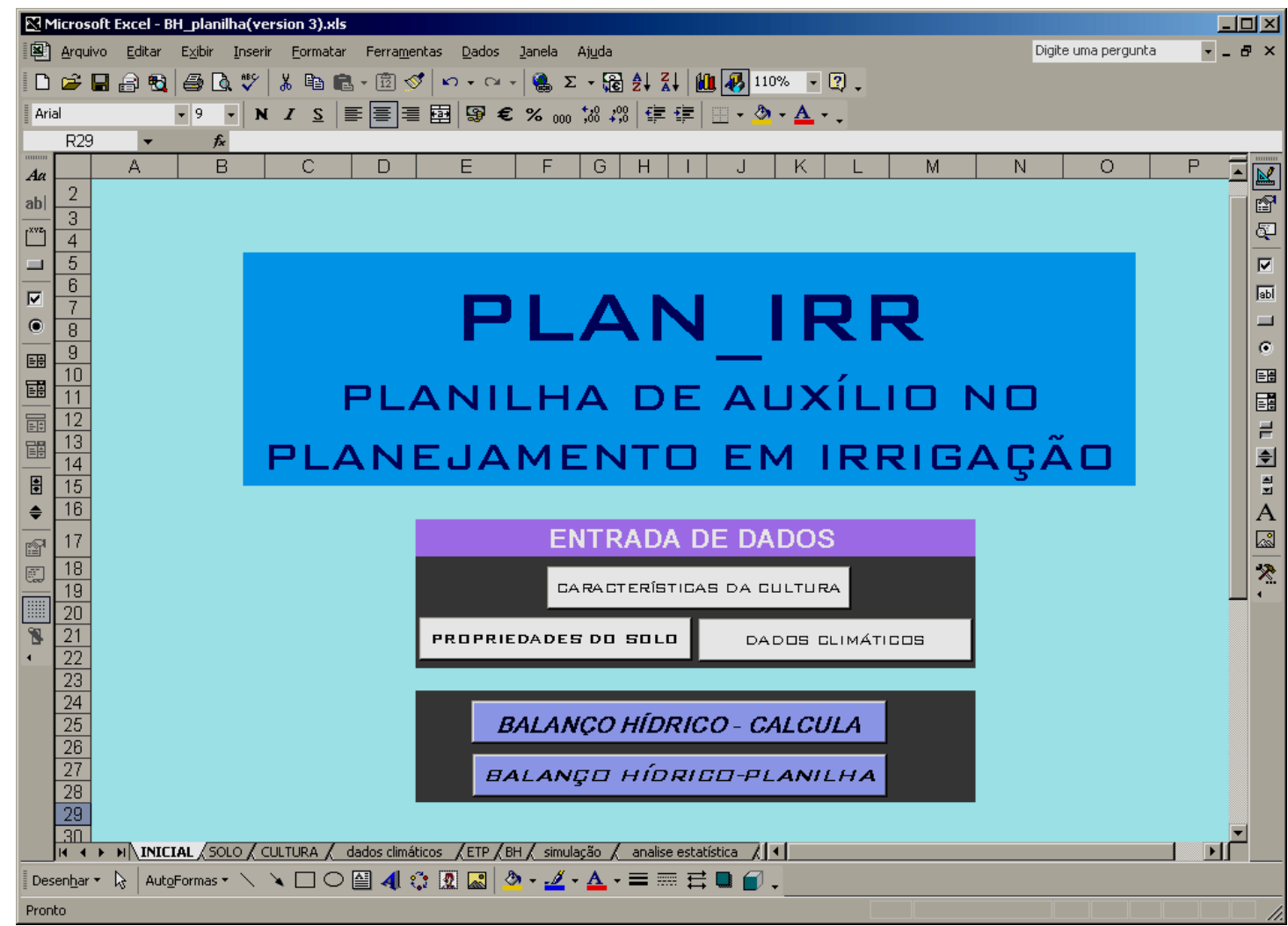

Figura 10 - Tela inicial do aplicativo PLAN_IRR

Essa tela é dividida em três opções para entrada de dados, representada pelos botões: "CARACTERÍSTICAS DA CULTURA"; "PROPRIEDADES DO SOLO" e "DADOS CLIMÁTICOS".

Além da entrada de dados há o botão de processamento do balanço hídrico diário, denominado por "BALANÇO HÍDRICO - CALCULA" e o botão "BALANÇO HÍDRICO - PLANILHA" que encaminha até a tela de resultado do balanço hídrico calculado para a série histórica dos dados climáticos.

A seguir são descritas as alternativas de uso do programa PLAN_IRR. 


\subsubsection{Entrada de dados no programa}

\subsubsection{Botão "PROPRIEDADES DO SOLO”}

Esta opção acessa a tela para entrada de dados referentes às características de armazenamento de água no solo. A tela desta opção é observada na Figura 11.

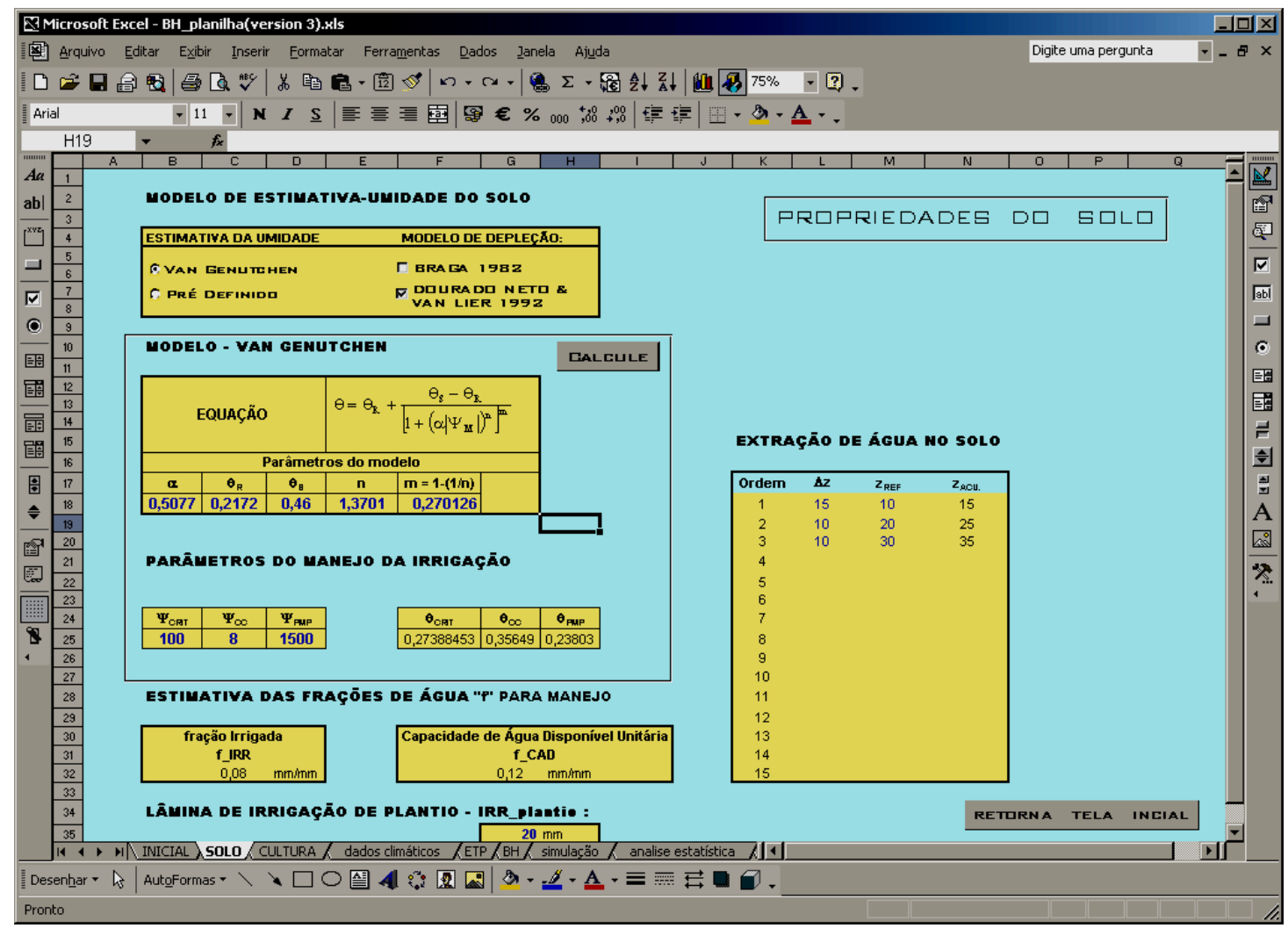

Figura 11 - Tela de entrada: propriedades do solo e dimensionamento da capacidade de armazenamento 
Como se observa no canto esquerdo, ao alto da Figura 11, há um quadro de opções. Esse quadro permite o usuário escolher o modelo de estimativa do armazenamento da água do solo e a metodologia de depleção.

Observa-se que, caso seja acessado o modelo de van Genuchten é necessário que o usuário insira os parâmetros dessa equação: (i) $\alpha$; (ii) m; (iii) $\mathrm{n}$; (iv) $\theta \mathrm{r}$ e (v) $\theta$ s. Além desses parâmetros, deve-se fornecer ao modelo os potenciais mátricos na capacidade de campo $\left(\Psi_{\mathrm{CC}}\right)$, no ponto de murcha permanente $\left(\Psi_{\mathrm{PMP}}\right)$ e no momento crítico ( $\left.\Psi_{\mathrm{CRIT}}\right)$, definido também, como momento de irrigação.

O botão "CALCULA" determina as respectivas umidades do solo nos potenciais acima descritos, além de quantificar a fração da capacidade de água disponível (f_CAD) e a fração do armazenamento mínimo (f_IRR), por unidade de profundidade de solo explorado.

No canto inferior direito da tela "SOLO" observa-se uma tabela de entrada com os dados referentes às profundidades: (i) profundidade parcial de solo considerada $(\Delta z)$; (ii) profundidade de referência $\left(z_{R E F}\right)$ e (iii) profundidade acumulada de solo ( $\mathrm{Z}_{\mathrm{ACU}}$.). Essas informações são empregadas para determinar a profundidade efetiva do sistema radicular e quando esta ocorre durante o ciclo da cultura.

Observa-se, centralizada na parte inferior dessa tela, a informação final, Lâmina de Irrigação de Plantio. O modelo desenvolvido permite inserir uma lâmina de irrigação inicial, realizada logo após o plantio. Esta lâmina é necessária para manter o "reservatório do solo" cheio d’água e, portanto, garantindo um stand uniforme de plantas. 


\subsubsection{Botão "CULTURA"}

Este botão acessa a tela para entrada de dados referentes às características da cultura analisada. A tela desta opção é observada pela Figura 12.

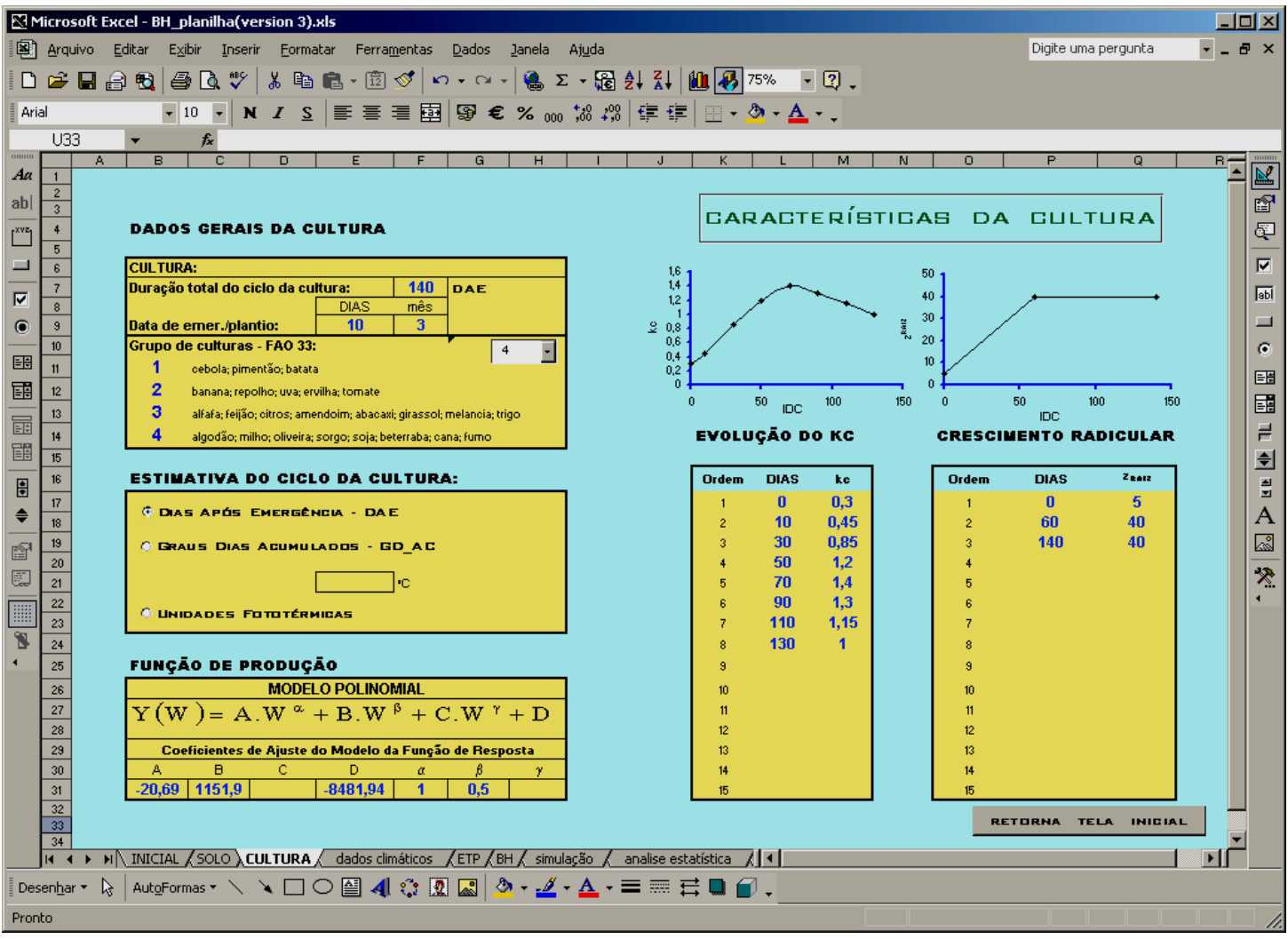

Figura 12 - Tela de entrada: características da cultura

No quadro denominado "DADOS GERAIS DA CULTURA", localizado ao alto do lado esquerdo dessa tela, é necessário inserir as informações básicas: (i) cultura estudada; (ii) duração total do ciclo em dias após a emergência (DAE), ou, em graus dias acumulados ( $G D_{A C}$ ); (iii) provável data (dia e mês) de emergência, ou seja, data de início dos balanços hídricos seqüenciais e (iv) 
grupo de culturas, segundo $\mathrm{FAO}$ - 33 que se classifica quanto à sensibilidade ao déficit hídrico.

Logo abaixo desse quadro há outro, identificado por "ESTIMATIVA DO CICLO DA CULTURA". O modelo permite acessar três opções: (i) contabilização dos dias sucessivos após a emergência (DAE); (ii) estimativa dos graus dias acumulados $\left(G D_{A C}\right)$ e (iii) estimativa das unidades fototérmicas. Observa-se que a opção pelo modelo de graus dias acumulados $\left(G D_{A C}\right)$, implica no fornecimento da temperatura base da cultura $(\mathrm{Tb})$, pelo usuário. Este dado insere-se neste mesmo quadro, conforme apresenta a Figura 12.

No quadro "FUNÇÃO DE PRODUÇÃO", o usuário insere os coeficientes da função de resposta específica da cultura analisada. Conforme se observa pela Figura 12, cada coeficiente é identificado no modelo polinomial, também identificado neste quadro.

A inserção da função de resposta da cultura não é obrigatória para o processamento do balanço hídrico. Por outro lado, sem esta opção, não é possível a análise da produtividade esperada na área irrigada em questão.

A tabela denominada "EVOLUÇÃO DO kc", localizada no lado direito dessa tela refere-se à listagem de valores da duração do ciclo da cultura (IDC) com os respectivos coeficientes de cultura $(\mathrm{kc})$.

Na tabela ao lado "CRESCIMENTO RADICULAR", insere-se, de forma semelhante à tabela anterior, os valores de IDC e as respectivas profundidades esperadas do sistema radicular da cultura. Essa tabela será empregada para a estimativa da profundidade atual do sistema radicular da cultura em função da duração do ciclo.

Observa-se que o usuário deve fornecer ao modelo as informações descritas nas duas tabelas acima. 


\subsubsection{Botão "dados climáticos"}

Este botão acessa a tela "dados climáticos". A tela desta opção é observada na Figura 13.

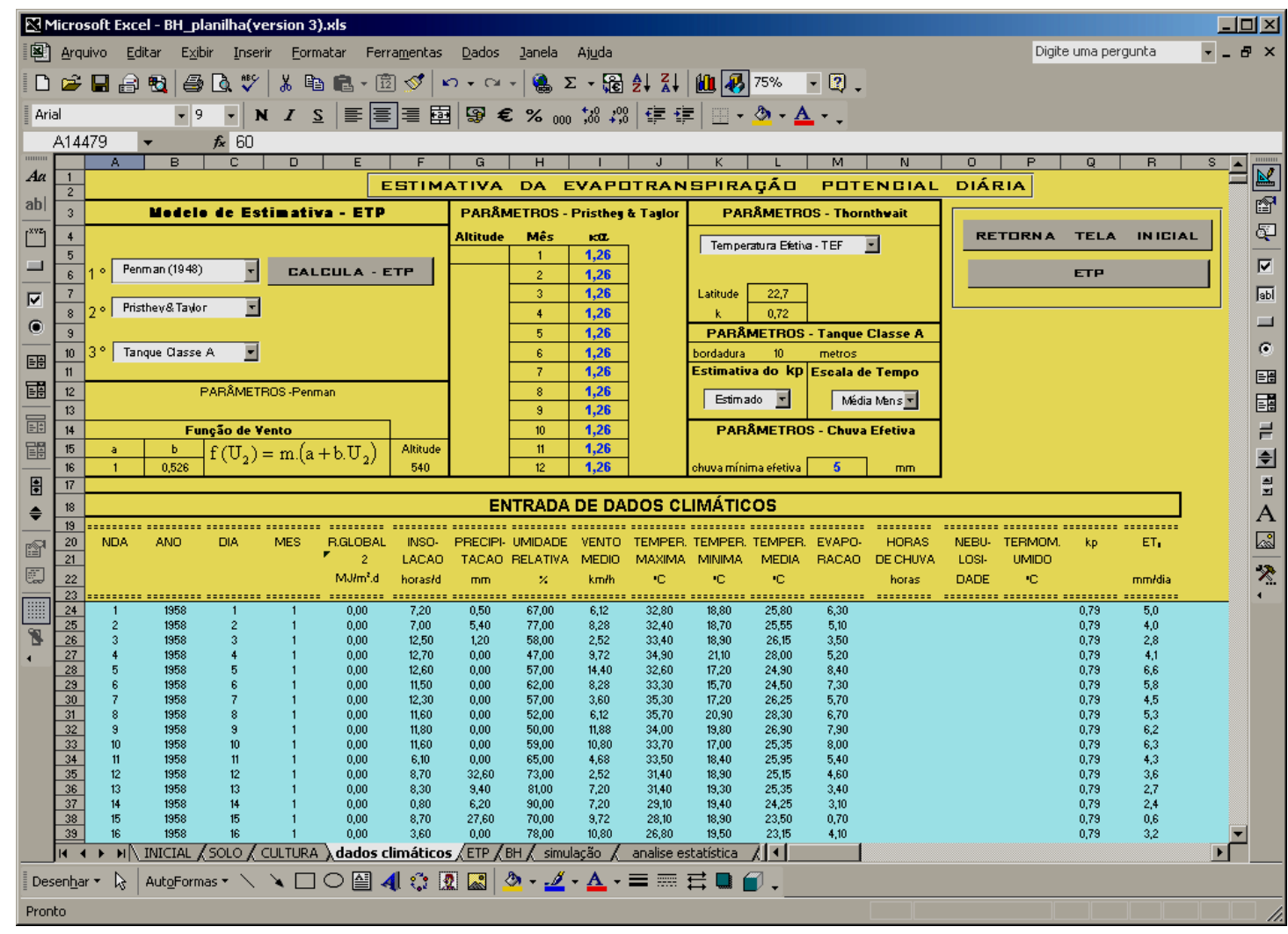

Figura 13 - Tela de entrada: dados climáticos

A tela "dados climáticos" apresenta duas funções principais: (i) entrada dos dados climáticos da série histórica regional, fornecidos pelo usuário e (ii) estimativa da evapotranspiração potencial $\left(E T_{0}\right)$, por meio dos modelos e parâmetros regionais definidos pelo usuário deste aplicativo.

Ao alto do lado esquerdo dessa tela, observa-se o quadro identificado por "Modelo de Estimativa - ETP". Neste quadro, o usuário encadeia os 
métodos de estimativa da evapotranspiração potencial a serem utilizados na série histórica disponível.

Exemplificando, observa-se pela Figura 13 a seguinte listagem dos modelos para estimativa da ETP: $1^{\circ}$ Penman (1948); $2^{\circ}$ Priestley-Taylor e $3^{\circ}$ Tanque Classe A.

O programa interpreta, por esta seqüência de métodos que, primeiramente, deve-se estimar a ETP, ao longo de todo o período fornecido, pelo modelo de Penman. Nos dias que não existem alguma das variáveis deste modelo, o aplicativo estimará a ETP pelo modelo de Priestley-Taylor. Caso nestes dias, não haja, também, alguma das variáveis do modelo de PriestleyTaylo, o programa adotará, automaticamente, o modelo do Tanque Classe A.

Nos dias que não se disponha de informações suficientes para qualquer dos três modelos listados, o programa atribui, automaticamente, o valor médio mensal do ano em questão.

Abaixo deste quadro, observa-se outro quadro identificado como: "Parâmetros - Penman". Neste quadro insere-se: (i) coeficientes, a e b da função de vento local e (ii) altitude local.

Nota-se que caso o usuário não disponha dos valores regionais dos parâmetros da função de vento, o modelo insere, inicialmente, os valores padrões definidos por Penman: $a=1$ e $b=0,526$.

No quadro "Parâmetros - Priestley-Taylor", o usuário fornece os valores regionais, na escala mensal, do coeficiente de Priestley-Taylor ( $\kappa \alpha)$.e a altitudẹ.

Caso o usuário não disponha de valores regionais deste parâmetro, o programa adota, inicialmente, o valor de 1,26 para todos os meses, conforme recomenda Pereira (1990).

No quadro "Parâmetros -Thornthwaite", o usuário define: (i) qual o modelo de Thornthwaite, selecionando o modelo original ou a modificação proposta em Pereira (2004); (ii) latitude local em graus e (iii) coeficiente w local, obrigatório para a seleção do modelo de Thornthwaite modificado por Pereira (2004). 
O quadro "Parâmetros - Tanque Classe A", apresenta as definições para a determinação do coeficiente de tanque $\mathrm{kp}$. Neste quadro há duas caixas de seleção: (i) "Estimativa do kp", onde define se o valor deste coeficiente será estimado ou fornecido diretamente pelo usuário e (ii) se o valor de kp adotado será a média mensal ou a média anual.

Observa-se que no caso de estimativa do $\mathrm{kp}$, é necessário que o usuário defina o tamanho da bordadura, esta informação está localizada, também, neste quadro.

Abaixo desse quadro, observa-se o quadro "PARÂMETROS - Chuva Efetiva" onde se define qual o valor mínimo de precipitação diária a ser considerado para o balanço hídrico seqüencial.

Abaixo dos quadros acima descritos, notam-se os campos de entrada das variáveis climáticas: (i) NDA - número de dias do ano; (ii) ANO; (iii) DIA; (iv) MÊS; (v) Radiação global; (vi) insolação; (vii) precipitação; (viii) umidade relativa; (ix) vento médio; $(\mathrm{x})$ temperatura máxima; (xi) temperatura mínima; (xii) temperatura média; (xiii) evaporação do tanque classe $A$; (xiv) horas de chuva diária; (xv) nebulosidade; (xvi) temperatura do termômetro úmido; (xvii) coeficiente de tanque kp e (xviii) evapotranspiração potencial diária estimada ou fornecida.

Nestes campos o usuário insere diretamente os valores das variáveis climáticas acima citadas.

O botão de seleção "ETP" encaminha para a tela, também denominada, "ETP", conforme apresenta a Figura 14.

Esta tela exerce função apenas demonstrativa, onde são apresentados os valores médios mensais e anuais da evapotranspiração potencial estimada, para cada ano da série histórica. 


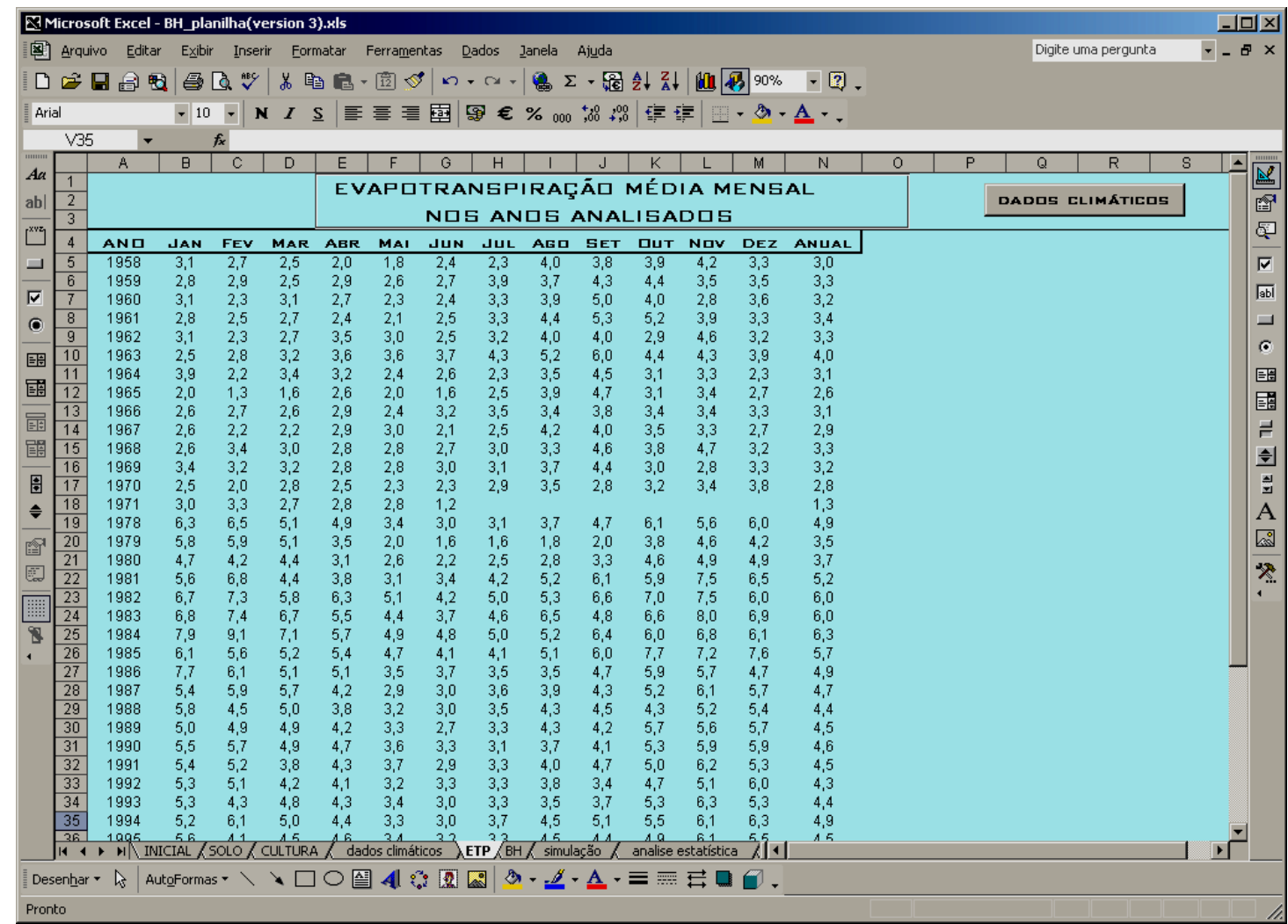

Figura 14 - Tela demonstrativa ETP

\subsubsection{Processamento dos dados}

Após finalizar a entrada de dados e a estimativa da ETP diária, retornase na tela inicial, apresentada pela Figura 10.

Para a execução dos balanços hídricos diários seqüenciais, estimando as irrigações suplementares, seleciona-se o botão "BALANÇO HÍDRICO CALCULA". 


\subsubsection{Botão "BALANÇO HÍDRICO - PLANILHA"}

O botão "BALANÇO HÍDRICO - PLANILHA", encaminha para a tela demonstrativa dos valores processados do balanço hídrico, executado pelo botão anterior. A Figura 15 apresenta a tela "BALANÇO HÍDRICO - PANILHA".

Nesta tabela há os seguintes botões de seleção: (i) RETORNA TELA INICIAL; (ii) ANÁLISE ESTATÍSTICA e (iii) SIMULAÇÃO.

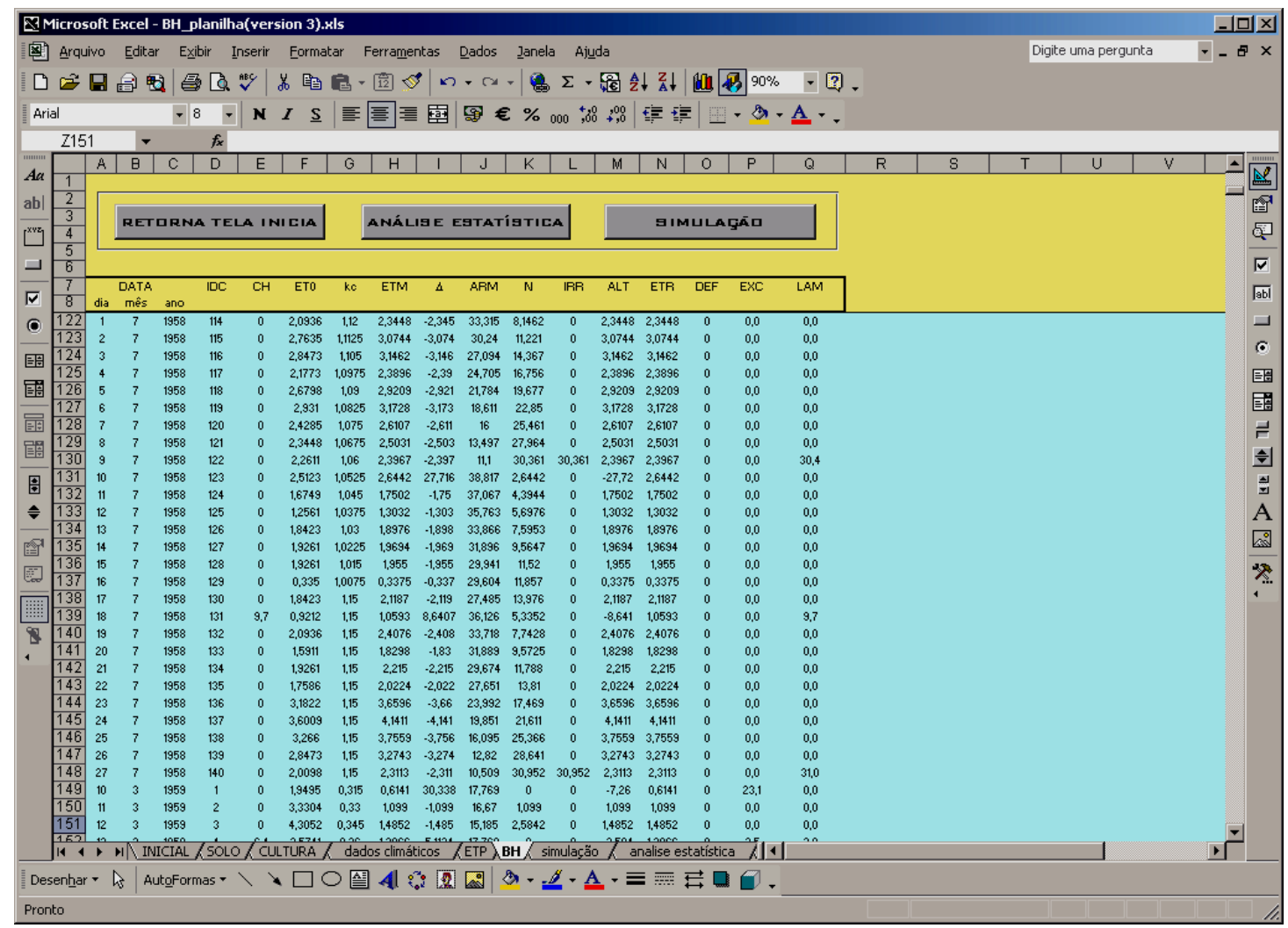

Figura 15 - Tela demonstrativa: balanço hídrico

Acessando o botão "SIMULAÇÃO" o aplicativo encaminha para a tela de simulação das lâminas acumuladas ao longo de cada ciclo da cultura e em sub períodos, definidos pelo usuário, conforme apresenta a Figura 16. 


\subsubsection{Botão "Simulação"}

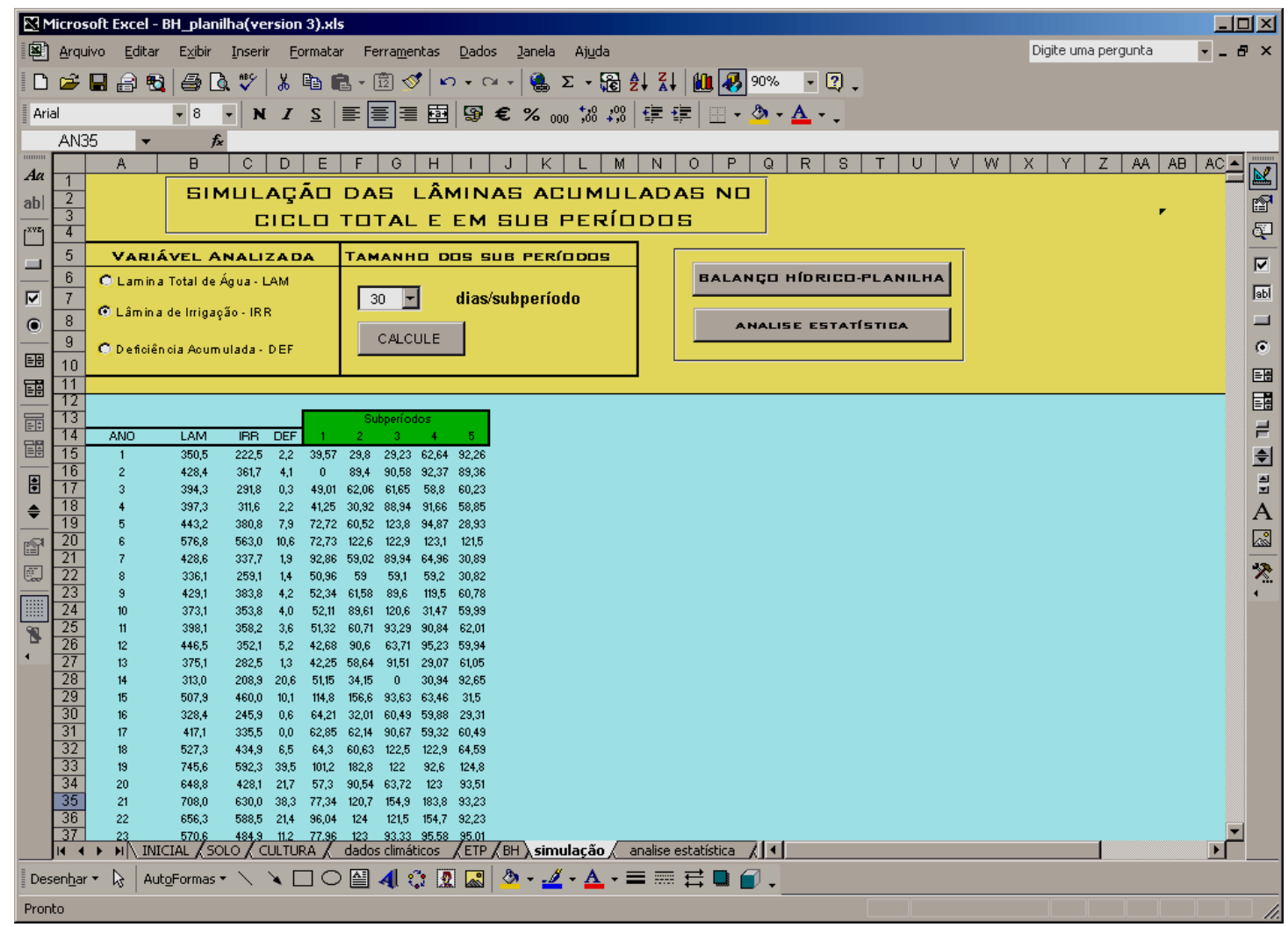

Figura 16 - Tela de processamento: simulação

Nesta tela, observa-se no lado esquerdo, ao alto, o quadro "VARIÁVEL ANALISADA". Neste quadro, o usuário define quais as lâminas de água a serem acumuladas nos sub períodos, sendo estas: (i) lâmina acumulada de água - $\mathrm{LAM}_{\mathrm{AC}}$, que contabiliza a irrigação suplementar e as chuvas efetivas disponíveis durante cada sub-periodo; (ii) Lâmina de irrigação - $\operatorname{IRR}_{\mathrm{AC}}$ e (iii) Deficiência Acumulada.

Adjacente a este, observa-se o quadro "TAMANHO DOS SUB PERÍODOS" onde se define qual o número de dias por sub período. O aplicativo desenvolvido apresenta três opções: (i) 5; (ii) 10 e (iii) 30 dias.

Abaixo destes quadros de seleção observa-se os campos das variáveis: (i) ANO; (ii) $L_{A M}$ - a lâmina total disponível acumulada no ciclo da cultura; (iii) $I R R_{A C}$ - a lâmina de irrigação suplementar acumulada ao longo do ciclo; (iv) 
$D F_{A C}$ - deficiência hídrica acumulada no ciclo. Ao lado direito do campo DEF, há os campos das lâminas de água acumuladas nos sub períodos de tamanhos pré-definidos com a variável selecionada, anteriormente.

Observa-se que as variáveis são acumuladas para cada ano da série histórica disponível ao modelo.

Nesta tela observa-se o botão de seleção "ANÁLISE ESTATÍSTICA" que encaminha para a tela que analisa, em base probabilística, as variáveis acumuladas na tela "SIMULAÇÃO".

\subsubsection{Botão "Análise Estatística"}

Esta tela é demonstrada pela Figura 17.

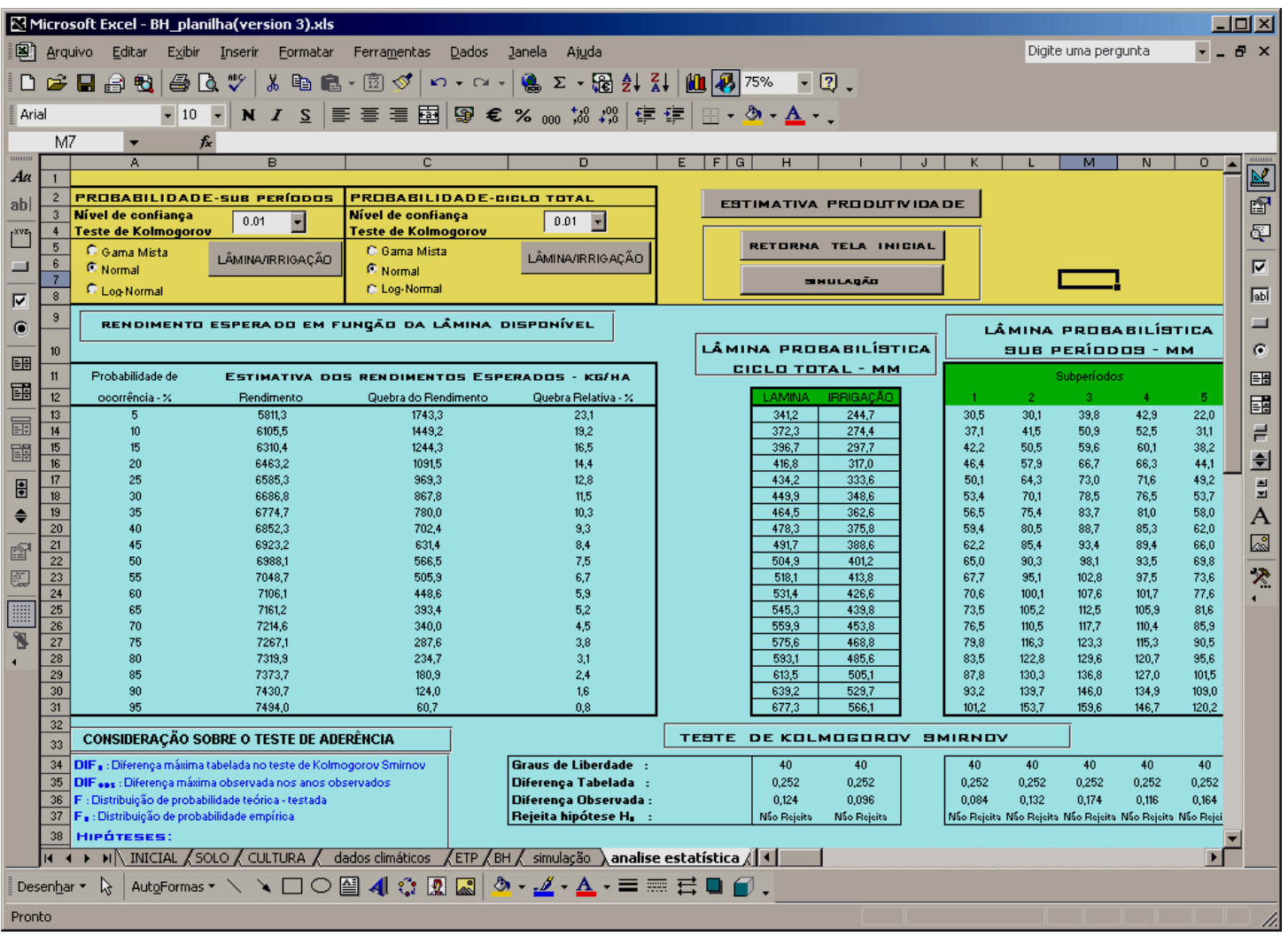

Figura 17 - Tela de processamento: análise estatística 
Observa-se, inicialmente, no lado esquerdo, ao alto, os quadros de seleção "PROBABILIDADE - SUB PERÍODOS" e "PROBABILIDADE - CICLO TOTAL". Nestes quadros, o usuário define qual o modelo teórico de distribuição de probabilidade e o nível de confiança do teste de aderência de KolmogorovSmirnov.

Conforme demonstrado nesta tela, o programa desenvolvido permite ajuste de três distribuições teóricas de probabilidade: (i) Gama Mista; (ii) Normal e (iii) Log Normal e dois intervalos de confiança: (i) $5 \%$ e (i) $1 \%$.

Definidos os parâmetros para o teste de aderência e a distribuição teórica, o botão "LÂMINA/IRRIGAÇÃO", localizado dentro de cada quadro de seleção, calcula as lâminas esperadas para os níveis probabilísticos, definidos no quadro "RENDIMENTO ESPERADO EM FUNÇÃO DA LÂMINA PROBABILÍSTICA".

O quadro "LÂMINA PROBABILÍSTICA - CICLO TOTAL - mm" apresenta os valores calculados das lâminas probabilísticas para as variáveis: (i) "LAMINA" - lâmina total de água acumulada no ciclo da cultura $\left(\operatorname{LAM}_{A C}\right)$ e (ii) "IRRIGAÇÃO" - lâmina de irrigação suplementar acumulada ao longo do ciclo da cultura (IRR $\mathrm{AC})$.

Semelhantemente, o quadro LÂMINA PROBABILÍSTICA - SUB PERÍODOS - mm" apresenta os valores calculados das lâminas probabilísticas para cada sub período do ciclo da cultura, da variável definida na tela "SIMULAÇÃO".

Para as variáveis "LÂMINA"; "IRRIGAÇÃO" e para cada sub período o programa elabora o teste de kolmogorov-Smirnov, testado se a distribuição de probabilidade teórica ajusta-se aos valores observados. O resultado destes testes é apresentado abaixo dos quadros das lâminas prováveis.

O botão "ESTIMATIVA DA PRODUTIVIDADE" quantifica o rendimento médio esperado para cada lâmina provável da variável "LÂMINA" do quadro “LÂMINA PROBABILÍSTICA - CICLO TOTAL - mm”. 
Esses valores de produtividade são apresentados no quadro "RENDIMENTO ESPERADO EM FUNÇÃO DA LÂMINA PROBABILÍSTICA".

Além do rendimento médio esperado este quadro apresenta os valores estimados de: (i) quebra do rendimento médio em relação ao máximo esperado; e (ii) o valor da quebra relativa em função do rendimento máximo esperado.

\subsection{Exemplo de utilização}

Para demonstrar o uso do programa PLAN_IRR, bem como apresentar a sua utilidade, é proposto o exemplo a seguir. Este servirá para demonstrar como manusear o programa.

O dados climáticos utilizados pertencem ao posto meteorológico do departamento de Ciências Exatas, setor de física e meteorologia da Escola Superior de Agricultura "Luiz de Queirooz", localizado em Piracicaba, SP. Este posto está situado na latitude de $22^{\circ} 42^{\prime} 30^{\prime \prime}$ sul e longitude de $47^{\circ} 38^{\prime} 00^{\prime \prime}$ oeste, tendo altitude de 546 metros.

Utilizou-se a cultura do milho para esta simulação proposta.

\subsubsection{Dados disponíveis e critérios considerados}

1. Propriedades do solo:

i. Modelo de estimativa do armazenamento do solo: van Genuchten.

Os parâmetros da equação são apresentados na Tabela 8. Observa-se que estes parâmetros são ajustados à unidade de potencial mátrico $\mathrm{kPa}$.

Tabela 8. Parâmetros de ajuste da equação de van Genuchten

$\mathrm{N} \quad \mathrm{m} \quad \alpha \quad \theta \mathrm{r} \quad \theta \mathrm{s}$

$\begin{array}{lllll}1,3701 & 0,27012 & 0,5077 & 0,2172 & 0,46\end{array}$


ii. Potencial mátrico na capacidade de campo: $8 \mathrm{kPa}$;

iii. Potencial mátrico no ponto de murcha permanente: $1.500 \mathrm{kPa}$;

iv. Momento de Irrigação: 40; 75; 100 e 200 kPa;

A Tabela 9 apresenta as umidades volumétricas calculadas para os potenciais mátricos na capacidade de campo ( $\left.\Psi_{\mathrm{CC}}\right)$, no ponto de murcha permanente ( $\left.\Psi_{\mathrm{PMP}}\right)$, e nos momentos de irrigação acima descritos.

Tabela 9. Parâmetros do manejo da irrigação adotados: umidades volumétricas estimadas

\begin{tabular}{ccccccc}
\hline$\Psi \mathrm{m}(\mathrm{kPa})$ & 8 & 1500 & 40 & 75 & 100 & 200 \\
$\theta\left(\mathrm{m}^{3} \mathrm{~m}^{-3}\right)$ & 0,356 & 0,238 & 0,296 & 0,28 & 0,274 & 0,261 \\
\hline
\end{tabular}

$\mathrm{Na}$ Tabela 10, são apresentados os valores estimados do armazenamento unitário de água, em $\mathrm{mm} \mathrm{mm}^{-1}$, para a capacidade de água disponível (f_CAD); e para os momentos de irrigação adotados (f_IRR).

Tabela 10. Parâmetros do manejo da irrigação adotados: armazenamento unitário de água estimado

\begin{tabular}{ccc}
\hline Denominação & $\begin{array}{c}\text { Intervalo de potencial } \\
\text { mátrico em } \mathrm{kPa}\end{array}$ & $\begin{array}{c}\text { Armazenamento unitário de } \\
\text { água em } \mathrm{mm} \mathrm{m}^{-1}\end{array}$ \\
\hline f_CAD & $8-1500$ & 0,12 \\
F_IRR $(40 \mathrm{kPa})$ & $8-40$ & 0,060 \\
F_IRR $(75 \mathrm{kPa})$ & $8-75$ & 0,076 \\
f_IRR $(100 \mathrm{kPa})$ & $8-100$ & 0,082 \\
f_IRR $(200 \mathrm{kPa})$ & $9-200$ & 0,095 \\
\hline
\end{tabular}

v. Modelo de estimativa da depleção da água do solo: Dourado Neto \& van Lier (1992); 
vi. Extração de água pelo sistema radicular: Tabela 11.

Tabela 11. Parâmetros do manejo da irrigação adotados: profundidades consideradas de exploração do solo

\begin{tabular}{ccc}
\hline$\Delta z$ & $Z_{\text {REF }}$ & $z_{\text {ACU. }}$ \\
\hline 15 & 10 & 15 \\
10 & 20 & 25 \\
10 & 30 & 35 \\
\hline
\end{tabular}

vii. Lâmina de irrigação de plantio: $20 \mathrm{~mm}$.

2. Características da cultura:

i. Cultura: Milho;

ii. Possível data de emergência: 10 de março;

iii. Modelo de estimativa da duração do ciclo: Dias após emergência (DAÍ);

iv. Ciclo da cultura: 140 dias;

v. Evolução do kc: Tabela 12:

Tabela 12. Características da cultura: Valores do coeficiente kc para a cultura de milho e respectivos DAI

\begin{tabular}{cc}
\hline DAÍ & Kc \\
\hline 0 & 0,3 \\
10 & 0,45 \\
30 & 0,85 \\
50 & 1,2 \\
70 & 1,4 \\
90 & 1,3 \\
110 & 1,15 \\
130 & 1 \\
\hline
\end{tabular}


vi. Crescimento do sistema radicular: Tabela 13:

Tabela 13. Características da cultura: Valores da profundidade do sistema radicular da cultura do milho ( $\left.\mathrm{Z}_{\mathrm{RAI}}\right)$ e respectivos $\mathrm{DAI}$

\begin{tabular}{cc}
\hline DAÍ & Z $_{\text {RAIZ }}$ \\
\hline 0 & 5 \\
60 & 40 \\
140 & 40 \\
\hline
\end{tabular}

vii. Função de produção: Tabela 14:

Tabela 14. Características da cultura: Coeficientes de Ajuste do Modelo da Função de Resposta

\begin{tabular}{ccccccc}
\hline A & B & C & D & $\alpha$ & $\beta$ & $\gamma$ \\
$-20,69$ & 1151,9 & - & $-8481,94$ & 1 & 0,5 & - \\
\hline
\end{tabular}

3. Dados climáticos:

i. Região: Piracicaba-SP;

ii. Série histórica dos dados: 1/1958 até 6/1971 e 1/1978 até 2/2004;

iii. Modelos de estimativa da evapotranspiração potencial: $1^{\circ}$ Penman (1948); $2^{\circ}$ Priestley-Taylor; $3^{\circ}$ Tanque Classe A;

iv. Parâmetros da função de vento: $a=1$ e $b=0,526$;

v. Altitude local : $540 \mathrm{~m}$

vi. Coeficiente de Priestley-Taylor regional $(\kappa \alpha): \kappa \alpha=1,26$ para todos os meses;

vii. Tipo de kp adotado: Estimado;

viii. Período considerado para estimativa: Média mensal;

ix. Bordadura considerada: $10 \mathrm{~m}$;

x. Chuva mínima efetiva: $5 \mathrm{~mm}$. 


\subsubsection{Resultados Obtidos}

Na tabela 15 são apresentadas as lâminas totais esperadas, em base probabilísticas, para os diferentes momentos de irrigação, definidos previamente.

Tabela 15. Valores simulados da lâmina total acumulada $(\mathrm{mm})$ para diferentes níveis de probabilidade e diferentes momentos de irrigação

\begin{tabular}{ccccc}
\hline $\begin{array}{c}\text { Nível de Probabilidade } \\
\%\end{array}$ & $40 \mathrm{kPa}$ & $75 \mathrm{kPa}$ & $100 \mathrm{kPa}$ & $200 \mathrm{kPa}$ \\
\hline 5 & 344,1 & 348,3 & 341,2 & 338,8 \\
10 & 376,5 & 379,2 & 372,3 & 366,0 \\
15 & 402,0 & 403,5 & 396,7 & 387,4 \\
20 & 422,9 & 423,5 & 416,8 & 405,1 \\
25 & 441,1 & 440,9 & 434,2 & 420,3 \\
30 & 457,4 & 456,5 & 449,9 & 434,1 \\
35 & 472,6 & 471,0 & 464,5 & 446,9 \\
40 & 487,0 & 484,7 & 478,3 & 459,0 \\
45 & 501,0 & 498,1 & 491,7 & 470,7 \\
50 & 514,7 & 511,2 & 504,9 & 482,3 \\
55 & 528,5 & 524,3 & 518,1 & 493,8 \\
60 & 542,4 & 537,6 & 531,4 & 505,6 \\
65 & 556,8 & 551,4 & 545,3 & 517,7 \\
70 & 572,0 & 565,9 & 559,9 & 530,5 \\
75 & 588,4 & 581,5 & 575,6 & 544,3 \\
80 & 606,7 & 599,0 & 593,1 & 559,7 \\
85 & 628,0 & 619,3 & 613,5 & 577,6 \\
90 & 654,8 & 644,9 & 639,2 & 600,1 \\
95 & 694,5 & 682,8 & 677,3 & 633,5 \\
\hline
\end{tabular}


Para os dados simulados, a distribuição de probabilidade normal apresentou melhor aderência, segundo o teste de Kolmogorv.

A partir dos dados da Tabela 15, elaborou-se a Figura 18.

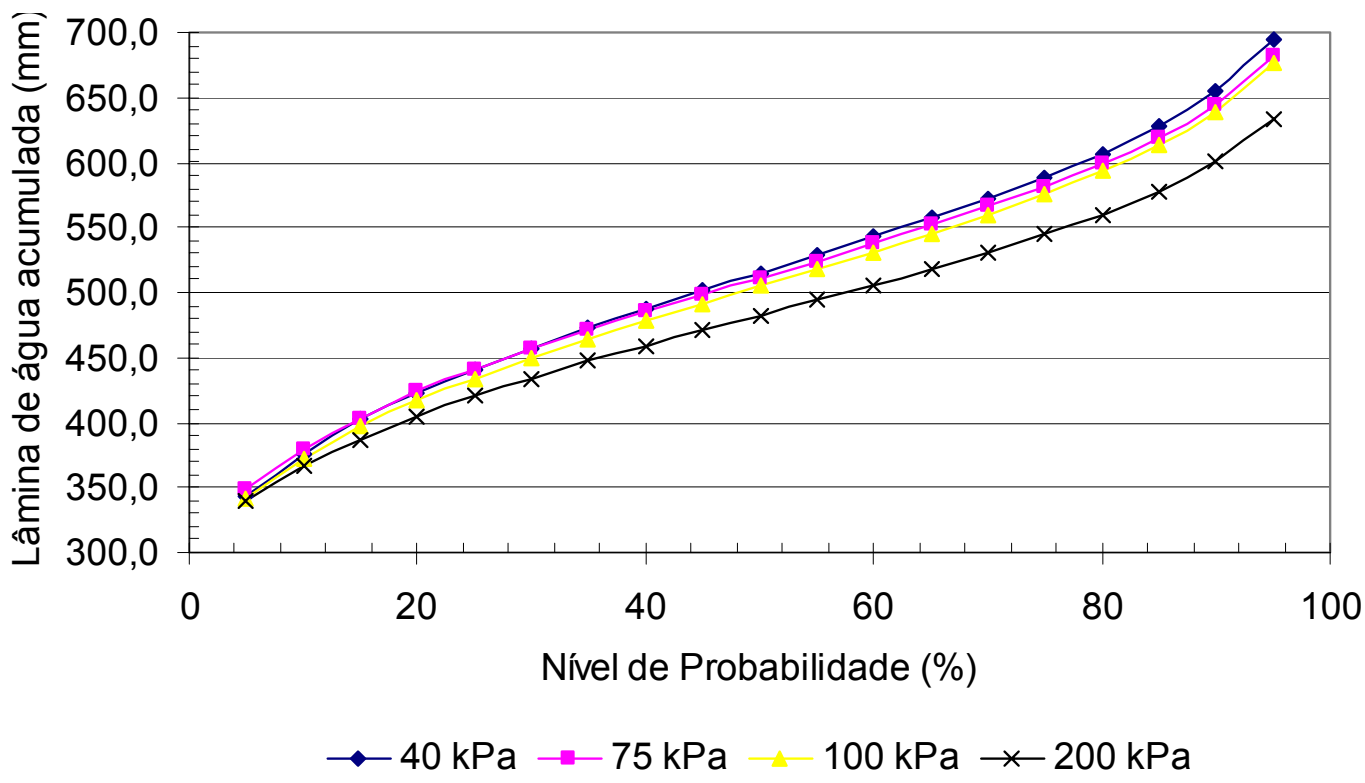

Figura 18 - Lâminas de água acumuladas esperadas, em base probabilística, para diferentes momentos de irrigação

Pelos dados de lâmina simulados observa-se que para o nível de probabilidade de $5 \%$, a diferença das lâminas acumuladas entre a simulação mais irrigada (40 kPa) e a menos irrigada (200 kPa) é de $6,0 \mathrm{~mm}$ o que corresponde a $98 \%$ da lâmina maior $(40 \mathrm{kPa})$. Para o nível de probabilidade de $95 \%$, a diferença das lâminas acumuladas entre essas simulações é de $61 \mathrm{~mm}$ o que corresponde a $91 \%$ da maior lâmina (40 kPa).

Pelos dados acima expostos observa-se um ligeiro aumento de lâmina aplicada para os diferentes momentos de irrigação simulados. Entretanto, este valor torna-se, praticamente, insignificante quanto à quantidade de lâmina de água considerada.

Semelhantemente, elaborou-se a Tabela 16 e a Figura 19, para a variável irrigação suplementar acumulada. 
Tabela 16. Valores simulados da lâmina de irrigação suplementar acumulada $(\mathrm{mm})$ para diferentes níveis de probabilidade e diferentes momentos de irrigação

\begin{tabular}{|c|c|c|c|c|}
\hline $\begin{array}{c}\text { Nível de Probabilidade } \\
\qquad \%\end{array}$ & $40 \mathrm{kPa}$ & $75 \mathrm{kPa}$ & $100 \mathrm{kPa}$ & $200 \mathrm{kPa}$ \\
\hline 5 & 255,2 & 250,0 & 244,7 & 216,8 \\
\hline 10 & 287,5 & 280,7 & 274,4 & 245,0 \\
\hline 15 & 312,8 & 304,8 & 297,7 & 267,2 \\
\hline 20 & 333,7 & 324,6 & 317,0 & 285,4 \\
\hline 25 & 351,7 & 341,9 & 333,6 & 301,3 \\
\hline 30 & 368,0 & 357,4 & 348,6 & 315,5 \\
\hline 35 & 383,2 & 371,8 & 362,6 & 328,7 \\
\hline 40 & 397,5 & 385,4 & 375,8 & 341,3 \\
\hline 45 & 411,4 & 398,6 & 388,6 & 353,5 \\
\hline 50 & 425,1 & 411,7 & 401,2 & 365,4 \\
\hline 55 & 438,7 & 424,7 & 413,8 & 377,4 \\
\hline 60 & 452,6 & 437,9 & 426,6 & 389,5 \\
\hline 65 & 467,0 & 451,6 & 439,8 & 402,1 \\
\hline 70 & 482,1 & 466,0 & 453,8 & 415,3 \\
\hline 75 & 498,5 & 481,5 & 468,8 & 429,6 \\
\hline 80 & 516,7 & 498,8 & 485,6 & 445,5 \\
\hline 85 & 537,9 & 519,0 & 505,1 & 464,1 \\
\hline 90 & 564,5 & 544,4 & 529,7 & 487,4 \\
\hline 95 & 604,1 & 582,0 & 566,1 & 522,0 \\
\hline
\end{tabular}




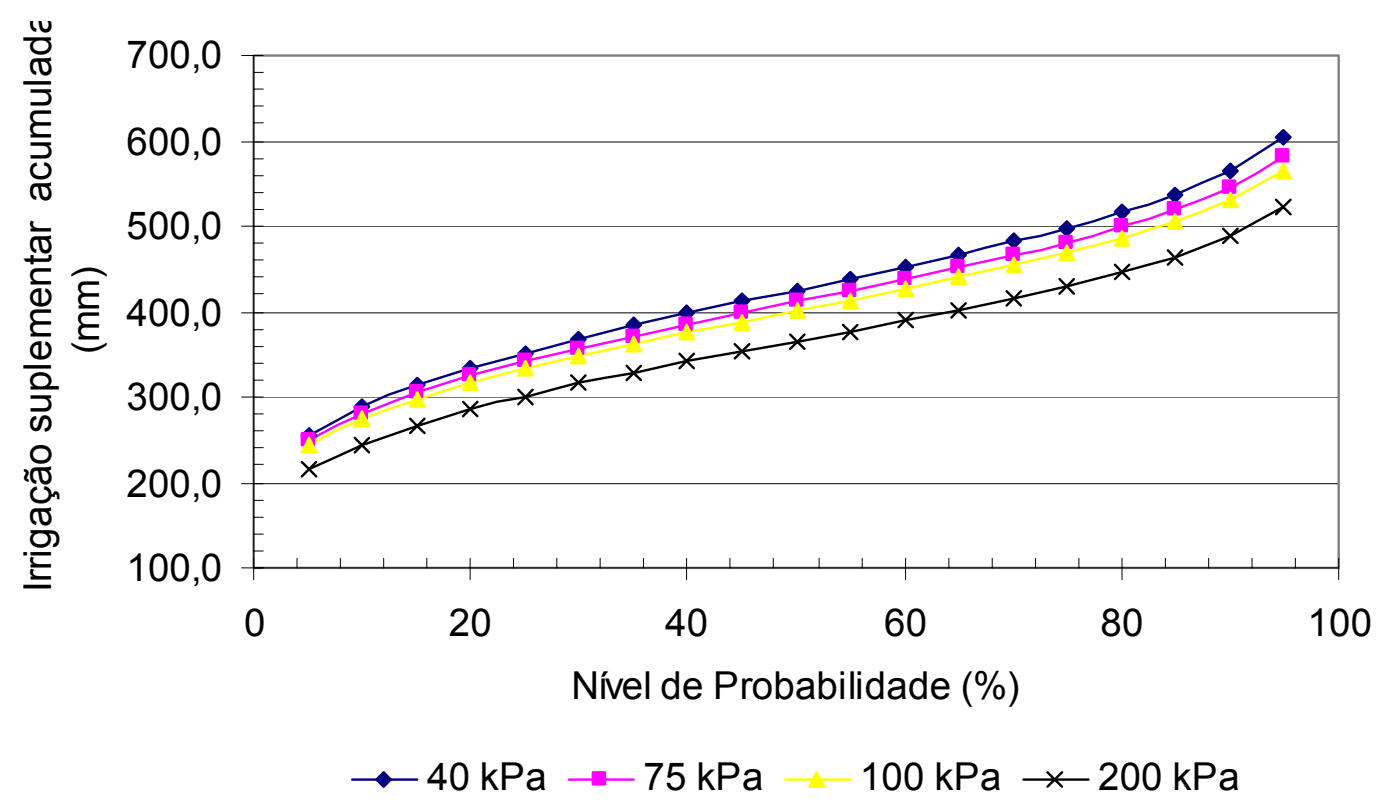

Figura 19 - Lâminas de irrigação suplementar acumuladas, em base probabilística, para diferentes momentos de irrigação

Pelos dados de irrigação suplementar simulados observa-se que para o nível de probabilidade de $5 \%$, a diferença das lâminas acumuladas entre a simulação mais irrigada (40 kPa) e a menos irrigada (200 kPa) é de $38,3 \mathrm{~mm}$ o que corresponde a $84,9 \%$ da lâmina maior (40 kPa). Para o nível de probabilidade de $95,0 \%$, a diferença das lâminas acumuladas entre essas simulações é de $82 \mathrm{~mm}$ o que corresponde a 86,0 \% da maior lâmina (40 kPa).

Pelos dados acima expostos o acréscimo do nível de probabilidade de ocorrência proporciona um aumento da lâmina de irrigação suplementar aplicada, além de proporcionar uma diferença maior das lâminas entre os diferentes momentos de irrigação simulados.

Como a região em estudo encontra-se sob clima sub tropical, portanto, com boa distribuição das chuvas ao longo do ano, a utilização de irrigação suplementar não apresenta grandes diferenças de lâminas totais disponíveis ao longo do ciclo das principais culturas. Este fato deve-se a distribuição das 
chuvas serem suficientes para suplementar as eventuais deficiências hídricas, mesmo para a época de inverno quando o déficit hídrico é mais acentuado.

A partir das lâminas probabilísticas simuladas e da função de produção adotada, elaborou-se as Tabelas 17 e 18 e as respectivas Figuras 20 e 21.

Tabela 17. Valores simulados do rendimento esperado $\left(\mathrm{kg} \mathrm{ha}^{-1}\right)$ em função da lâmina probabilística para diferentes níveis de probabilidade e diferentes momentos de irrigação

\begin{tabular}{|c|c|c|c|c|}
\hline $\begin{array}{c}\text { Nível de Probabilidade } \\
\qquad \%\end{array}$ & $40 \mathrm{kPa}$ & $75 \mathrm{kPa}$ & $100 \mathrm{kPa}$ & $200 \mathrm{kPa}$ \\
\hline 5 & 5767,85 & 5811,30 & 5737,50 & 5712,40 \\
\hline 10 & 6081,03 & 6105,50 & 6042,80 & 5984,40 \\
\hline 15 & 6298,10 & 6310,40 & 6254,90 & 6176,90 \\
\hline 20 & 6458,54 & 6463,20 & 6413,20 & 6322,90 \\
\hline 25 & 6586,44 & 6585,30 & 6539,20 & 6439,50 \\
\hline 30 & 6692,23 & 6686,80 & 6644,50 & 6538,60 \\
\hline 35 & 6783,81 & 6774,70 & 6735,80 & 6625,10 \\
\hline 40 & 6864,60 & 6852,30 & 6816,40 & 6702,20 \\
\hline 45 & 6937,81 & 6923,20 & 6889,70 & 6772,80 \\
\hline 50 & 7004,57 & 6988,10 & 6957,30 & 6838,90 \\
\hline 55 & 7067,14 & 7048,70 & 7020,40 & 6900,80 \\
\hline 60 & 7125,60 & 7106,10 & 7079,70 & 6960,80 \\
\hline 65 & 7181,52 & 7161,20 & 7137,20 & 7018,60 \\
\hline 70 & 7235,61 & 7214,60 & 7192,90 & 7075,90 \\
\hline 75 & 7288,53 & 7267,10 & 7247,70 & 7133,30 \\
\hline 80 & 7341,18 & 7319,90 & 7302,70 & 7192,30 \\
\hline 85 & 7394,35 & 7373,70 & 7359,10 & 7254,30 \\
\hline 90 & 7449,50 & 7430,70 & 7418,90 & 7323,00 \\
\hline 95 & 7508,71 & 7494,00 & 7486,20 & 7406,70 \\
\hline
\end{tabular}




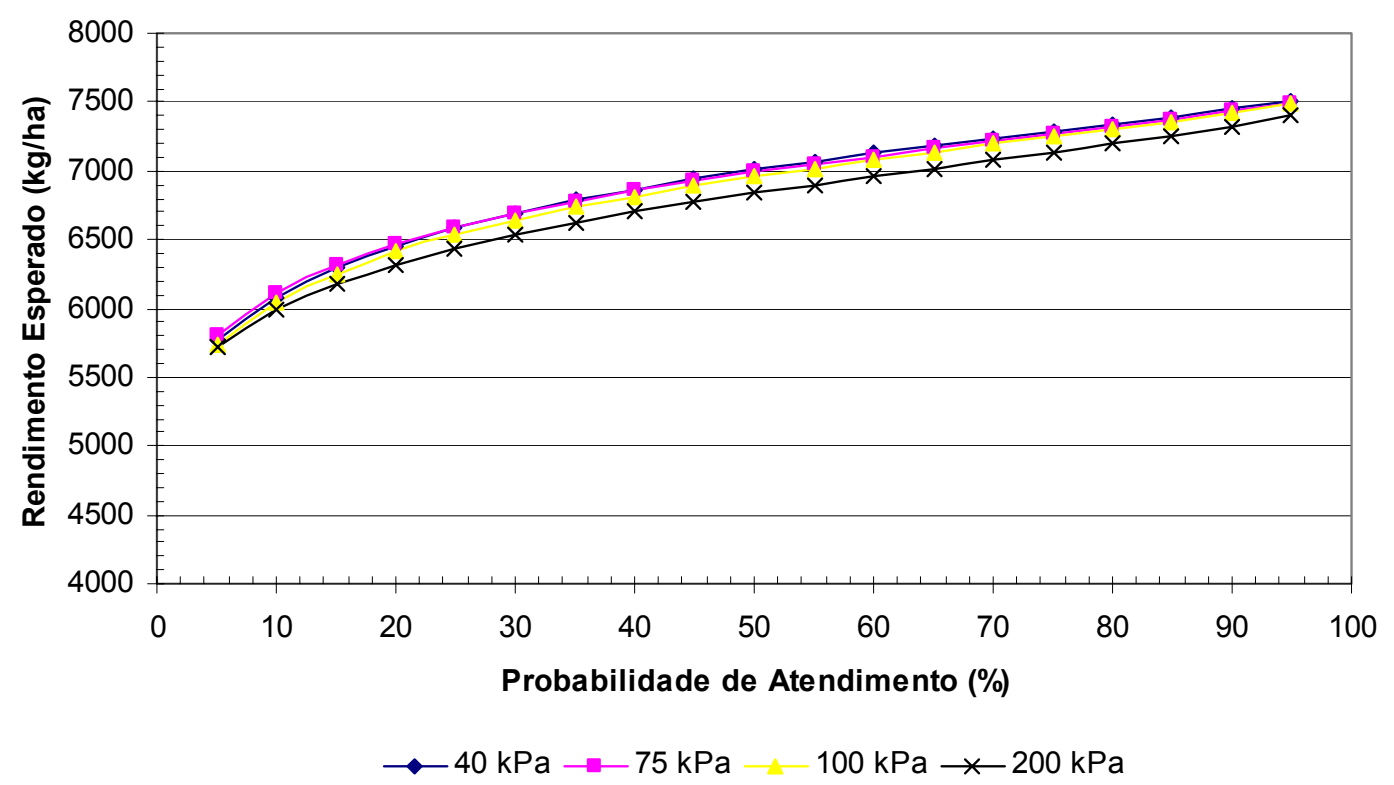

Figura 20 - Rendimento esperado em função das lâminas probabilísticas, para diferentes momentos de irrigação

Pelos dados de rendimento simulados observa-se que para o nível de probabilidade de $5 \%$, a diferença entre a simulação mais irrigada (40 kPa) e a menos irrigada (200 kPa) é de $55,5 \mathrm{~kg} \mathrm{ha}^{-1}$ o que corresponde a 99,0\% da maior lâmina (40 kPa). Para o nível de probabilidade de 95,0\%, a diferença dos rendimentos médios esperados entre essas simulações é de $102 \mathrm{~kg} \mathrm{ha}^{-1}$ o que corresponde a 98,0 \% da maior lâmina (40 kPa).

Esses dados estão coerentes aos apresentados pelas Tabela 15. visto que não há diferença significativa da lâmina acumulada entre as simulações com diferentes momentos de irrigação, o que proporciona, diferentes níveis de déficit, portanto, não haverá diferença significativa dos rendimentos esperados também. 
Tabela 18. Valores simulados da quebra do rendimento esperado (kg ha $\left.{ }^{-1}\right) \mathrm{em}$ função da lâmina probabilística para diferentes níveis de probabilidade e diferentes momentos de irrigação

\begin{tabular}{|c|c|c|c|c|}
\hline $\begin{array}{c}\text { Nível de Probabilidade } \\
\%\end{array}$ & $40 \mathrm{kPa}$ & $75 \mathrm{kPa}$ & $100 \mathrm{kPa}$ & $200 \mathrm{kPa}$ \\
\hline 5 & 1786,8 & 1743,3 & 1817,1 & 1842,3 \\
\hline 10 & 1473,6 & 1449,2 & 1511,8 & 1570,2 \\
\hline 15 & 1256,5 & 1244,3 & 1299,7 & 1377,8 \\
\hline 20 & 1096,1 & 1091,5 & 1141,4 & 1231,7 \\
\hline 25 & 968,2 & 969,3 & 1015,5 & 1115,2 \\
\hline 30 & 862,4 & 867,8 & 910,1 & 1016,1 \\
\hline 35 & 770,8 & 780,0 & 818,9 & 929,6 \\
\hline 40 & 690,0 & 702,4 & 738,2 & 852,4 \\
\hline 45 & 616,8 & 631,4 & 664,9 & 781,9 \\
\hline 50 & 550,1 & 566,5 & 597,4 & 715,8 \\
\hline 55 & 487,5 & 505,9 & 534,3 & 653,8 \\
\hline 60 & 429,0 & 448,6 & 475,0 & 593,9 \\
\hline 65 & 373,1 & 393,4 & 417,4 & 536,0 \\
\hline 70 & 319,0 & 340,0 & 361,7 & 478,8 \\
\hline 75 & 266,1 & 287,6 & 307,0 & 421,4 \\
\hline 80 & 213,5 & 234,7 & 252,0 & 362,4 \\
\hline 85 & 160,3 & 180,9 & 195,6 & 300,3 \\
\hline 90 & 105,2 & 124,0 & 135,7 & 231,7 \\
\hline 95 & 45,9 & 60,7 & 68,4 & 147,9 \\
\hline
\end{tabular}




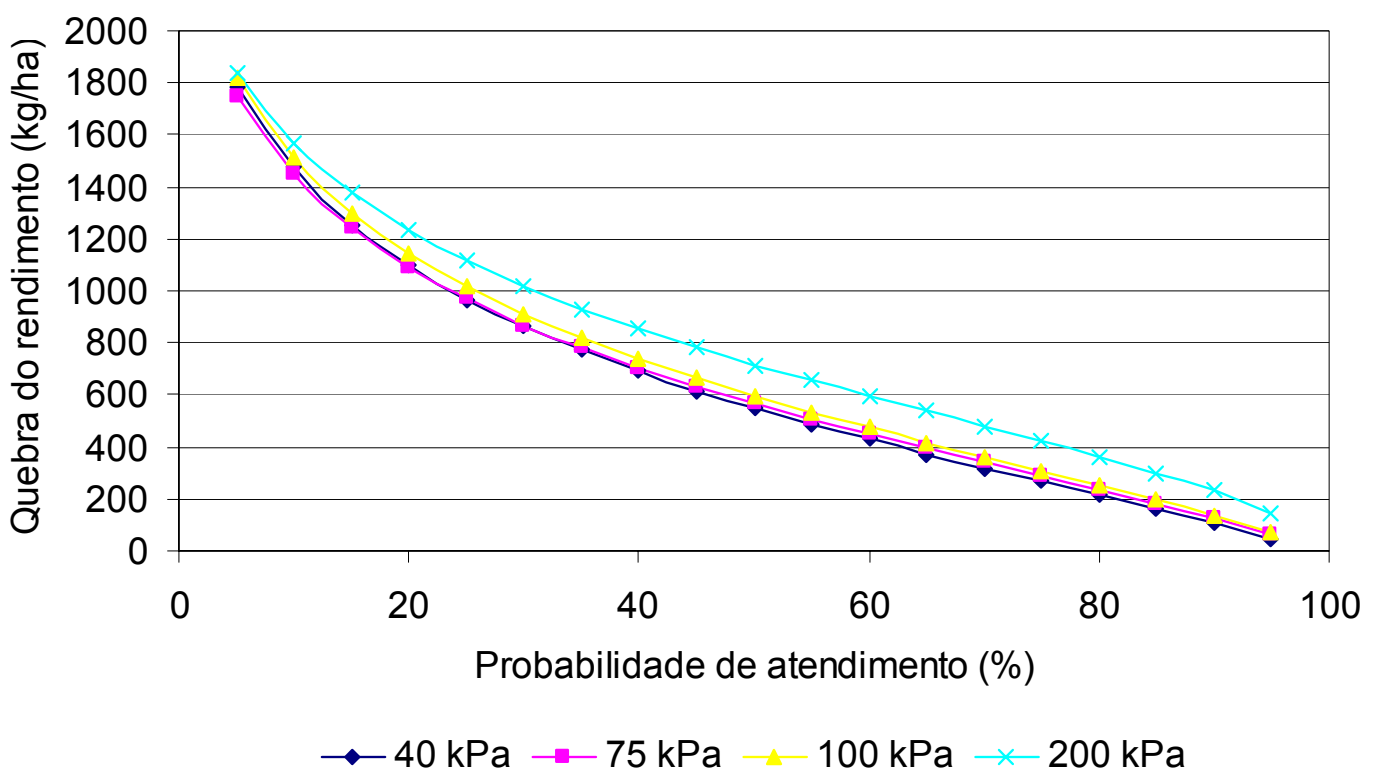

Figura 21 - Quebra do rendimento em função das lâminas probabilísticas, para diferentes momentos de irrigação

\subsection{Considerações finais}

A partir da simulação efetuada para a região de Piracicaba, optando-se pelos vários métodos disponibilizados pelo programa, nota-se que o aplicativo não demonstra diferenças significativas entre os mesmos para diferentes níveis de manejo para regiões onde o déficit hídrico não é acentuado, ou seja, onde a irrigação é apenas suplementar. Acredita-se que se a mesma simulação for realizada com dados de uma região onde a irrigação é total (regiões mais secas), as diferenças observadas poderão ser potencializadas. 


\section{CONCLUSÕES}

O aplicativo desenvolvido apresentou ser uma ferramenta prática e de fácil manuseio pelo usuário. A opção da utilização de várias metodologias para o cálculo da evapotrasnpiração potencial mostrou-se válida e desse modo adaptável às mais variadas realidades brasileiras tanto no seu aspecto climático regional, como principalmente, na disponibilidade das informações necessárias para alimentar o sistema. 


\section{REFERÊNCIAS BIBLIOGRÁFICAS}

ALFONSI, R.R.; VICTORIA FILHO, R.; SENTELHAS, P.C. Épocas de semeadura para a cultura do milho no Estado de São Paulo, baseadas na probabilidade de atendimento hídrico. Revista Brasileira de Agrometeorologia, v.5, n.1, p. 43-49, 1997.

ASSIS, F.N., ARRUDA, H.V. de; PEREIRA, A.R. Aplicações de estatística à climatologia: teoria e prática. Pelotas: Ed. Universitária, 1996. 161p.

AMERICAN SOCIETY OF CIVIL ENGINEERS. Evapotranspiration and irrigation water requirements. New York: ASCE, 1990. 465p. (Manual and Reports on Engineering Practice, 70).

ANDRADE JÚNIOR, A.S.; FRIZZONE, J.A.; BASTOS, E.A.; CARDOSO, M.J.; RODRIGUES, B.H.N. Estratégias ótimas de irrigação para a cultura da melancia. Pesquisa Agropecuária Brasileira, v.36, n.2, p.301-305, 2001.

BERNARDO, S. A computerized model to predict supplemental irrigation in tropical and subtropical climate. Logan, 1975. 155p. Thesis (PhD) - Utah State University.

BERNARDO, S. Impacto ambiental da irrigação no Brasil. Engenharia na Agricultura, v.1, n.13, p.1-7, 1992.

BERNARDO, S. Manual de irrigação. 6. ed. Viçosa: Imprensa Universitária da FV, 1995. 657p. 
BRAGA, H. Caracterização da seca agronômica através de um novo modelo de balanço hídrico, na região de Laguna, litoral Sul de Santa Catarina, Piracicaba, 1982.157p. Dissertação (Mestrado)- Escola Superior de Agricultura “Luiz de Queiroz”, Universidade de São Paulo.

CALHEIROS, C.B.M.; QUEIROZ, J.E.; FRIZZONE, J.A; PESSOA, P.C.S. Estratégias ótimas de irrigação do feijoeiro: água como fator limitante da produção. Pesquisa Agropecuária Brasileira, v.31, n.7, p.509-515, 1996.

CAMARGO, A.P. Contribuição para a determinação da evapotranspiração potencial no Estado de São Paulo. Bragantia, v.21, p.163-213, 1962.

CAMARGO, A.P., MARIN, F.R., SENTELHAS, P.C. PICINI, A.G. Adjust of the Thornthwaite's method to estimate the potential evapotranspiration for arid and superhumid climates, based on daily temperature amplitude. Revista Brasileira de Agrometeorologia. v.7, n.2, p.251-257, 1999.

CAMPOS, H. Estatística experimental não-paramétrica. 4.ed. Piracicaba: ESALQ-USP, 1983. 349p.

CUENCA, R.H. Irrigation systems design: An engineering approach. New Jersey: Prentice Hall, Englewood Cliffs, 1989. 551p.

DANTAS NETO, J. Modelos de decisão para otimização do padrão de cultivo, em áreas irrigadas, baseados nas funções de resposta das culturas à água. Botucatu, 1994. 125p. Dissertação (Mestrado) Universidade Estadual Paulista "Júlio de Mesquita Filho".

DENMEAD, O.T.; SHAW, R.H. Avaliability of soil water to plants as affected by soil moisture content and meteorological condictions. Agronomy Journal, v.54, p.385-390, 1962

DOORENBOS, J.; PRUITT, W.O. Guidelines for predicting crop water requeriments. Roma: FAO, 1977. 179p. (Irrigation and Drainage Paper, 24).

DOORENBOS, J.; KASSAN, A.H. Yield response to water. Roma: FAO, 1979. 193p. (Irrigation and Drainage Paper, 33) 
DOURADO NETO, D. Previsão do rendimento da cultura de feijão. Piracicaba, 1992. 124p. Tese (Doutorado) - Escola Superior de Agricultura "Luiz de Queiroz", Universidade de São Paulo.

DOURADO NETO, D.; VAN LIER, Q. de J. Estimativa do Armazenamento de água no solo para realização de balanço hídrico. Revista Brasileira de Ciência do Solo, v. 17, n.1, p.9-15, 1993.

ENGLISH, M.J.; NAKAMURA, B.C. Effects of deficit irrigation and irrigation frequency on wheat yields. Journal of Irrigation and Drainage Engineering, v.115, n.2, p.172-184, 1989.

ENGLISH, M.J. Deficit irrigation. I: Analytical framework. Journal of Irrigation and Drainage Engineering, v.116, n.3, p.399-412, 1990.

ENGLISH, M.J.; NUSS, G.S. Designing for deficit irrigation. Journal of Irrigation and Drainage Engineering, v.108, n.2, p.91-106, 1982.

ENGLISH, M.J; RAJA, S.N. Perspectives on deficit irrigation. Agricultural Water Management, v.32, p.1-14, 1996.

ENGLISH, M.J.; SOLOMON, K.H.; HOFFMAN, G.J. A paradigm shift in irrigation management. Journal of Irrigation and Drainage Engineering, v.128, n.5, p.267-277, 2002.

FIGUERÊDO, S.F. Estabelecimento do momento de irrigação com base na tensão da água no solo para a cultura do feijoeiro. Piracicaba, 1998. 94p. Dissertação (Mestrado) - Escola Superior de Agricultura "Luiz de Queiroz", Universidade de São Paulo.

FRIZZONE, J.A. Análise de cinco modelos para o cálculo da distribuição e freqüência de precipitações na região de Viçosa. Viçosa, 1979. 100p. Dissertação (Mestrado) - Universidade Federal de Viçosa.

FRIZZONE, J.A. Funções de resposta do feijoeiro (Phaseolus vulgaris $L$ ) ao uso de nitrogênio e lâmina de irrigação. Piracicaba, 1986. 133p. Tese (Doutorado) - Escola Superior de Agricultura "Luiz de Queiroz", Universidade de São Paulo. 
FRIZZONE, J.A. Função de produção. In: FARIA, M.A.; SILVA. E.L.; VILELLA, L.A.A.; SILVA, A.M. (Ed.). Manejo da irrigação. Lavras: UFLA/Sociedade Brasileira de Engenharia Agrícola, 1998. p.86-116.

FRIZZONE, J.A.; TEODORO, R.E.F.; PEREIRA, A.S.; BOTREL, T.A. Lâminas de água e doses de nitrogênio na produção de forragem de aveia (Avena sativa L.). Scientia Agricola, v.52, n.3, p.578-586, 1995.

FRIZZONE, J.A.; COELHO, R.D.; DOURADO NETO, D.; SOLIANI, R. Linear programming model to optimize the water resource use in irrigation projects: an application to the Senador Nilo Coelho Project. Scientia Agricola, v.54, p.136-148, 1997.

FRIZZONE, J.A.; MATIOLI, C.S.; REZENDE, R.; GONÇALVES, A.C.A. Viabilidade econômica da irrigação suplementar da cana-de-açúcar, Saccharum spp., para a região Norte do Estado de São Paulo. Acta Scientiarum, v.23, n.5, p.1131-1137, 2001.

GORANTIWAR, S.D.; SMOUT, I.K. Allocation of scarce water resources using deficit irrigation in rotational systems. Journal of Irrigation and Drainage Engineering. v.129, n.3, p.155-163, 2003.

HARGREAVES, G.H.; SAMANI, Z.A. Economics consideration of deficit irrigation. Journal of irrigation and Drainage engineering, v.3, n.110, p.343-358, 1984.

HEINEMANN, A.B.; SOUSA, S.A.V; FRIZZONE, J. A. Determinação da lâmina ótima de água para a cultura do milho doce na região de Sete Lagoas, MG. Revista Brasileira de Engenharia Agrícola e Ambiental. v.5, n.1, p.147$151,2001$.

HEINEMANN, A.B.; HOOGENBOOM, G.A.; GEORGIEV, G.A.; FARIA, R.T.; FRIZZONE, J.A. Center pivot irrigation management optimization of dry beans in humid areas. Transactions of the ASAE, v.43, n.6, p.1507-1516, 2000.

JAMES, L.G. Principles of farm irrigation systems design. New York: John Wiley, 1988. 542p. 
JOSHI, M.B.; MURTHY, J.S.R.; SHAH,M.M. CROSOWAT: A decision toll for irrigation schedule. Agricultural Water Management,v.77,p.203-223,1995

KELLER, J.; BLIESNER, R.D. Sprinkle and trickle irrigation. New York: Van Nostrand Reinhold, 1990.651p.

KRAMER, P.J. The Role of water in the phisiology of plants. Advances in Agronomy, v.11, p.51-70,1959.

KUMAR, R.; KHEPAR, S.D. Decision models for optimal cropping patterns in irrigation based on crop water production functions. Agricultural Water Management, v.3, n.1, p.65-76, 1980.

OMETTO, J.C. Bioclimatologia vegetal. São Paulo: CERES, 1981. 440p.

PANIGRAHI, B.; PANDA, S.N. Optimal sizing of on-farm reservoirs for supplemental irrigation. Journal of Irrigation and Drainage Engineering, v.129, n.2, p.117-128, 2003.

PAZ, V.P.S. Condições ótimas de operação de sistemas de irrigação por aspersão. Piracicaba, 1995. 125p. Tese (Doutorado) - Escola Superior de Agricultura "Luiz de Queiroz", Universidade de São Paulo.

PAZ, V.P.S, FRIZZONE, J.A.; BOTREL, T.A.; FOLEGATTI, M.V. Otimização do uso da água em sistemas de irrigação por aspersão. Revista Brasileira de Engenharia Agrícola e Ambiental, v.6, n.3, p.404-408, 2002.

PEREIRA, A.R. Análise do modelo de Priestley-Taylor para estimativa da evapotranspiração potencial. Piracicaba, 1990. 68p. Tese (Livre-Docência) Escola Superior de Agricultura "Luiz de Queiroz", Universidade de São Paulo. PEREIRA, A.R.; PRUITT W.O. Adaptation of the Thornthwaite scheme for estimating daily reference evapotranspiration. Agicultural Water Management, n.66, p.251-257, 2004.

PEREIRA, A.R.; VILLA NOVA, N.A.; SEDIYAMA, G.C. Evapo(transpi)ração. Piracicaba: FEALQ, 1997. 183 p.

PEREIRA, A.R.; VILLA NOVA, N.A.; SENTELHAS, P.C. O parâmetro de Pristley - Taylor para estimativa da evapotranspiração de referência na escala mensal. Revista Brasileira de Agrometeorologia, v.5, n.1, p.83-87, 1997. 
PERES, J.G. Avaliação do modelo de Penman-Monteith, padrão FAO, para a estimar a evapotranspiração de referência nas condições climáticas do Estado de São Paulo. Piracicaba, 1994. 116p. Tese (Doutorado) - Escola Superior de Agricultura "Luiz de Queiroz", Universidade de São Paulo.

PERES, J.G.; PEREIRA, A.R; FRIZZONE, J.A.; VILLA VOVA, N.A. Calibração do modelo de Priestley-Taylor para estimar a evapotranspiração potencial da cana-de-açucar. Revista Brasileira de Agrometeorologia, v.5, n.1, p.77-82, 1997.

PERI, G.; HART, W.E.; NORUM, D.I. Optimal Irrigation Depths - A Method of Analysis. Journal of the Irrigation and Drainage Division, v.105, n.4, p.341-355,1979.

PHENE, C.J. Techniques for computerized irrigation management. Computer and Eletronics in Agriculture, v.3, n.3, p.189-208, 1989.

PICCININI, M.R.D. Distribuições de probabilidade de precipitação de intensidade máxima para Piracicaba, SP. Piracicaba, 1993. 94p. Dissertação (Mestrado) - Escola Superior de Agricultura “Luiz de Queiroz”, Universidade de São Paulo.

SOUSA, S.A.V. FRIZZONE, J.A.; PERES, F.C. Otimização da irrigação para diferentes déficits nas lâminas de água aplicadas às culturas. Engenharia Rural, v.9, n.1, p.1-9, 1998.

REICHARDT, K. Capacidade de campo. Revista Brasileira de Ciência do Solo, v.12, p.211-216, 1988.

REICHARDT, K. Dinâmica da matéria e da energia em ecossistemas. 2.ed.

Piracicaba: USP/ESALQ. Depto. Física e Meteorologia, 1996. 505p.

SAAD, J.C.C. Estudo das distribuições de freqüência da evapotranspiração de referência e da precipitação pluvial para fins de dimensionamento de sistemas de irrigação. Piracicaba, 1990. 124p. Dissertação (Mestrado) Escola Superior de Agricultura "Luiz de Queiroz", Universidade de São Paulo. 
SOUSA, S.A.V.; FRIZZONE, J.A.; PERES, F.C. Otimização da irrigação para diferentes déficits nas lâminas de água aplicadas às culturas. Engenharia Rural, v.9, n.1, p.1-9, 1998.

STEWART, J.I.; HAGAN, R.M. Functions to predict effects of crop water déficits. Journal of the Irrigation and Drainage Division, v.99, p.421-439, 1973.

STEWART, J.I; HAGAN, R.M.; PRUITT, W.O. Functions to predict optimal irrigation programs. Journal of the Irrigation and Drainage Division, v.100, n.2, p.179-197, 1974.

VAUX JR.; PRUITT, W.O. Crop-water production functions. In: HILLEL, D., (Ed).

Advances in irrigation. New York: Academic Press, 1983. p.61-97.

VAN GENUCHTEN, M.T. A closed-form equation for predicting the hydraulic conductivity of unsaturated soils. Soil Science Society America Journal, v.44, p.892-898, 1980.

VILLA NOVA, N.A.; PEREIRA, A.R.; BARBIERI, V. Evapotranspiração como uma função do índice de área foliar e da evaporação de tanque classe $A$. Revista Brasileira de Agrometeorologia, v. 4, n.2, p. 35-37, 1996.

VIVALDI, L.J. Utilização da distribuição gama em dados pluviométricos. Piracicaba, 1973. 77p. Dissertação (Mestrado) - Escola Superior de Agricultura "Luiz de Queiroz", Universidade de São Paulo.

WALKER, W.R.; SKOGERBOE, G.V. Surface irrigation: theory and practice. Prentice Hall, Englewood Cliffs: New Jersey, 1987. 386p.

WREGE, M.S; GONÇALVES, S.L.; CARAMORI, P.H. et al. Risco de deficiência na cultura do feijoeiro durante a safra das águas no Estado do Paraná. Revista Brasileira de Agrometeorologia, v.5, n.1, p. 51-59, 1997. 